\title{
Pour une géo-archéologie du Patrimoine : pierres, carrières et constructions en Bretagne
}

Deuxième partie : Roches sédimentaires

For a Geo-Archaeology of Heritage: Stones, quarries and buildings in Brittany.

Part two: Sedimentary rocks

\section{Louis Chauris}

\section{OpenEdition}

\section{Journals}

Édition électronique

URL : https://journals.openedition.org/rao/1384

DOI : $10.4000 /$ rao. 1384

ISSN : $1775-3732$

\section{Éditeur}

Presses universitaires de Rennes

\section{Édition imprimée}

Date de publication : 31 décembre 2010

Pagination : 171-208

ISBN : 978-2-7535-1383-9

ISSN : 0767-709X

\section{Référence électronique}

Louis Chauris, «Pour une géo-archéologie du Patrimoine : pierres, carrières et constructions en Bretagne », Revue archéologique de l'Ouest [En ligne], 27 | 2010, mis en ligne le 25 février 2012, consulté le 15 septembre 2022. URL : http://journals.openedition.org/rao/1384 ; DOI : https://doi.org/10.4000/ rao.1384

Ce document a été généré automatiquement le 15 septembre 2022.

Tous droits réservés 


\section{Pour une géo-archéologie du Patrimoine : pierres, carrières et constructions en Bretagne}

Deuxième partie : Roches sédimentaires

For a Geo-Archaeology of Heritage: Stones, quarries and buildings in Brittany. Part two: Sedimentary rocks

\section{Louis Chauris}

\section{Grès et quartzites}

1 La péninsule bretonne est si riche en roches gréseuses des plus variées qu'il s'avère presque impossible d'offrir un tableau exhaustif de la composition, des gisements et de l'utilisation de ces matériaux, et ce d'autant plus que l'emploi de ces roches se perd dans la nuit des temps. Néanmoins, au sein de cette nébuleuse se détachent quelques grands ensembles, suivis par un immense cortège de roches moins connues aujourd'hui. (Chauris, 2003a) ${ }^{1}$.

2 Les grès peuvent être classés selon divers critères :

3 Composition minéralogique. Ce sont des roches détritiques, formées de grains de quartz plus ou moins soudés, auxquels peuvent s'adjoindre du feldspath (grès arkosiques) ou du mica (grès psammitiques). Lorsque la recristallisation est forte, les grès passent à des quartzites dont le façonnement s'avère plus difficile, mais la ténacité singulièrement plus élevée; la dissémination de fines paillettes de mica blanc conduit aux quartzites séricitiques.

4 Texture. Elle peut être très diverse, passant des faciès extrêmement fins - comme le "grès armoricain » de la presqu'île de Crozon - à des faciès graveleux - à Plourivo voire à de véritables poudingues (Erquy). La roche peut être fortement indurée (quartzites de La Roche-Maurice), ou au contraire presque friable («roussard» du 
Pliocène en Haute-Bretagne). La texture joue un rôle essentiel dans le façonnement: certains grès ne supportent qu'une taille médiocre par éclatement.

Couleur. C'est la caractéristique la plus apparente et la plus variée : blanc à gris très clair (grès armoricain); vert (bassin de Châteaulin) ; rose (Erquy) ; rouge (Fréhel, Redon); lie-de-vin (Plourivo) ; gris-noir (environs de Morlaix) ; bleu-noir (phtanites) ; parfois bicolores (vert et rouge à Redon et à Fréhel, blanc et rouge à Landévennec...). En règle générale, la coloration est due à l'oxyde de fer.

6 Âge. Des grès se sont formés tout au long des périodes géologiques: Briovérien (phtanites de Lamballe et de Callac); Cambro-Ordovicien (grès d'Erquy); Ordovicien inférieur («grès armoricain» de la presqu'île de Crozon, des Montagnes Noires, de Quénécan...); Ordovicien supérieur (grès de Vitré ou de Redon); Dévonien inférieur (quartzites de Plougastel, grès de Landévennec); Carbonifère inférieur (grès verts du bassin de Châteaulin); Pliocène (« roussard »).

7 Emploi. C'est un ultime critère de classement : empierrement, enrochements, granulats (à présent, en Bretagne, c'est le débouché majeur des grès, extraits et concassés dans de très importantes carrières); pavés (industrie naguère florissante dans la péninsule: Erquy, Fréhel...) ; bâti (rôle essentiel dans les terroirs gréseux); dallages (Redon); roches ornementales (Erquy); sculpture (grès vert du bassin de Châteaulin ; grès grisnoir de Morlaix). À ces emplois majeurs s'ajoutaient dans le passé quelques utilisations particulières (pierres à aiguiser; pierres réfractaires), sans oublier l'érection des mégalithes.

\section{Grès blancs : les " grès armoricains "}

8 Dans l'ouest de la France, la roche connue sous l'appellation de " grès armoricain » est fort répandue; elle forme fréquemment les points hauts du relief - dénommés «Menez» quand leur morphologie est quelque peu adoucie (Menez Mikaël; Menez Hom...) et «Roc'h» quand elle est acérée (Roc'h Veur...) ainsi que de vertigineuses falaises marines (Pen- Hir à Camaret...).

9 Ces grès sont généralement à granulométrie très fine, de teinte blanchâtre, souvent très purs ; ils sont fréquemment recristallisés et passent alors à des quartzites. Par suite de leur dureté et de leur ténacité, ils se façonnent difficilement; ils ont été et sont encore aujourd'hui recherchés comme matériau d'empierrement, granulats et enrochements. Dans les terroirs dépourvus d'autres pierres de construction, ils ont été utilisés dans le bâti auquel ils confèrent une pérennité exceptionnelle et une blancheur qui évoque celle de certains calcaires.

10 Du fait de leur extension à travers la péninsule armoricaine, il a semblé opportun de limiter leur examen au terroir où ils sont les mieux caractérisés, à savoir la presqu'île de Crozon. Le grès armoricain y était déjà recherché au Néolithique: les alignements mégalithiques de Lagatjar en Camaret témoignent à la fois de l'abondance locale du matériau et des difficultés à le façonner; de là les silhouettes capricieuses et frustes de ces singuliers menhirs blanchâtres, dressés sur la lande (photo I).

11 Ce même grès a été très employé naguère pour l'habitat rural ; sa prédominance dans le bâti du Cap de la Chèvre est une émanation directe du sous-sol, les extractions se faisant pratiquement sur place. Mais pour les villes (Camaret, Crozon...), les pierres étaient extraites dans de véritables carrières, telles celles de Guenvenez. 
12 Dans les édifices religieux, un large appel a été fait à ces grès pour les élévations en moellons. À Sainte-Marie-du-Menez-Hom ( $\mathrm{XVI}^{\mathrm{e}}, \mathrm{XVII}^{\mathrm{e}}$ et XVIII ${ }^{\mathrm{e}}$ siècles), le grès local est en association avec un granite allochtone réservé à la pierre de taille. La chapelle SaintJean, en Saint-Nic, édifiée au XVI ${ }^{\mathrm{e}}$ siècle et remaniée au XVII ${ }^{\mathrm{e}}$, fait également appel au grès tout proche et au granite d'origine plus lointaine. Dans son état actuel, l'église paroissiale de Crozon offre la juxtaposition de trois époques de construction : le porche latéral sud, remontant au $\mathrm{XVI}^{\mathrm{e}}$ siècle et en remploi, est typiquement polylithique (leucogranite gris clair des environs de Douarnenez, microgranite jaunâtre de Logonna, microgranite blanchâtre de Crozon) ; la tour massive (1866) est en kersanton noir et les élévations latérales (1899-1901) essentiellement en moellons gréseux, associés de manière aléatoire aux deux microgranites précités et à des leucogranites. Ces trois derniers matériaux paraissent être des remplois de l'ancien édifice, tandis que le grès apparaît essentiellement en pierres «neuves ». Les entourages des baies, datant de la reconstruction, sont en kersanton ou en leucogranite; les pierres d'angle et les contreforts sont en kersanton; les piliers en leucogranite (Chauris, 2002b).

Ouvrages militaires: du fait de sa situation géographique, la presqu'île de Crozon constitue l'une des zones avancées pour la protection du port de Brest, d'où l'érection, échelonnée sur plusieurs siècles, de nombreux ouvrages défensifs. Dans ces constructions, le grès armoricain a été largement mis à contribution pour les moellons des murailles, tant pour le parement vu que pour le blocage. Dans le complexe de la pointe du Toulinguet en Camaret, le fortin (1812) est en moellons de grès local, associé aux granites de Trégana et de Plouarzel (en provenance du pays de Léon) ; la muraille barrant la pointe est édifiée en moellons gréseux; dans les batteries de la seconde partie du XIX $X^{e}$ siècle, le même grès, en moellons, est associé au kersanton gris, en pierres de taille. Au Kador, en Crozon, le réduit (1861) montre l'association du grès au granite rose de l'Aber-Ildut; les batteries, plus tardives, offrent encore la même association (photo II). À Landaoudec, en Crozon, la redoute (1885-1887) montre également l'emploi de moellons gréseux (et microgranitiques) avec le granite de l'AberIldut limité au grand appareil (Chauris, 2005a).

14 En ce qui concerne les travaux publics, le grès armoricain a été aussi très apprécié. Dans les infrastructures ferroviaires de la presqu'île, il a été utilisé en moellons pour les gares du chemin de fer, en association avec le granite de l'Aber-Ildut comme pierres de taille : Telgruc, Crozon, Plomodiern (photo III). Il en est de même pour les installations portuaires (jetée de Morgat, sous un couronnement de parapet en granite de l'AberIldut). Aujourd'hui, les aménagements littoraux exigent d'énormes volumes de gros blocs bruts, livrés en presqu'île par la carrière du Menez-Luz en Telgruc (qui produit aussi des granulats); un excellent exemple de tels enrochements est fourni par le nouveau môle de Morgat, abritant le port de plaisance ; le même matériau a été utilisé pour le port du Fret.

15 Les emplois du grès armoricain notés en presqu'île de Crozon peuvent être, à quelques nuances près (absence d'enrochements littoraux et d'ouvrages défensifs) observés un peu partout en Bretagne. Dans les monts d'Arrée, An Eured Vein - la Noce de Pierre - de Brasparts est un alignement mégalithique en grès armoricain. Au Moyen Âge, la même roche a été utilisée pour bâtir des châteaux forts : les ruines de Roc'h-Morvan, à La Roche-Maurice se dressent encore sur un chicot de quartzite. Comme en écho aux mégalithes de la Préhistoire, il est fréquent aujourd'hui de voir se dresser des stèles commémoratives des évènements de la dernière guerre; plusieurs sont en grès 
armoricain (à Roscanvel, la stèle érigée en mémoire de la reddition allemande le 19 septembre $1944 . .$.$) .$

16 Comme en presqu'île de Crozon, les exploitations actuelles du grès armoricain se rapportent essentiellement aux matériaux de viabilité et aux granulats pour centrales à béton. Les nombreuses carrières artisanales ont fait place à quelques très grandes exploitations : dans le Finistère, outre le Menez-Luz en Telgruc déjà cité, mentionnons le Hinguer en Cast, le Plessis en Laz (la carrière de Castel-Ruphel en Saint-Goazec est aujourd'hui arrêtée) ; dans le Morbihan, ce sera la carrière de Conveau en Gourin ; dans les Côtes-d'Armor, celle de Bellevue en Saint-Gelven (la célèbre carrière de Trévéjan à Mûr-de-Bretagne a suspendu son activité depuis juin 2001 - cf. infra, fig. 3).

\section{Les grès verts du bassin de Châteaulin}

Des niveaux gréseux affleurent au sein des schistes bleus du bassin carbonifère de Châteaulin. Tous les intermédiaires apparaissent entre des schistes gréseux encore fissiles, riches en minéraux phylliteux, et des grès feldspathiques plus massifs, caractérisés par leur teinte verte ou gris-vert. Le faciès gréso-feldspathique est formé de quartz non jointifs - ce qui facilite le façonnement - et de plagioclases, moins nombreux, dans un fond phylliteux qui rend compte du caractère tendre de la roche (la nuance verdâtre est due à la chlorite). Ce grès feldspathique fournit de beaux moellons et des pierres de taille, voire même des éléments aptes à la sculpture (Eveillard, 2001).

Ce matériau a déjà été utilisé dans la cité gallo-romaine de Vorgium (aujourd'hui Carhaix - cf. photo IV). Son emploi, à nouveau attesté dès le XvI ${ }^{e}$ siècle, prend une place essentielle dans les constructions, à Carhaix et dans ses environs : manoir de Lanoënnec (porte avec cintre en deux éléments, fenêtre avec linteau à accolade); manoir de Crec'h Henan (xvII ${ }^{\mathrm{e}}$ siècle? avec beaux moellons); manoir de Kerledan (xvi ${ }^{\mathrm{e}}$ siècle, avec érosion en cupules) ; château de Kerampuil (1760, soubassement); Kergorvo (portes); manoirs de Kerniguez: grand manoir (superbes moellons) et petit manoir (moellons pouvant atteindre un mètre de long, en assises d'épaisseurs diverses, correspondant à la puissance des bancs dans les carrières). A Carhaix même, dans la maison du Sénéchal ( $x I^{e}$ siècle), belle cheminée à l'étage. On retrouve ce grès dans les élévations de l'église de Plouguer, ainsi que dans celles de l'église de Saint-Trémeur (parties du XIX ${ }^{e}$ s.), dans la façade occidentale de la chapelle du couvent des Hospitalières (xvII ${ }^{e}$ siècle) ou au manoir de Maezroz près de Landeleau : photo V, VI... (Chauris, 2001c).

Les Travaux publics ont également fait appel à cette pierre locale. Dans les ouvrages du canal de Nantes à Brest (première moitié du xIX siècle), toujours aux environs de Carhaix, elle a été utilisée sous des modalités diverses: en beaux moellons pour le couronnement du parapet d'un pont près de l'écluse de l'île; en petits moellons pour le soubassement des maisons éclusières de Pont Dauvlas, de Kergouthis...; les faciès plus schisteux - et par suite plus fissiles - ont été recherchés pour le dallage médian des bajoyers de quelques écluses (Kervouledic, Goariva), voire comme dalles devant la maison éclusière (Goariva...). De même, les infrastructures ferroviaires ont aussi employé ce matériau local (pont franchissant le canal au sud-est de Kergadigen).

Mais cette pierre n'a pas été recherchée uniquement autour de Carhaix ; en fait, elle a été utilisée un peu partout dans le bassin de Châteaulin. À Pleyben, dans l'église paroissiale - qui remonte en partie au $\mathrm{xVI}^{\mathrm{e}}$ siècle - le grès vert joue un rôle essentiel en sus du granite : élévation méridionale ; sacristie édifiée au début du XVIII ${ }^{\mathrm{e}}$ siècle (le grès 
est alors extrait des carrières de Menez Harz et de Ster-en-Golven) ; la même roche a été aussi utilisée pour l'ossuaire ( $\mathrm{xVI}^{\mathrm{e}}$ siècle) et l'arc de triomphe ( $\left.\mathrm{xVIII}{ }^{\mathrm{e}}\right)$, où elle présente quelques éléments bréchiques. également à Pleyben, la chapelle de GarsMaria, y recourt localement en association avec des leucogranites. À Châteauneuf-duFaou, dans la vaste chapelle Notre-Dame-des-Portes (fin du XIX ${ }^{e}$ siècle), ce grès est en association avec divers granites; les traces d'outils de façonnement y sont très nettes sur les parements vus. Comme aux environs de Carhaix, les grès verts ont également été recherchés, plus à l'ouest, pour l'habitat.

Ces grès ont aussi été mis en oeuvre dans la statuaire : parmi bien d'autres, évoquons les statues dressées au chevet de l'église de Laz, la statue de Saint-Maudez au VieuxMarché (Châteauneuf-du-Faou), celle de Saint-Nicolas dans la chapelle N.-D. de Hellen (Edern), plusieurs personnages du célèbre calvaire de Pleyben... Quelques éléments de la chapelle - ruinée - de Saint-Nicodème, en Kergloff, ont été remployés lors de la reconstruction de la chapelle Saint-Fiacre de Crozon, après la dernière guerre; en particulier de superbes sculptures d'animaux ont été emplacés à la base du toit dans la façade occidentale (Chauris et Cadiou, 2002).

Cette analyse entraîne quelques remarques de portée générale.

Dans un terroir dépourvu de granite, artisans et artistes locaux ont su mettre en œuvre un matériau qui, au premier abord, ne paraissait pas offrir les atouts de la " pierre de grain » qui affleure au nord et au sud du bassin.

Ce matériau local, utilisé dans les édifices les plus variés, confère au bâti du bassin de Châteaulin une originalité architecturale. Son association fréquente aux granites « importés » induit un polylithisme du plus heureux effet. Parfois, le grès a même été exporté vers les bordures du bassin, au-delà de ses sites d'extraction.

Du fait de ses aptitudes à la sculpture, le grès vert a été très tôt recherché pour la statuaire. Il joue localement le rôle des célèbres kersantons de la rade de Brest, à tel point que, dans un musée dont nous tairons le nom, une statue $\mathrm{du} \mathrm{XvI}^{\mathrm{e}}$ siècle, a été rapportée au kersanton, alors qu'en fait elle est en grès vert : hommage inconscient à ce dernier matériau!

L'emploi de cette roche singulière, constant pendant plusieurs siècles (au moins du xvi ${ }^{\mathrm{e}}$ au début $\mathrm{du} \mathrm{xx}^{\mathrm{e}}$ siècle) parait aujourd'hui totalement tombé dans l'oubli. Ses qualités devraient susciter une reprise artisanale, tant pour les restaurations que pour les constructions neuves.

\section{Grès roses... Grès rouges}

Sur le littoral des Côtes-d'Armor, affleurent des formations gréseuses d'âge paléozoïque inférieur - liées à la destruction de la chaîne cadomienne érigée à la fin des temps précambriens. Les trois « bassins » principaux - Erquy, Fréhel et Plourivo - ne sont, en fait, que les reliques d'un ensemble primitif nettement plus étendu. Ces grès, localement feldspathiques, à grain fin ou parfois graveleux, affleurent en bancs de puissance et d'inclinaison variables. La teinte rose domine à Erquy; à Fréhel s'y adjoignent des faciès rougeâtres ; à Plourivo, la coloration est parfois lie-de-vin. 


\section{Draperies de grès roses dans les falaises d'Erquy}

28 contrôleur des mines, le 17 octobre 1911, est particulièrement bien documenté. L'exploitation porte alors sur une surface de 18 hectares 10 ares dont la Société est propriétaire. Cinq chantiers s'échelonnent le long de la côte, donnant une longueur d'environ huit cents mètres. Une voie ferrée de $0,50 \mathrm{~m}$ relie tous les chantiers; la traction est animale. Le chantier le plus voisin du port, où vient aboutir la voie, est à l'altitude de 26 mètres au-dessus du quai. Les produits sont descendus par un plan incliné à $45^{\circ}$. Le môle d'Erquy permet le chargement sur des voiliers. Au moment de la visite, le personnel se répartit de la manière suivante : 67 extracteurs-coupeurs, 56 tailleurs de pavés, 5 casseurs de pierres, 47 manoeuvres, 5 chefs de chantier, 1 charretier, 21 enfants apprentis, soit au total 202 personnes. Les accidents les plus fréquents sont dus aux projections dans les yeux de grains de pierre ou d'acier, ainsi qu'à l'écrasement des extrémités lors de la manutention des pavés et des blocs (Rondel, 2003). La société met à la disposition des ouvriers des lunettes grillagées, mais elles ne sont pas utilisées... Les pavés sont taillés sur place et expédiés par mer à Paris, Bordeaux, Brest, Le Havre, Rouen, Dunkerque, Boulogne. Le prix moyen du pavé rendu à Paris, qui est le principal consommateur, est de $300 \mathrm{~F}$. le mille. La production de 1910 s'est élevée à 850000 pavés.

En sus de son utilisation pour l'obtention des pavés, le grès d'Erquy livrait également de bons moellons et même des pierres de taille (bordures de trottoirs, linteaux et montants pour portes et fenêtres) dans toute la région : église d'Hénansal, château de Bienassis... et, à Erquy même, pierres d'angle de la tour de l'église, encadrements des ouvertures de demeures, jetée du port, porte et fenêtres du phare.

en des carrières abandonnées qui échancrent partout la falaise ne laisse pas d'impressionner. Plusieurs de ces excavations sont aujourd'hui noyées et assez abusivement dénommées «les lacs bleus ». À présent, la falaise d'Erquy apparaît comme le résultat d'une gigantesque entreprise de démolition! Cette modification anthropique du paysage expose ici ses deux aspects complémentaires : les excavations 
avec leur relief en creux, les éboulis de taille, témoins de dépôts sédimentaires artificiels.

Aujourd'hui, le grès d'Erquy est exploité de manière artisanale par le groupe Graniouest, principalement à des fins ornementales, dans une carrière ouverte sur le plateau. Le grès est disposé en bancs de 0,40 à 1,60 m d'épaisseur et divisé par des plans verticaux. Le sciage des blocs subparallèlement au litage naturel permet l'obtention de dalles qui offrent des figures extraordinaires dues à l'interférence du plan de coupe avec la stratification. Ces motifs non figuratifs, mimant des plis sans en être, sont soulignés par des teintes de grande douceur, oscillant entre les nuances rosées et violines (photo VII). Offrant un excellent poli et une résistance exceptionnelle à l'usure, ce grès présente ainsi les avantages des marbres (coloration) sans en avoir les inconvénients (fragilité). La pierre peut aussi être clivée en pavés haut de gamme, de toutes dimensions (aménagements urbains à Loudéac, à Angers...). Tout en continuant à fournir occasionnellement des pavés ainsi que des pierres de construction pour l'habitat, l'entreprise tend aujourd'hui à se spécialiser dans le mobilier d'intérieur. La dureté singulière de cette roche explique aussi la demande de blocs en vue de la confection de meules... pour l'écrasement des grains de moutarde, à Dijon !

\section{Un littoral remodelé : carrières de grès à Fréhel}

Les plus grandes carrières littorales, non seulement des Côtes-d'Armor, mais de toute la Bretagne - et les seules qui soient en exploitation aujourd'hui (par la Société des Carrières de l'Ouest) - sont situées dans l'ancienne commune de Pléhérel (à présent Fréhel). Les points abandonnés ou en activité s'échelonnent sur $2,5 \mathrm{~km}$, du nord-est (Chapelle-aux-Chèvres) au sud-ouest (Port-Barrier). Les extractions ont complètement modifié l'environnement primitif, les falaises naturelles ayant disparu pour faire place à d'impressionnantes échancrures. Les premières exploitations ont eu lieu naguère en bordure même de la mer ainsi que l'atteste la présence de perrières abandonnées en faveur de sites un peu en retrait, à l'abri des eaux. Comme à Erquy, les rapports de visites des chantiers par le contrôleur des mines sont une source majeure de renseignements sur les carrières de Fréhel dans le passé, en particulier sur la production des pavés (Arch. départ. Côtes-d'Armor, S, supplément 252).

À présent, les carrières exploitent toujours les mêmes grès roses, mais pour l'obtention de granulats (chaussées et bétons) et de sables, mais aussi de blocs en vue d'enrochements littoraux. Actif jusqu'aux alentours de la guerre de 1939-1945 avec l'expédition des pavés, Port-Barrier semblait devoir être abandonné pour toujours lorsqu'en 1994, après un demi-siècle de léthargie, le quai fut remis en état par la Société des Carrières de l'Ouest, afin d'acheminer les énormes volumes de blocs exigés par les enrochements du nouveau port de Saint-Hélier à Jersey (600000 tonnes). Des enrochements littoraux en grès de Fréhel ont eu lieu également en Bretagne (ports de Saint-Cast, du Dahouët...).

L'exportation récente par mer de plusieurs centaines de milliers de tonnes de grès extraits des carrières de Fréhel mérite de retenir l'attention.

Le cas est idéal pour l'exploitation puisque la production est acheminée directement d'un littoral vers un autre littoral, le gisement de Fréhel possédant l'avantage de disposer d'un quai d'embarquement dans le site même d'extraction. Calcul fait, il serait 
moins coûteux d'acheminer le grès de Fréhel par mer jusqu'à Amsterdam que de le transporter par route jusqu'à Rennes!

C'est un excellent exemple de la compétitivité internationale d'une entreprise installée en Bretagne, diversifiant sa production (granulats pour la voirie et le béton, sables, blocs pour les enrochements).

On a là une reprise de la tradition, à savoir le transport par eau, comme dans le passé, mais sur une échelle beaucoup plus importante que naguère.

D'aucuns s'inquiéteront des impacts d'une telle exploitation littorale sur l'environnement. En fait, à l'issue des extractions, le site, réaménagé, apparaîtra plus grandiose qu'il ne l'était naturellement! En effet, les fronts de taille des carrières formeront de hautes falaises subverticales, accidentées de profondes échancrures : le nouveau littoral sera à la fois plus abrupt et plus découpé. L'Homme, puissant agent d'érosion, aura ici laissé sa marque ; cette empreinte anthropique rivalisera avec les forces de la Nature qui, jadis, agissaient seules. Mieux, le paysage se sera enrichi d'une touche archéologique...

\section{Les grès de Plourivo}

Le bassin gréseux où Plourivo occupe une position médiane s'étend entre Hengoat et Plouézec, mais ici les affleurements côtiers restent limités (bords de la ria du Trieux à la hauteur de La Roche-Jagu; environs de Port-Lazo). Du fait de leur coloration variée (blanc, gris-beige, rose pâle, rouge lie-de-vin...) et de leur façonnement aisé, les grès de Plourivo constituent un matériau estimé pour l'obtention de moellons; en particulier, le faciès rouge lie-de-vin (à feldspaths détritiques et ciment d'hématite), le plus recherché, confère aux constructions de toute la région un cachet original.

Dans le passé, les sites d'extraction ont été fort nombreux. E. de Fourcy (1844b) mentionne les carrières ouvertes sur la rive droite du Trieux, au pied des landes de Plourivo ; il précise que, vers 1840 , la production annuelle est seulement de l'ordre de $600 \mathrm{~m}^{3}$; il indique aussi l'acheminement de ces grès par eau - grâce au Trieux "jusqu'à Pontrieux où ils constituent les matériaux rosés et rouges, employés à la construction d'un grand nombre de maisons ". À Port-Lazo, une grande carrière était située dans le versant de la falaise. Des carrières étaient ouvertes assez haut sur la rive orientale de la ria du Trieux, en particulier près de Coat-Ermit en Plourivo, à proximité immédiate de la voie ferrée Guingamp-Paimpol. Au sud de l'abbaye de Beauport, près de Paimpol, les carrières étaient proches les unes des autres.

Contrairement aux grès d'Erquy et de Fréhel, les grès de Plourivo n'ont eu qu'une diffusion essentiellement locale, parfois régionale (on les note à Pontrieux, à Lanvollon...). Les causes de cette répartition restreinte sont à rechercher, au moins en partie, dans le fait que les sites d'extraction n'étant pas en bordure de mer, ils restaient handicapés par rapport aux grès précités, aux époques où les transports lointains étaient envisageables seulement par eau. La présence des grès de Plourivo dans le «temple » de Lanleff (édifice religieux très probablement roman) atteste un emploi précoce ; ils y offrent un faciès graveleux et une nuance rosée qui ont conduit certains archéologues à les confondre avec un granite.

Ces grès ont été largement utilisés en moellons dans de nombreuses églises paroissiales, en association avec divers granites - en particulier en provenance de l'île Grande réservés à la pierre de taille (Yvias, Plounez, Plourivo, Kerity, Plouézec, Kerfot...) et 
dans plusieurs chapelles (Sainte-Barbe près de Kerity, Petit Saint-Loup en Plouézec, Saint-Michel en Pléhédel, Kerleau en Plourivo...). Ils ont aussi été recherchés pour des ouvrages d'art de la ligne du chemin de fer Pontrieux-Paimpol, où le faciès lie-de-vin a été privilégié (viaducs de Pontrieux et du Leff; nombreux ponts). On les retrouve dans quelques phares reconstruits après la dernière guerre (Coatmer amont, Coatmer aval, Bodic), en association avec le granite, et surtout dans l'habitat de toute la région paimpolaise.

\section{Le grès gris-beige de Vitré}

Cette roche d'âge ordovicien, à grain très fin et relativement tendre, offre une agréable tonalité gris-beige clair. Elle admet de minuscules paillettes de muscovite (mica blanc) et présente assez souvent des cernes subconcentriques brunâtres d'hydroxyde de fer; elle est traversée localement par de minces veines quartzeuses. Certains bancs peuvent montrer une décomposition vacuolaire pulvérulente. À l'inverse de nombreux grès bretons, elle offre une excellente aptitude au façonnement, non seulement à la taille, mais même à la sculpture (Chauris, 2006c). Ce grès était exploité - entre autres - dans la grande carrière du Bas-Pont, ouverte dans la commune même de Vitré, à environ $1 \mathrm{~km}$ de la gare; dans ce site, il affecte une hauteur d'assise de 0,25 à 0,35 m.

L'église Notre-Dame, à Vitré, représente la plus remarquable mise en œuvre de cette pierre, et c'est même l'un des édifices de toute la Bretagne où un grès a été si largement recherché : façade occidentale avec sa porte monumentale, élévation méridionale et sa chaire extérieure, piliers à l'intérieur... Le même grès a été également utilisé pour l'église Saint-Martin, associé à divers granites: dans l'élévation méridionale, sur le soubassement granitique, la pierre présente localement une étonnante érosion en creux, parfois sur une dizaine de centimètres de profondeur. Quant à l'imposant portail de l'église Sainte-Croix, il témoigne des possibilités du grès de Vitré à fournir des éléments de grand appareil.

Dans le château de Vitré, le grès a été recherché tant dans la construction (où il est souvent en concurrence avec les schistes) que lors des travaux de restauration (dans ce dernier cas, pour la série de piliers et arcades d'un des côtés de la cour; ici, un seul pilier, à l'une des extrémités, paraît avoir été conservé en l'état). Dans les remparts de la même cité, les deux pierres locales (grès et schistes) ont été largement mises en œuvre, sous forme de moellons hétérométriques. Dans certains cas, les grès sont nettement dominants, les schistes ne formant que quelques assises espacées. Souvent les deux pierres sont associées sans ordonnance particulière ou, rarement, avec au contraire un certain agencement esthétique (poterne Saint-Pierre). La tour d'En-Bas est une restauration remontant seulement à une centaine d'années; le parement vu y fait un large appel au grès.

Mais c'est surtout dans l'habitat qu'à Vitré le grès occupe une place exceptionnelle : rue Notre-Dame, l'hôtel Ringues de La Troussanais (seconde partie du Xvi siècle), avec ses sculptures façonnées dans le grès; rue de La Baudrairie, au n 16 , une superbe porte Renaissance (photo VIII) ; rue de La Poterie, les piliers extérieurs en moellons ou en pierres de taille des maisons à colombage ; rue d'En-Bas, $n^{\circ} 4$, un grès avec cernes, très érodé, offre des formes adoucies, au toucher poussiéreux; le $\mathrm{n}^{\circ} 10$ est essentiellement en grès, avec quelques grands éléments schisteux; au $\mathrm{n}^{\circ} 16$, toutefois, les marches d'accès, en grandes dalles, sont en schiste bleu; le $n^{\circ} 30$ est une maison en grès, aux 
éléments arrondis et creusés par l'érosion pluriséculaire; rue du Rachapt, le $n^{\circ} 18$, montre une étonnante altération du grès.

Les Travaux publics ont également fait appel au grès de Vitré : viaduc à l'ouest de la ville pour la voie ferrée en direction de Fougères (toutefois, les chaînes d'angle, en pierres de taille, sont en granite, le grès étant réservé aux moellons); un pont sous la voie ferrée Paris-Brest, un peu à l'ouest de Vitré, associe lui aussi le granite (pierre de taille) au grès (moellons). En fait, les utilisations du grès local sont extrêmement nombreuses jusqu'à une période récente : pour partie, la caserne du $70^{\mathrm{e}} \mathrm{RI}$; les piliers d'entrée à l'école Pierre Lemaître ; pour partie, l'entrée monumentale du cimetière (1898) ; la Poste, en éléments soigneusement assisés (le soubassement est toutefois en pierre de taille granitique).

\section{Les quartzites gris-vert sombre de Plougastel}

50 En Bretagne occidentale affleure largement un complexe connu sous le nom de «schistes et quartzites de Plougastel ». Cette formation, rapportée à la base du Dévonien inférieur, forme fréquemment les points hauts du relief (Roc'h Trévézel...). Les niveaux schisteux peuvent localement fournir des ardoises rustiques, les quartzites livrant partout des moellons tenaces de façonnement difficile. La teinte de ces quartzites est généralement gris-vert, souvent fort sombre, et leur grain est fin; la caractéristique la plus frappante est la présence de minces veinules de quartz blanchâtre recoupant la roche. Dans les terroirs d'affleurement, ces roches ont été utilisées pour l'habitat, mais aussi pour les édifices religieux (église du Vieux-Bourg de Quimerc'h); lorsque leur taille s'avère plus aisée, elles ont pu être recherchées pour l'obtention de pavés (Châteaulin...).

51 Parmi les innombrables exemples d'emploi de ces quartzites, citons la vieille abbaye de Landévennec, aujourd'hui en ruines. Le site sur lequel les moines allaient édifier, agrandir et transformer leur abbaye offre un sous-sol d'une singulière monotonie et, plus grave, ne recelant que des matériaux de construction médiocres - en particulier les quartzites de Plougastel (surmontés toutefois par des grès moins durs de façonnement plus aisé, offrant des colorations variées passant du blanc au rouge et dénommés précisément "grès de Landévennec »). L'examen des ruines montre qu'un large appel a été fait - et ce dès le IX $x^{e}$ siècle - à ces quartzites et grès locaux, en dépit de leurs défauts ; c'est que ces matériaux frustes sont ici surabondants. Par suite du climat périglaciaire quaternaire, des blocs fendus par le gel, dispersés sur les pentes des versants et accumulés sur l'estran tout proche pouvaient être facilement recueillis sur place: les moines disposaient d'une ressource qui, à défaut de qualité, s'avérait inépuisable. Ces roches ont même été utilisées sous forme de galets ramassés sur les grèves. Les pierres locales ont ainsi joué un rôle essentiel dans les constructions du $\mathrm{IX}^{\mathrm{e}}$ siècle mais on les retrouve avec abondance dans l'église $\mathrm{du} \mathrm{XI}$, dans les remparts (en gros éléments informes), dans l'arc de la porte donnant sur la cour dite "puits de lumière " (en éléments exceptionnellement assez bien façonnés), dans le pavage du XVII ${ }^{\mathrm{e}}$ siècle... Au total, ces matériaux ont approvisionné les bâtisseurs pendant près d'un millénaire (Chauris, 2002a). 


\section{D'autres grès}

52 De nombreuses autres roches gréseuses ont été exploitées en Bretagne. Quelques informations succinctes sont ici présentées sur certaines d'entre elles.

\section{Les grès multicolores de Redon}

53 C'est sans doute à l'Ordovicien supérieur qu'il faut rapporter les formations gréseuses connues depuis longtemps des géologues sous le nom de "grès de Redon ». Dans le passé, ces roches ont été utilisées pour l'habitat (dans la ville de Redon...) et les édifices religieux (Saint-Sauveur, également à Redon...). Leur teinte va du rose-rougeâtre au mauve-violacé sombre mais elle peut aussi être verdâtre ou beige. Les faciès susceptibles de fournir des dalles ou lauzes rouges ont été exploités par la Société MenArvor, fondée à Avessac (Loire-Atlantique), dans les carrières du Pont, non loin de la vallée du Don, à l'extrémité orientale de la commune, sous les appellations commerciales de « Men Arvor Rouge » et de « Men Arvor Rustique ».

\section{Les grès pyriteux de Saint-Germain-sur-Ille}

Les roches gréseuses qui affleurent à Saint-Germain-sur-Ille, au nord de Rennes, appartiennent à l'étage ordovicien. Claires, voire blanchâtres aux affleurements, elles deviennent sombres en profondeur et renferment de la pyrite disséminée. Dans les constructions, ce sulfure de fer s'oxyde avec apparition de "rouille». L'emploi concomitant des faciès clairs et des faciès sombres, en voie d'oxydation, confère à de nombreuses constructions rennaises, un aspect bariolé peu esthétique. Par ailleurs, ces grès, posés à même le sol, conduisent l'humidité vers les parties supérieures des bâtiments ; aussi, en règle générale, ont-ils été élevés sur un soubassement schisteux (schistes rouges à Rennes). Ces grès, exploités surtout à partir de la fin du XIX $x^{\mathrm{e}}$ siècle, dans de grandes carrières à Saint-Germain, pouvaient être facilement acheminés jusqu'à Rennes par le canal d'Ille-et-Rance.

\section{Les grès en plaquettes des environs de Morlaix}

Loin d'être aussi répandu que dans le cas des schistes, le débit des grès en dalles plates est cependant assez fréquent. Aux environs de Coat-Conval, au sud de Morlaix, cette aptitude à fournir des moellons plats allongés était naguère appréciée par les maçons qui pouvaient élever leurs murs avec un minimum de mortier. Ailleurs, ce débit est accentué par une fine dissémination de séricite (variété de mica blanc) le long des plans de séparation de la roche, alors connue sous le nom de quartzite séricitique; parfois, le débit s'exaspère jusqu'à l'apparition de minces plaquettes. À Carantec, les quartzites séricitiques présentent une nette concentration dans les constructions rurales situées à proximité du principal point d'extraction (carrière de Gouezou) ; leur emploi reste plus sporadique au-delà. Ils fournissent ainsi un exemple-type d'utilisation essentiellement locale; leur aptitude à livrer des plaques a conduit aussi à les employer pour le couronnement des murettes (Chauris, 1997c). 


\section{Les grès gris-noirâtres de Plouézoc'h}

Ces dépôts du bassin carbonifère de Morlaix, appelés naguère "grès des houillères " par le comte de La Fruglaye, ont été utilisés pour les constructions (église des Jacobins à Morlaix : Chauris, 1991) et même pour la sculpture (chapiteaux de la fin du $\mathrm{XI}^{\mathrm{e}}$ siècle couronnant les piliers de la croisée du transept à l'église de Locquénolé; croix hosannière de Plouézoc'h : Chauris, 1992).

\section{Les « phtanites de Lamballe » (et d'ailleurs)}

Roches silico-carbonées très résistantes, de teinte noirâtre à nuance bleutée mais recoupées par des veinules de quartz blanc, les phtanites sont essentiellement constitués de quartz microcristallin ; leur coloration est due à la présence d'un pigment charbonneux qui, par métamorphisme, se transforme en graphite. En Bretagne, les phtanites sont connus dans deux ensembles stratigraphiques : Briovérien, au nord, sous le nom de phtanites de Lamballe ; Paléozoïque, parfois encore mal daté, au sud. Du fait de leur ténacité, les phtanites ont été recherchés dans le passé comme matériau d'empierrement. Dans les constructions, ils ne sont jamais utilisés seuls, mais apparaissent le plus souvent sous forme d'éléments disséminés de façon aléatoire au milieu d'autres roches (région de Lamballe, environs de Sarzeau...).

\section{Le grès réfractaire de la Lande du Course}

Exploités près des forges des Salles de Rohan, les grès de la Lande du Course, dans la forêt de Quénécan, sont aujourd'hui bien oubliés (cf. infra, fig. 3). Ils étaient fort estimés au XIX ${ }^{e}$ siècle pour la fourniture de pierres réfractaires. Selon E. de Fourcy (1844b), la carrière livrait «les pierres d'ouvrage de tous les hauts fourneaux de Bretagne »; les expéditions avaient même lieu "jusque dans le département de la Mayenne ». Vers 1840 , l'extraction annuelle portait sur une centaine de mètres cubes au prix moyen de $90 \mathrm{~F} / \mathrm{m}^{3}$ (à titre de comparaison, le prix du mètre cube de grès de Plourivo n'était alors que de $2,50 \mathrm{~F}$ ) : c'est dire la haute valeur alors attachée à ce grès réfractaire (Chauris, 2003b).

\section{Les « Roussards »}

Les grès rougeâtres des petits bassins pliocènes de Haute-Bretagne, appelés localement roussards, sont parfois assez indurés pour pouvoir être utilisés dans les constructions : églises de Malestroit, Glénac, Guipry, Langon, Le Grand-Fougeray en Ille-et-Vilaine, de Malestroit (Morbihan)... et tout particulièrement de Saint-Gildas-des-Bois en LoireAtlantique (photo IX).

Aujourd'hui, en Bretagne, les grès sont essentiellement extraits pour les Travaux publics (empierrements, centrales à béton, enrochements); les grès d'Erquy et d'Avessac, utilisés principalement pour la décoration, restent des exceptions. Or la variété presque infinie de leurs coloris laisse penser que plusieurs de ces matériaux, souvent originaux, pourraient être plus valorisés qu'ils ne le sont à présent. 


\section{Schistes}

61 En Bretagne, les schistes appartiennent à toutes les époques de son évolution géologique, depuis les temps briovériens jusqu'à la fin de l'ère primaire. Les différences dans les conditions de sédimentation, puis dans les contraintes tectoniques subies, les modifications introduites éventuellement par le métamorphisme, voire par les influences météoriques, ont conduit à la genèse de multiples variétés (Chauris, 2001a)

Parmi les critères de distinction, celui de la coloration est sans doute le plus frappant. Les nuances les plus fréquentes oscillent dans la palette des bleus - du bleu-gris pâle au bleu-noir - mais on connaît aussi des schistes noirs, mauves, violacés, rosés, rouges à lie-de-vin, verts, gris, mordorés... L'alternance de minces lits gréseux clairs dans le fond schisteux sombre entraîne la formation de schistes «zébrés ». Au contact d'intrusions granitiques, le métamorphisme conduit à l'apparition de schistes tachetés, noduleux, ou fortement enrichis en andalousite (faciès chiastolite) ; ces roches seront cependant évoquées ici, avec les schistes sédimentaires dont elles conservent de nombreux caractères, y compris parfois la présence de fossiles. Dans la chiastolite, le silicate d'alumine cristallise en baguettes à section carrée dont la cassure transversale montre des inclusions carbonées; leur répartition régulière mime une croix sombre sur fond clair (fig. 1 et 2).

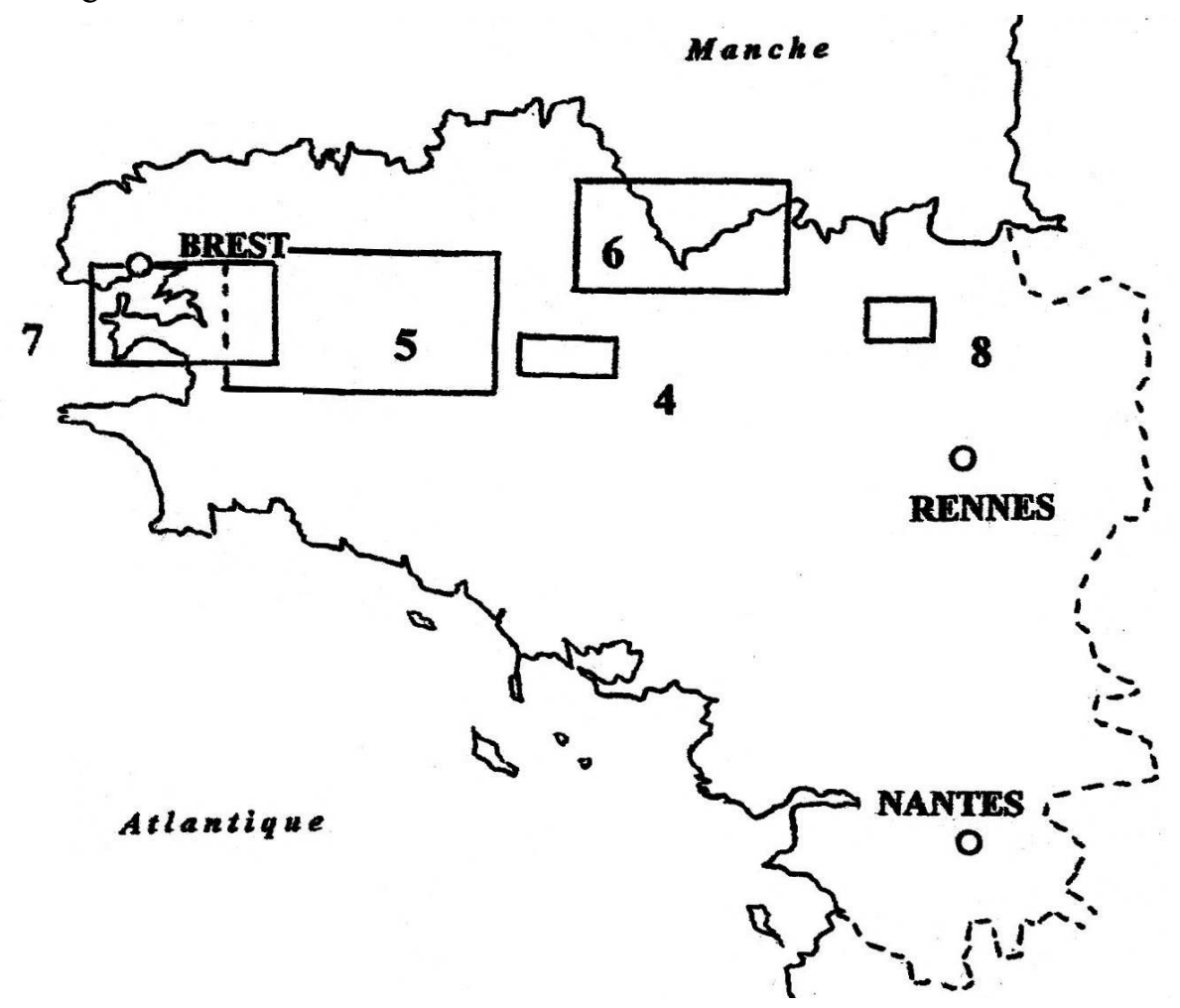

Figure 1 : Carte de localisation générale des districts étudiés (cf. fig. 2 et 4 à 8).

Figure 1: General location map of studied areas. 


\section{La Manche}

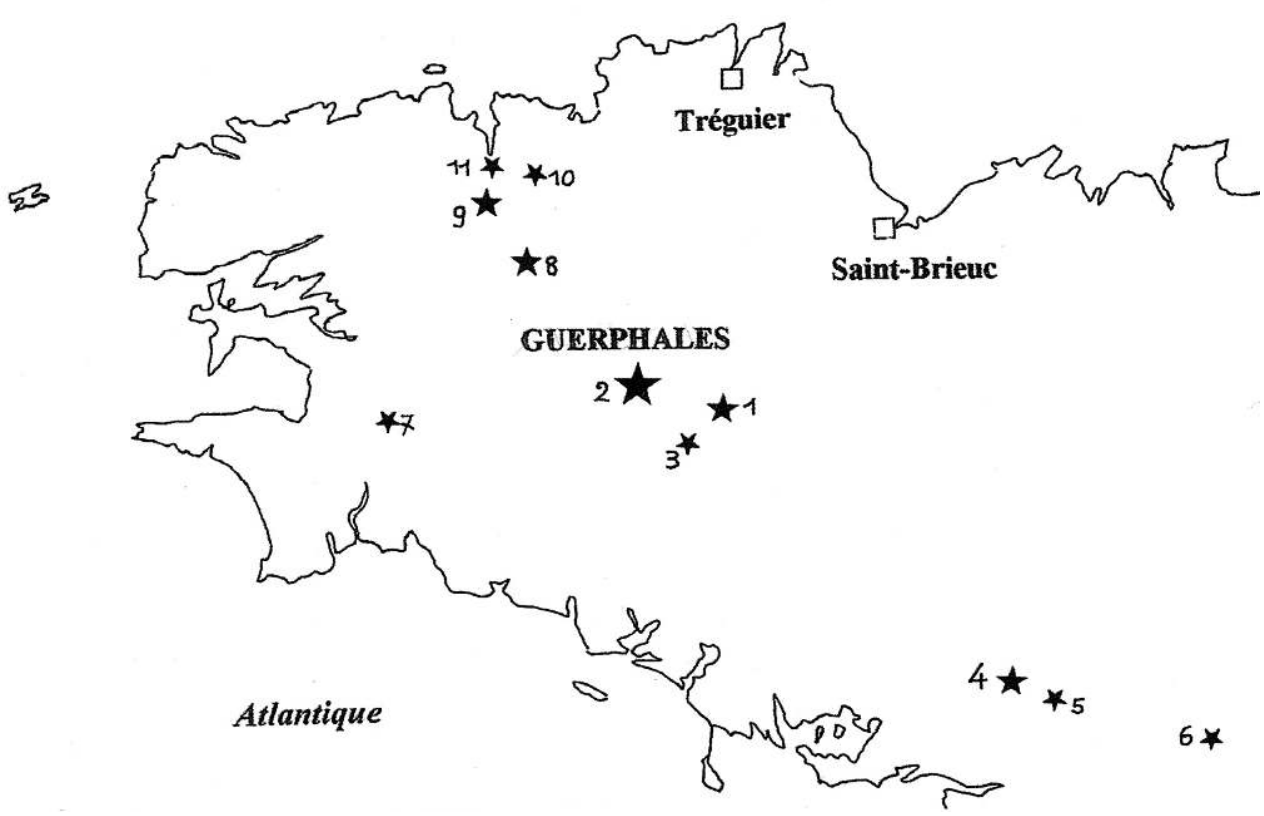

Figure 2 : Localisation des principales occurrences d'andalousite intra-schisteuses en Bretagne. 1, Les Salles-de-Rohan ; 2, Guerphalès ; 3, Séglien ; 4, Rochefort-en-Terre ; 5, Saint-Jacut-lesPins ; 6, Nozay ; 7, Landrévarzec ; 8, Huelgoat ; 9, Pleyber-Christ ; 10, Plouigneau ; 11, Morlaix (Tréguier et Saint-Brieuc sont les ports d'expédition actuels de la «Kerphalite »).

Figure 2: Location of the main intra-schist andalousite occurrences in Brittany (Tréguier and Saint-Brieuc are the today's expedition ports of "Kerphalite »).

De cette énumération liminaire, il ressort qu'en Bretagne les schistes offrent à l'activité humaine des utilisations diversifiées : feuillets minces pour ardoises; plaques épaisses pour dallage, palis ou art tumulaire ; moellons, piquets, voire pierres de taille... Mieux, si dès la Préhistoire, les schistes ont été recherchés pour l'érection de mégalithes, leur exploitation actuelle pour l'obtention de l'andalousite, matière première dans l'industrie des réfractaires, hausse la Bretagne, en ce domaine, à la première place en Europe (Chauris, 1997a).

Toutefois, en Bretagne, de nombreux schistes ne présentent aucun intérêt architectural; ils ne fournissent que de mauvais moellons, de faibles dimensions ou trop friables. Tel est le cas des schistes briovériens, gris-verdâtre, terreux et tendres du bassin de Rennes ; leur décomposition est souvent si prononcée qu'ils n'ont même pas $\mathrm{pu}$ alimenter l'habitat rural, d'où ces bâtiments en pisé, encore fréquents dans les campagnes de cette région. Toutefois, dans l'auréole de contact des massifs granitiques, ces schistes briovériens se sont transformés en cornéennes très dures, recherchées pour l'obtention de granulats (Fougères ou Saint-Broladre en Ille-et-Vilaine...); de telles roches peuvent évidemment être utilisées pour la construction (châteauforteresse de Fougères)... D'autres schistes, noirs et tachant les doigts, très répandus dans l'étage Silurien, sont totalement inutilisables pour le bâti (ampélites, riches en matière carbonée, du Houx près d'Abbaretz en Loire-Atlantique, naguère exploitées pour l'industrie des colorants). 


\section{Les schistes dinantiens bleu sombre de Châteaulin-Carhaix}

Les schistes de ce bassin carbonifère fournissent de nombreux exemples d'emploi à toutes époques. Ils sont susceptibles de livrer avec abondance des moellons plats, de larges dalles et même, localement, d'excellentes ardoises (cf. infra); toutefois, leur fissilité les empêche d'être utilisés en pierres de taille (Chauris, 1996e).

Dès l'âge du Bronze, il existait, notamment entre Châteaulin et Carhaix, des cimetières avec de petites tombes individuelles composées de dalles de schiste (Lecerf, 1979). à l'époque gallo-romaine, ces mêmes schistes ont été largement utilisés à Vorgium (l'actuelle Carhaix) : pour le recouvrement des égouts de la ville par des dalles non cimentées; comme dallage et plinthe; en carrelages sciés, de forme losangique : leur association avec un calcaire blanchâtre, de provenance lointaine, témoigne d'un goût très sûr, basé sur le contraste des coloris : les gallo-romains, qui n'hésitaient pas à importer, savaient, en même temps, tirer le meilleur parti possible des ressources du terroir (Galliou, 1987).

67 Le pont de Sainte-Catherine, sur l'Hyère, au nord de Carhaix, n'a de "gaulois » qu'un qualificatif abusif, l'ouvrage remontant probablement au Moyen Âge; les piles, aux têtes triangulaires, sont constituées par l'empilement horizontal de dalles et de moellons schisteux, s'avançant en porte-à-faux pour former les arches. La forteresse médiévale de Châteaulin a fait un énorme appel aux schistes extraits sur place. En moellons plats, les schistes bleus ont aussi été utilisés dans la ville pour la confection de murettes, de murs de soutènement de jardins et, parfois, pour l'habitat ; leur appareil irrégulier n'est cependant pas favorable au bâti.

68 Les mêmes schistes ont été mis en oeuvre pour certains ouvrages du canal de Nantes à Brest. À l'écluse de Roc'h-Caër (en Carhaix), ils forment le dallage médian du bajoyer entre les tablettes bordières en granite du Huelgoat. Cette pierre a pu aussi être utilisée en dallage devant les maisons éclusières (Roc'h-Caër, Pont-Dauvlas, Kergouthis ou Kervoulédic, également en Carhaix). Les schistes ont été également employés en moellons dans les élévations de maisons éclusières (Kervoulédic).

69 Ce matériau était naguère apprécié pour l'obtention de dalles tumulaires, tant dans la seconde partie du XIx ${ }^{e}$ siècle qu'au début $d u \mathrm{xx}^{\mathrm{e}}$, ainsi que l'attestent encore quelques tombes; mais cette pierre, aujourd'hui totalement délaissée, n'est plus qu'un témoin d'une époque révolue.

\section{Autres schistes}

70 Dans le pays de Porzay (Finistère) ont été exploités des schistes à nuance violette, souvent utilisés dans les élévations anciennes en alternance régulière avec le clair granite de Locronan. L'église de Cléguérec (Morbihan) et l'habitat ancien de Mûr-deBretagne (Côtes-d'Armor) montrent l'emploi d'un schiste bleu-gris très pâle, offrant une excellente aptitude au façonnement. À Saint-Just (Ille-et-Vilaine), des schistes mauves à rosés sont exploités par l'entreprise Men Arvor. À Ploërmel (Morbihan) étaient extraits des schistes de teinte verte.

71 Les schistes rouge sombre qui affleurent au sud de Rennes - les "schistes pourprés " des géologues - sont sans doute les plus originaux. Leur exploitation remonte loin dans le temps; l'un des sites d'extraction les plus célèbres était celui de Cahot près Pont- 
Réan, sur les bords de la Vilaine. Ces schistes rouges confèrent au bâti de la région rennaise un cachet remarquable, comme l'attestent les églises de Pont-Réan, Maure-deBretagne, Campel, Maxent, le Rheu, Orgères, Saint-Herblon, La Chapelle-des-Fougerets, L'Hermitage ou Sainte-Jeanne-d'Arc à Rennes... Leur association assez fréquente avec d'autres pierres blanchâtres (granite, calcaire), voire avec du béton (photo X), éclaire des ouvrages par trop sombres... Les schistes pourprés ont été également utilisés dans les constructions industrielles (mine de Pont-Péan...), dans les ouvrages d'art (pont sur la Vilaine au sud de Bruz...), dans les murs de clôture... Ils ont même permis de tailler des croix monolithes, caractéristiques de cette région (photo XI).

Aux environs de Saint-Nicolas-des-Eaux (Morbihan), à l'est du massif leucogranitique de Pontivy, des schistes briovériens de teinte bleu sombre, livrant de beaux moellons plats, ont été largement mis en œuvre dans l'habitat, en association avec les clairs granites voisins, réservés plus généralement aux encadrements des ouvertures (photo XII).

73 Les schistes du Dévonien inférieur (Gédinnien) du moulin de Bothoa, dans la vallée de Daoulas en Saint-Gelven (Côtes-d'Armor), peuvent livrer des dalles de grandes dimensions pour les sols et même des plaques permettant les véritables constructions en "préfabriqué » que l'on observe dans l'habitat ancien de la région (Plussulien, Laniscat...). Par diffusion d'hydroxyde de fer, leur teinte gris-bleu foncé revêt superficiellement diverses nuances de couleur rouille, ocre ou mordorée (Anonyme, 1976).

74 Des conditions de sédimentation rythmique ont provoqué la formation de roches marquées par l'alternance, indéfiniment répétée, de minces lits pélitiques bleu-noir et gréseux gris-beige, dénommées "schistes zébrés». De telles roches affleurent aux environs de Morlaix, où elles ont été exploitées dans le passé pour l'obtention de moellons fort décoratifs (photo XIII). Les carrières sont aujourd'hui abandonnées, si bien que les architectes désirant utiliser ce matériau original sont obligés de remployer les pierres de vieux bâtiments. Il ne fait guère de doute que cette roche pourrait connaître un bel avenir avec les moyens actuels de façonnage (sciage...) qui limiteraient les déchets. Parmi les très nombreux exemples d'utilisation, citons le couvent de Cuburien ( $\mathrm{XVI}^{\mathrm{e}}$ et $\mathrm{XVII}^{\mathrm{e}}$ siècles) en Saint-Martin-des-Champs (Chauris, 1996a), celui des Ursulines (xvII e siècle) à Morlaix (photo XIV)... (Chauris, 1996b, c et d).

75 Quelques schistes singulièrement compacts se signalent par leur aptitude au façonnement, mise à profit pour l'obtention de pierres de taille ouvragées, particulièrement des linteaux droits ou des cintres. De tels schistes sont connus dans la formation dévonienne du "Coblencien ${ }^{1}$ " où ils offrent une coloration d'un bleu très sombre (ancien presbytère de Gouarec, Côtes-d'Armor, tout en schiste y compris son fronton sculpté). Une roche assez comparable, également du Dévonien inférieur, a été exploitée au sud de Landerneau (Finistère). Elle est elle aussi apte à un façonnage soigné (photo XV) et, par ailleurs, elle livrait de superbes moellons dont l'allongement pouvait atteindre près de quatre mètres (église de la Roche-Maurice); la carrière de Saint-Eloy était réputée pour la longueur des éléments extraits.

Le schiste ordovicien de Nozay en Loire-Atlantique (carrières de La Vilatte...), à grain très fin, s'avère lui aussi remarquable. Connu sous le nom de "pierre bleue de Nozay ", il a été mis en œuvre pour la construction d'églises (Nozay, Joué-sur-Erdre, Conquereuil en Loire-Atlantique ; Corps-Nuds en Ille-et-Vilaine...) ou d'ouvrages d'art du chemin de fer, ainsi que dans l'habitat (linteaux, escaliers à vis, cheminées...), mais aussi en palis 
de clôture ou de construction (photo XVI), en bordure de trottoirs et pour la confection de croix et d'auges. (Anonyme, 1975); cette roche a même pu donner quelques réalisations d'art funéraire très élaborées (photo XVII). Le schiste de Juigné-lesMoutiers (carrière du Fertais), également en Loire-Atlantique, a été recherché pour l'édification d'églises (Saint-Julien-de-Vouvantes, Riaillé, Juigné-Les-Moutiers), pour les ouvrages d'art du chemin de fer de Nantes à Segré..., ainsi que pour des cheminées, linteaux ou monuments funéraires (monument aux morts de Saint-Julien-deVouvantes).

77 Localement, certains schistes présentent un débit en baguettes très allongées. Ces schistes esquilleux, dits « en barrettes » ont été exploités dans la région de Nozay : ne pourrissant pas, ils remplaçaient avantageusement le bois pour échalas dans les vignes et piquets de parcs à huîtres.

78 Alors que les schistes "classiques ", du fait de leur fissilité plus ou moins accusée, se révèlent le plus souvent inaptes à l'obtention de moellons bien équarris, les schistes à andalousite (faciès chiastolite), par suite de leur texture de type cornéenne, constituent de bons matériaux de construction, susceptibles parfois de fournir des pierres de grand appareil (fig. 2). Un remarquable exemple est donné par l'abbaye de Bon-Repos (SaintGelven, Côtes-d'Armor), érigée non loin de l'étang des Salles de Rohan: la façade principale des bâtiments conventuels a fait un large appel aux schistes truffés de chiastolite qui lui confèrent un aspect des plus singuliers. Mais ici la minéralogie confine à l'héraldique. Les cristaux de chiastolite étaient connus par les anciens auteurs sous le nom de "macles" (parfois orthographié "mâcles»). Comme le rappelle le minéralogiste A. Lacroix (1893), "il semble que l'introduction de ce terme dans la langue héraldique tienne à ce que les Rohan sur les terres desquels se trouvait le célèbre gisement des Salles, au pied du château, les avaient représentés dans leurs armes ». Marc Vulçon de La Colombière (cité par Lacroix) écrivait en 1744 : «J'estime que les seigneurs de Rohan, qui sont les premiers à mon advis qui ont porté ces figures dans leurs armes... les ont prises, pour ce que dans le très ancien vicomté de Rohan... il y a quantité de petits cailloux, lesquels estant couppez en deux, l'on y voit dedans cette figure marquée... Ce qui estant extraordinaire et particulier à cette contrée, ce n'est pas sans sujet que les anciens Seigneurs d'icelle ayans remarqué cette merveille, ont pris ces figures pour leurs armes, et les ont transmises à leurs descendans, et leur ont donné le nom de Macles, qui vient du latin Macula, qui signifie tache, une macule ou une marque; d'où quelques uns de cette maison ont pris pour devise sine macula macla..." (fig. 3). Bien plus à l'ouest, dans la région de Morlaix - Pleyber-Christ Plourin (Nord-Finistère), les schistes à chiastolite ont là aussi été fréquemment recherchés pour le bâti, tant en ville qu'en zone rurale.

79 Quelques extractions de schistes ont été observées au bord de la mer. Outre le cas des schistes tégulaires (cf. infra), citons les anciennes perrières du Porzay en baie de Douarnenez, et celles des environs de l'abbaye de Beauport près de Paimpol (Chauris, 1998a ; 2004).

80 L'emploi des schistes dès les temps néolithiques se doit d'être rappelé. Si la Bretagne est surtout connue pour ses menhirs et ses dolmens en granite, il ne faut pas oublier que, dans les districts où ce matériau vient à manquer, appel a pu être fait aux schistes plus proximaux. Parmi quelques exemples remarquables, vient en premier lieu le dolmen «à portique » de la Roche-aux-Fées (Essé, Ille-et-Vilaine). Cet ensemble qui dépasse $20 \mathrm{~m}$ de long et comporte 41 éléments a été édifié en schiste pourpré. L'examen 
morphologique des blocs suggère un prélèvement sur des affleurements naturels et non une extraction en carrière. Fait digne d'être souligné, les occurrences les plus proches de cette roche sont situées à près de $5 \mathrm{~km}$ au sud du mégalithe: bel exemple de transport de matériaux pondéreux à une époque reculée, d'autant plus que le poids de certains blocs est de l'ordre d'une quarantaine de tonnes! (Le Roux, 1998). Près de Saint-Just (Ille-et-Vilaine), plusieurs menhirs élancés, dressés sur la lande de Cojoux, sont en schiste de provenance locale. Les allées couvertes de Liscuis en Laniscat (Côtesd'Armor) ont utilisé d'épaisses et grandes dalles de schiste dévonien prélevées à proximité. De même, à Castel-Ruphel en Saint-Goazec (Finstère) ont été mises en œuvre d'épaisses dalles de schiste local (photo XVIII).

En fait, l'emploi des schistes en Bretagne est de toutes les époques et concerne tous les types de construction. En sus des cas déjà cités, différents exemples, rapidement énumérés et limités au seul Finistère, attesteront cette assertion :

- édifices religieux : abbaye du Relecq à Plounéour-Menez (Chauris, 1994a); couvents des Jacobins (Chauris, 1991) et du Carmel (Chauris, 1996 d) à Morlaix ; églises de Saint-Rivoal et de Saint-Cadou dans les monts d'Arrée; chapelles Saint-Gildas et Sainte-Barbe en Ploeven dans le Porzay; églises de Pleyber-Christ, de Loc-Eguiner-Ploudiry, du Vieux-Quimerc'h; église de Guipavas (reconstruite après la dernière guerre)...

- Château médiéval de La Roche-Maurice; châteaux récents de Keromnès et du Frout en Carantec (Chauris, 1997c).

- Habitat, entre autres à Morlaix, en association avec des granites, induisant un remarquable polylithisme (maison Penanault : photo XIX ; Chauris, 2005b)...

- Infrastructures routières : parapet de la route de corniche Morlaix-Carantec à Toul Mahot (Chauris, 1997b); ouvrages militaires de la défense avancée de Brest: Portzic, Capucins, Cornouaille (Chauris, 1998b) ; équipements maritimes : écluse de Morlaix (Chauris, 2003c), phare de la Lande à Carantec (Chauris, 1995); infrastructures ferroviaires : ponts sur la ligne Paris-Brest aux abords de Morlaix (Chauris, 1997d).
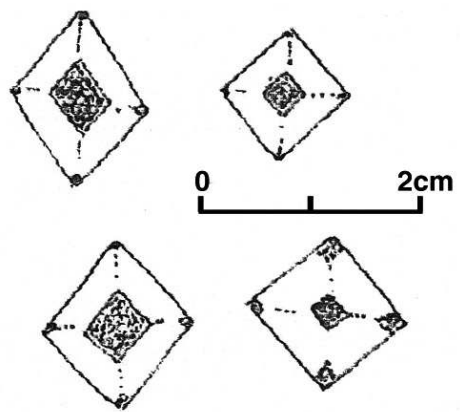
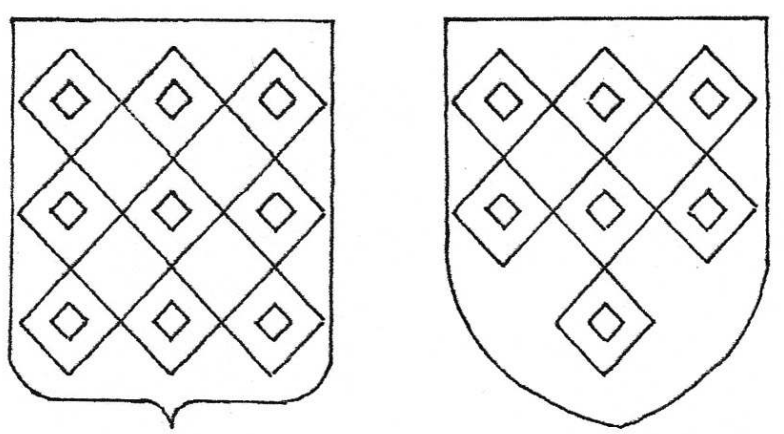

Figure 3 : Coupes dans des cristaux d'andalousite (faciès chiastolite) des Salles-de-Rohan, et blasons de Rohan, à sept ou neuf macles.

Figure 3: Sections of chiastolitic andalousite crystals from Les Salles-de-Rohan, and coats-of-arms of the Rohan family, with seven or nine «macles »

-Voire même statuaire : porche de l'église à Plomodiern.

\section{Schistes ardoisiers}

Les schistes tégulaires méritent un développement particulier, tant les toits d'ardoises font partie intégrante de l'environnement breton. Les nombreux districts exploités appartiennent à diverses périodes géologiques. Au Briovérien se rapportent les 
ardoisières de la Roche-Derrien (Côtes-d'Armor), du Trégorrois occidental vers la limite Côtes-d'Armor-Finistère (Plestin-les-Grèves, Plouégat-Guérand...), des environs de Callac (Bourgneuf), également dans les Côtes-d'Armor; en Ille-et-Vilaine, ce seront celles de Montfort, de Mauron, de Saint-Aubin-des-Landes près de Vitré... À L'Ordovicien moyen appartiennent les districts de Caurel-Mûr-de-Bretagne (Côtesd'Armor ; fig. 4), de Gourin (ardoisières de Kerrouec, Penquerhoët, Penhoat-Conveau), de Rochefort-en-Terre et de Sérent dans le Morbihan, de Tréogan (Liors-Margot et de Rest-Louët) dans les Côtes-d'Armor, de Riadan et de Renac en Ille-et-Vilaine, du GrandAuverné en Loire-Atlantique. Au Dévonien inférieur, on trouve Sizun, Commana, Plounéour-Menez dans les Monts d'Arrée (Finistère). Au «Coblencien » 1, le district de Lohuec et les environs de Rouillac (Côtes-d'Armor) et, au Carbonifère inférieur (Dinantien), les sites du bassin de Châteaulin, les plus importants de tous. Quelques ardoisières sont ouvertes dans des terrains d'âge imprécisé : Carantec, Bourbriac. (Autissier, 1891 ; Perret, 1927 ; Chaumeil, 1938 ; Mulot, 1971 ; Chauris, 1994b ; 1998a ; 2002c).

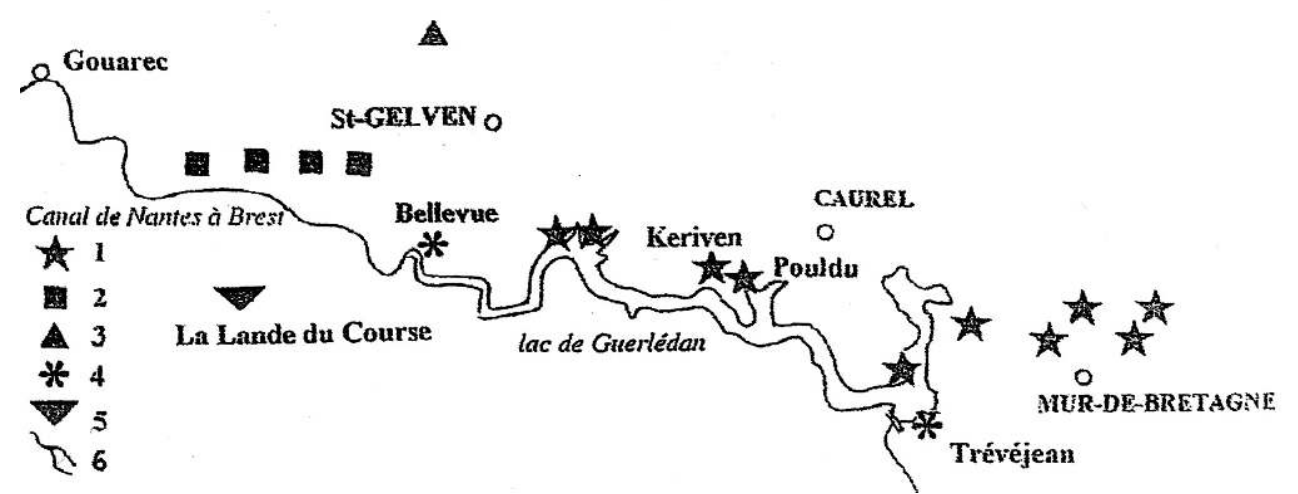

Figure 4 : Localisation schématisée des ardoisières du secteur de Gouarec - Mûr-de-Bretagne (Côtesd'Armor). 1, Caurel et Mûr-de-Bretagne (Ordovicien) ; 2, Saint-Gelven (Dévonien) ; 3, Correc, en SaintGelven (Dinantien). Sont également indiquées : 4, les carrières de granulats de Bellevue et Trévéjan ; 5 , l'ancienne exploitation des grès réfractaires de la Lande-du-Course ; 6, Canal de Nantes à Brest et lac de Guerlédan.

Figure 4: Schematic location of slate quarries in the Gouarec - Mûr-de-Bretagne area (1 to 3). Also indicated are Bellevue and Trelevan gravel quarries (4), as well as the ancient Lande-du-Course quarry of refractory sandstone (5), canal from Nantes to brest and lake of Guerlédan (6)

\section{Le bassin de Châteaulin}

L'époque des premières extractions à Châteaulin reste encore imprécisée mais elle remonterait au moins au XVI ${ }^{\mathrm{e}}$ siècle : l'église Saint-Maclou de Rouen a été en partie couverte avec de l'ardoise achetée à Châteaulin vers 1526 ; l'histoire du monastère de Landévénnec par Dom Noël Mars, datée de 1640, évoque la présence, à proximité du prieuré de Châteaulin, de «carrières d'ardoises très excellentes » et, en 1672, Jouvin de Rochefort est frappé par la présence "des perrières d'ardoise très fine qu'on vient quérir des pays étrangers par mer ». Les archives départementales du Finistère conservent un arrêt du parlement de Rennes, en date du 31 octobre 1766, se rapportant à «tous perreyeurs de perrières d'ardoises situées aux paroisses de Châteaulin, SaintCoulitz, Saint-Ségal »... (Chauris, 1996e). « Le pays est formé de montagnes schisteuses, de carrières d'ardoises ": c'est en ces termes que Cambry, à la fin du xvIII siècle, évoque Châteaulin et ses abords. Ogée, de son côté, écrit dans son dictionnaire de 
Bretagne (1778) : " Ses environs fournissent un grand nombre de carrières d'ardoises ». Dans son « Voyage dans le Finistère en 1829, 1830 et 1831 », Brousmiche, rapportant sa promenade "très agréable » sur le chemin de Port-Launay à Châteaulin, parle « des carrières d'ardoises... en pleine exploitation sur les deux rives de l'Aulne »; il va jusqu'à déplorer que « les débris qu'on en retire... fatiguent la vue par leur couleur sombre ».

E. de Fourcy (1844b) apporte des précisions sur cette activité extractive. "Les ardoisières les plus importantes du département sont, sans contredit, celles de Lothey, de Châteaulin et de Saint-Ségal. Les exploitations de ces communes sont si multipliées qu'elles touchent presque l'une à l'autre... Les carrières sont situées, pour la plupart, au bord même du canal ». De Fourcy note que les ardoises de Châteaulin s'expédient au loin, à partir de Port-Launay, jusque «sur les côtes de Normandie ». Mais l'ingénieur constate que l'industrie ardoisière n'a point encore fait à Châteaulin les mêmes progrès qu'aux environs d'Angers. Il avait remarqué, lors de son passage, que la fente des ardoises n'était «pas très soignée ». De plus, les exploitations étaient pour la plupart « mal conduites » et, plus grave, « quelques unes présentaient du danger pour l'ouvrier, et il arrivait fréquemment des accidents». Quelles étaient les causes de ce "mauvais aménagement du gîte ardoisier»? De Fourcy relève d'une part, "l'exiguïté des ressources »... et d'autre part, "l'absence de surveillance ». Il note cependant avec satisfaction que le «département a remédié, depuis, à ce dernier inconvénient, en allouant les fonds nécessaires à la création d'un conducteur garde-mines ", initiative dont on a pu mesurer rapidement « les heureux effets ». Toujours selon E. de Fourcy, le groupe ardoisier de Châteaulin, Saint-Ségal, Lothey et Gouézec comprenait, en 1838, 25 carrières à ciel ouvert, et 5 carrières souterraines, situées principalement sur les bords de l'Aulne canalisée. Il occupait 500 à 600 ouvriers.

Avec l'ouverture du canal de Nantes à Brest (1842), les sites d'extraction ont eu tendance à se déplacer vers l'est. En 1935, le nombre d'exploitations avait considérablement diminué, compensé, au moins en partie, par la concentration de l'activité sur quelques sites majeurs: Stéréon en Pleyben, Le Rick en Saint-Goazec, Moulin-Neuf en Motreff, Moulin-Lande en Maël-Carhaix, d'autres encore... Mais, après la dernière guerre, la concurrence nationale (Angers) et internationale (Espagne) va entraîner inexorablement la fermeture successive des gisements et la célèbre ardoisière de Moulin-Lande - «la Reine» pour les ardoisiers bretons - qui s'était maintenue jusqu'en 1984, s'arrête à son tour... Mais c'était sans compter sur l'énergie d'Y. Barazer qui, peu d'années après, en 1988, ranime le site. Dès 1989, la production atteint 1500 tonnes d'ardoises, et environ 4000 tonnes en $1993 \ldots$ preuve tangible à la fois de l'énergie bretonne et des atouts d'un matériau de grande classe. Malheureusement, Maël-Carhaix a dû fermer à nouveau en 2000.

La carte que nous avons dressée établit la part prépondérante prise par le bassin de Châteaulin dans la répartition des ardoisières ouvertes en Centre-Ouest Bretagne (fig. 5). Plus au nord, dans les Monts d'Arrée, principalement à Sizun et à Commana (le " district de Saint-Cadou »), les ardoises sont épaisses et qualifiées de rustiques - ce qui ne nuit d'ailleurs en rien à leur beauté. Plus au sud, dans les Montagnes Noires, près de Gourin, les ardoises naguère exploitées appartiennent au même étage géologique (Ordovicien moyen) que celles du district angevin (Trélazé...).

Dans le bassin de Châteaulin, les ardoisières sont principalement concentrées dans la partie méridionale de la structure géologique. Les affouillements dus à l'Aulne et à ses affluents y ont favorisé la reconnaissance des gisements, le canal de Nantes à Brest 
facilitant l'expédition des ardoises par Port-Launay ; le chemin de fer à voie étroite et l'amélioration du réseau routier ont également encouragé le développement des extractions par la suite. La plus importante exploitation à ciel ouvert était celle du Rick en Saint-Goazec, atteignant $80 \mathrm{~m}$ de profondeur, la veine ardoisière offrant ici $50 \mathrm{~m}$ de puissance. L'entreprise produisait elle-même son énergie dans une usine hydroélectrique installée sur l'Aulne et la situation du fond de la carrière au-dessus de la vallée de l'Aulne facilitait l'évacuation des eaux. Malheureusement, le 18 mars 1937, un gigantesque éboulement détruisit une partie de l'exploitation... Dans cette constellation, l'ardoisière de Moulin-Lande à Maël-Carhaix sera décrite en détails à titre d'exemple.
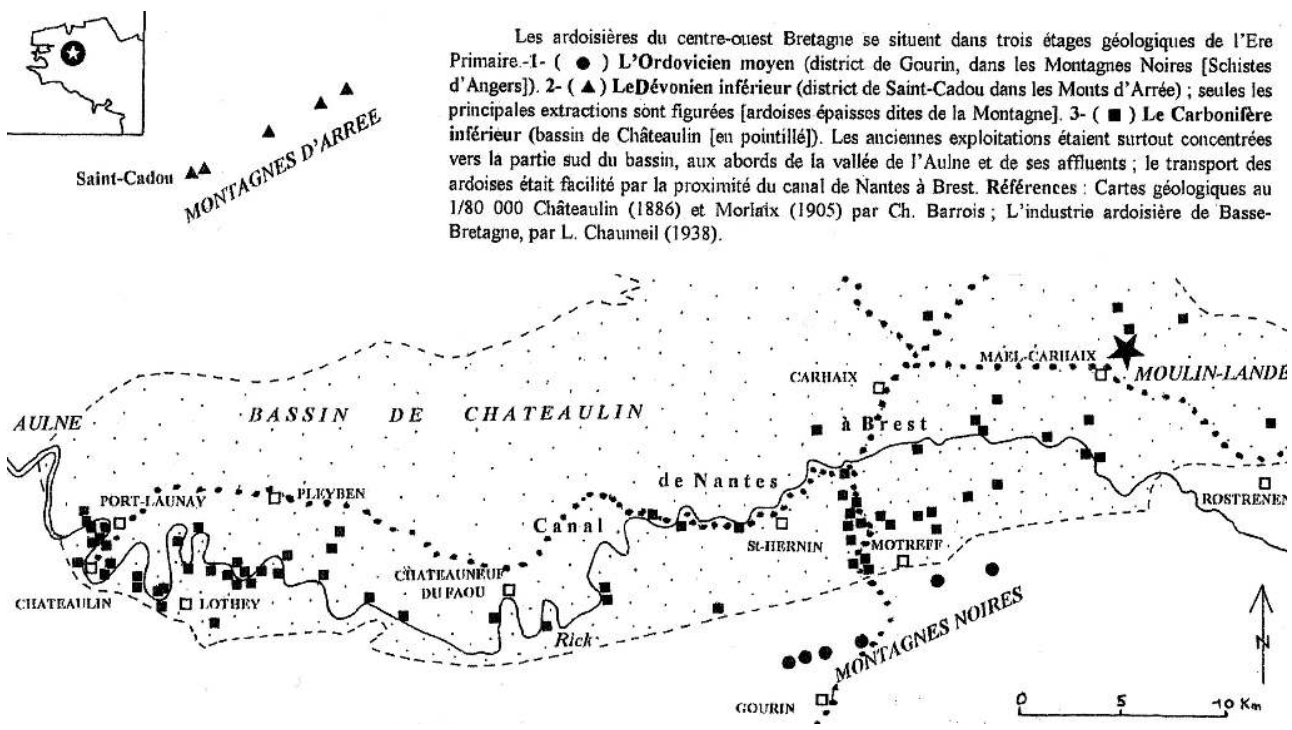

Figure 5 : Distribution des ardoisières du Centre-Ouest Bretagne par rapport au canal de Nantes à Brest et aux voies ferrées.

Figure 5: Location of slate quarries in Western Central Brittany, relative to the Nantes-Brest canal and railways.

\section{Moulin-Lande, « La reine » des ardoisières bretonnes}

Occupant une position quelque peu excentrée dans le bassin ardoisier de Châteaulin, ce gisement fut ouvert seulement à la fin du XIX $x^{e}$ siècle, en 1890. (Le Portal, 1989 ; Chauris, 2000). L'ardoise de Moulin-Lande offre une superbe coloration bleu-nuit. Elle présente une résistance exceptionnelle à l'altération météorique - elle est d'ailleurs "garantie à vie » - par suite de l'absence pratiquement totale de carbonate de chaux (elle est, en outre, dépourvue de pyrite). Sa densité est de $2760 \mathrm{~kg} / \mathrm{m}^{3}$. Jusqu'à la toute récente fermeture du site, l'accès aux chambres d'exploitation se faisait par le puits dit de $L a$ Prairie, foncé en 1929 jusqu'à $-60 \mathrm{~m}$; à partir de ce niveau, le fond de l'exploitation, à près de $-200 \mathrm{~m}$, était atteint par un autre puits. Le gisement était également accessible par le puits $d u$ Milieu, ouvert plus à l'ouest et servant éventuellement de puits de secours.

Le schiste ardoisier, qui présente une orientation générale est-ouest, était extrait dans d'impressionnantes chambres souterraines, pouvant atteindre jusqu'à $50 \mathrm{~m}$ de longueur sur une largeur de 17-18 m (correspondant à la puissance de la veine ardoisière) et une hauteur de voûte allant jusqu'à 30 à $40 \mathrm{~m}$ ! L'extraction s'effectuait par la méthode dite "en descendant ", ce qui explique la hauteur des chambres à la fin 
de leur exploitation. Cette méthode a l'inconvénient de nécessiter la montée au jour de tous les blocs de schiste, même inutilisables, puisqu'il n'est guère possible de laisser ces matériaux s'accumuler sur la sole - ou plancher - de la chambre, toujours en voie d'approfondissement. Mais elle offre en contrepartie un grand avantage sur l'autre méthode (dite « en montant ») qui, par suite de l'abattage des blocs depuis la voûte de la chambre, entraîne des risques de fracturation lors de leur chute.

Naguère, la découpe de la veine ardoisière s'effectuait à l'aide de coins, emplacés le soir. Selon une tradition orale encore bien ancrée, « la pierre travaille de minuit à une heure du matin et de midi à une heure de l'après-midi »... Toujours selon les dires des anciens, c'est à ces moments qu'avaient lieu les éboulements redoutés. Pour surveiller l'éventuel écroulement de la voûte, les anciens revêtaient les points sensibles avec de la boue, sa fissuration les prévenant des dangers. Ultérieurement, la solidité de la voûte était assurée par des boulons d'ancrage. La découpe de la veine ardoisière s'effectuait à partir de la foncée (tranchée exécutée préalablement dans la masse du schiste), à l'aide d'une haveuse, sorte d'énorme tronçonneuse. Les blocs de schiste, solidement enchaînés, étaient ensuite montés par le puits sur le carreau de l'exploitation.

91 En 1999, le rendement de Moulin-Lande a été de l'ordre de $30 \%$ - ce qui est tout à fait honorable, mais il a pu parfois être même supérieur. Ces fluctuations sont dues à l'apparition de veines quartzeuses qui perturbent la régularité du niveau ardoisier et à la présence de minces lits gréseux de quelques centimètres d'épaisseur maximale, connus en breton sous le nom de « kailh». Ces passées gréseuses empêchent le clivage du schiste et doivent impérativement être éliminées (en outre, contrairement au schiste, elles peuvent renfermer un peu de pyrite).

$\mathrm{Au}$ jour, la première opération de traitement du schiste consistait en l'obtention de grandes dalles, d'une dizaine de centimètres d'épaisseur, aussitôt débitées par une scie circulaire en parallélépipèdes rectangles de dimensions légèrement supérieure au gabarit prévu pour l'ardoise et dénommés repartons. Plus l'inclinaison des kailhs par rapport à la fissilité du schiste est faible, moins il sera possible d'obtenir de repartons par dalle... De là, les énormes tas de blocs rebutés qui confèrent à l'environnement des ardoisières une tonalité si caractéristique. Avant l'emploi de la scie, l'obtention des repartons se faisait par l'opération appelée "quernage ", à l'aide de coins emplacés dans une rainure, d'où un plan de coupe plus irrégulier. Si les blocs schisteux ne pouvaient être travaillés dès leur remontée, ils étaient protégés par une couverture humide. En l'absence de cette précaution, sous l'influence de la chaleur du soleil, voire même de l'air, la fente de l'ardoise n'avait pas lieu dans de bonnes conditions: le schiste était alors considéré comme " mort » car, toujours selon la tradition, au sortir de la carrière souterraine, «la pierre est vivante ».

Après sciage, les repartons ainsi formés étaient amenés aux fendeurs d'ardoises. Chaque ouvrier travaillait debout devant son lot de repartons, toujours recouverts jusqu'au moment de la fente. Pour cliver le reparton, placé verticalement, le fendeur frappait sur un ciseau à lame très fine, préalablement graissée au saindoux, avec un maillet en buis : aussitôt, le schiste se clivait en deux parties, qui allaient à leur tour être clivées jusqu'à l'épaisseur voulue pour l'ardoise. Le profane demeure béat d'admiration devant l'habileté de l'ouvrier qui, imperturbable, fend le schiste si aisément. Mais cette facilité n'est qu'apparente, comme en témoigne le long apprentissage nécessaire pour acquérir une telle maîtrise. À Moulin-Lande, il y avait, en 1999, trois fendeurs, produisant journellement, chacun, 3500 à 4000 ardoises. 
La dernière opération subie par l'ardoise était le rondissage, à savoir la formation d'un biseau sur ses quatre côtés. Rondir l'ardoise répond à un double but : technique (casser la goutte d'eau sur le toit) et esthétique (accroître la beauté de la couverture). Il ne restait plus alors qu'à emplacer les ardoises, selon leurs dimensions et leur épaisseur, dans des palettes en bois, déposées sur l'aire de stockage, prêtes à l'expédition. En 1999, 27 personnes travaillaient à Moulin-Lande : un dizaine " au fond », les autres « au jour " dans les ateliers (sciage, fente, rondissage, manutention...).

Du fait de ses qualités exceptionnelles, l'ardoise de Maël-Carhaix était très appréciée par le Service des Monuments historiques. Parmi ses utilisations les plus prestigieuses, on citera, entre autres, la couverture des Invalides à Paris, de la cathédrale du Mans, des Halles de Questembert... À juste raison, l'entreprise de Moulin-Lande était fière d'avoir été choisie lors de la restauration du parlement de Bretagne à Rennes antérieurement couvert avec les ardoises de Ploërmel : $5200 \mathrm{~m}^{2}$, soit 400 tonnes d'ardoises.

\section{D'autres gisements}

Faute de place, il n'est pas possible d'examiner ainsi les autres secteurs ardoisiers. Parmi les nombreux gisements, quelques sites méritent de retenir encore l'attention du fait de leur situation géographique originale, au bord de la mer comme à Carantec en baie de Morlaix, ou dans la «montagne » comme à Sizun et à Commana.

\section{Au bord de la mer...}

L'ardoisière de Roc'h-Glas en Carantec est ouverte sur la rive occidentale de la rade de Morlaix (photo XX). Ce toponyme, qui signifie « Roche bleue ", suggère que le site avait été repéré de longue date; son exploitation est attestée au milieu du XIX ${ }^{e}$ siècle. Son originalité repose sur le fait que les extractions avaient lieu sur l'estran lui-même c'est-à-dire dans la zone de balancement des marées - et un peu en retrait, dans la falaise littorale. L'examen du front de taille de la carrière «terrestre » montre qu'il y a d'abord eu des excavations peu profondes, entaillées ultérieurement par l'exploitation plus récente. Les déblais descendent jusqu'au rivage, formant une falaise anthropique. L'exploitation sur l'estran est soulignée par une morphologie artificielle, avec l'arrêt des extractions sur les plans des diaclases, jouant le rôle de sole. Tout l'estran est parsemé de débris de taille qui, mis en mouvement par la mer, tendent à s'émousser. Ces fragments sont entraînés vers le sud par la dérive littorale, jusqu'à plus d'un kilomètre de l'ardoisière. Ce transport naturel est évidemment facilité par leur forme en plaquettes (Chauris, 1994b).

À l'entrée de la baie de Morlaix, au droit de Roscoff, les récifs des Duon frappent par la teinte sombre des chicots rocheux qui en constituent la partie occidentale - et c'est à cette coloration que le site doit son nom (Duon = Les [roches] Noires). Or ces roches, d'accès fort difficile et battues des flots, ont été pourtant naguère exploitées pour l'obtention d'ardoises, que l'on peut encore observer sur quelques maisons de Carantec (ces schistes sont très bien caractérisés par l'abondance du minéral chloritoïde). Nous avons ici un témoignage éloquent sur les activités de nos pères : à la fois leur sens aigu des richesses naturelles locales et leur hardiesse pour les arracher à un milieu hostile... 


\section{...Et dans la « Montagne »}

En Bretagne, l'habitude est prise, depuis des temps immémoriaux, de désigner sous le terme de "montagne» les hauteurs dénudées de l'Arrée, dont les rocs déchiquetés surgissent de la lande comme les échines d'une horde de dragons. Cette ligne de crête est essentiellement constituée par des schistes et des quartzites d'âge dévonien; localement, sur son versant septentrional, les schistes offrent une fissilité grossière qui les rend aptes à l'obtention d'ardoises épaisses, extrêmement résistantes, de teinte grisbleuté à reflet argenté - connues sous le nom de «mein menez » (pierres de montagne). Dans le passé, de nombreuses petites excavations artisanales ont été ouvertes sur ces hauteurs. Leurs traces sont encore visibles par les accumulations de débris de taille au milieu des ajoncs et des bruyères. (Anonyme, 1991).

Les travaux de restauration entrepris par le service des Monuments historiques permettent le maintien de quelques exploitations. L'une est située au sud-ouest de Saint-Cadou en Sizun, en bordure du chemin GR 380 ; c'est la carrière de M. Ursule qui a récemment extrait et façonné environ 30000 ardoises pour la cathédrale de Quimper et environ 10000 pour celle de Tréguier. Deux autres carrières sont ouvertes au sud-sudest du bourg de Commana, non loin de la RD 11. La carrière connue sous le nom d'« Ardoisières de Commana " est l'ancienne exploitation des frères Rolland, devenue aujourd'hui la carrière Ahys. L'unique ouvrier du gîte extrait et fend les blocs de schiste mais ne les taille pas; le façonnage de l'ardoise s'effectue à Ploërmel dans le Morbihan. La carrière, à ciel ouvert, avait atteint une profondeur de $25 \mathrm{~m}$; le fond est à présent remblayé sur une dizaine de mètres. Une tranchée avait été pratiquée sur le flanc nord de l'excavation pour le passage de rails sur un plan incliné, mais actuellement les blocs sont remontés sur le terre-plein par une tractopelle. Parmi les travaux réalisés récemment avec les ardoises de cette carrière, citons les toitures de l'église de Bodilis dans le Finistère et du château de Suscinio dans le Morbihan.

La carrière voisine est exploitée par l'« Union des Couvreurs » de Morlaix. Elle travaille également pour partie avec le service des Monuments historiques (récemment pour la cathédrale de Saint-Pol-de-Léon). L'exploitation - qui atteint une quinzaine de mètres de profondeur - est assurée par deux ouvriers qui prennent en charge à la fois l'extraction, la fente et le façonnage de l'ardoise. La seule concession à la mécanisation est l'emploi d'une tractopelle qui facilite le transport sur le terre-plein des déblais et des dalles de schiste destinées à la fente. Chaque ardoise est percée de deux trous pour la fixation sur les toits au moyen de clous en cuivre. Les ardoises se chevauchant des deux tiers, il en faut environ une tonne pour couvrir $10 \mathrm{~m}^{2}$. Les ardoises obtenues sont de calibre divers ; certaines sont de véritables lauzes. Ces considérations expliquent que la production des deux ouvriers ne soit, en moyenne, que de 900 ardoises par semaine. $\mathrm{Du}$ fait de leur caractère artisanal, les ardoisières des Monts d'Arrée, devenues indispensables pour les restaurations, poursuivront sans doute encore à l'avenir leur longue histoire, à la satisfaction des amoureux de l'emploi persévérant des pierres du terroir.

\section{Poudingues et brèches}

102 Ces formations sédimentaires, d'origine détritique, sont regroupées sous le terme plus général de conglomérats. Au sens strict, les brèches montrent des éléments anguleux, 
les poudingues des éléments arrondis, tous réunis par un ciment à grain fin. Le plus souvent, les conglomérats sont polygéniques, à savoir constitués d'éléments de nature lithologique variée. Leur origine étant à rechercher dans l'érosion des reliefs, ils se sont souvent déposés à la base des terrains transgressifs sur les chaînes de montagnes arasées ; ainsi, en Bretagne, le conglomérat dit « de Montfort », à l'ouest de Rennes, ou celui d'Erquy-Fréhel, dans les Côtes-d'Armor... Le cas de la "pierre des landes » est totalement différent, en relation avec des processus pédogénétiques in situ. À part le poudingue de Montfort et la pierre des landes, ces roches sont en règle générale, du fait de leur hétérogénéité, peu utilisées pour les constructions.

\section{Le poudingue de Montfort}

103 Appelée ainsi par les géologues, cette pierre est un conglomérat à éléments quartzeux blanchâtres se détachant dans un fond dont la teinte rouge très sombre est due à l'oxyde de fer. Ce matériau original a été recherché à l'ouest de Rennes, souvent avec les schistes rouges, pour la construction d'églises : à Saint-Péran (où le bénitier a même été façonné dans le conglomérat) ; à Talensac, dans les contreforts ; à Montfort-surMeu, dans le soubassement et même en pierres de taille dans les contreforts ; à SaintGilles (porte...) ; à L'Hermitage... La pierre de Montfort a été également utilisée pour l'habitat, et ce jusqu'à Rennes même (photo XXI) ; au Rheu, elle a servi à bâtir la Poste...

\section{Le conglomérat d'Erquy}

104 À Erquy, la base du Paléozoïque est constituée par un puissant niveau de roches conglomératiques, à dominante quartzeuse, présentant en outre de fréquents galets de phtanite noir-bleuté et de cornaline rougeâtre, matériaux particulièrement résistants en provenance des formations briovériennes érodées. D'excellents affleurements sont observables à l'extrémité orientale de la plage de Sables-d'Or-les-Pins à proximité de Port-Barrier, ainsi qu'au cap d'Erquy (photo XXII). Bien que très hétérogène, ce matériau a été localement mis en œuvre : corps de garde du Cap d'Erquy ; travaux de construction d'une jetée dans ce port. Le 22 mars 1833, la commission nommée par le préfet estime que « la pierre de pudding [sic] doit être admise dans la maçonnerie [de la jetée] au même titre que le grès » et ce pour les raisons suivantes : « Le pudding se taille bien, est généralement d'une grande dureté, résiste à toutes les influences météoriques ». Dans son rapport en date du 9 avril 1833, l'ingénieur des Ponts et Chaussées note de son côté qu'« il n'y a pas d'inconvénient à se servir de la pierre dite pouddingue [sic] ». Dans l'ouvrage exécuté (adjudication le 30 avril 1836) ont été mis en œuvre $33,18 \mathrm{~m}^{3}$ de poudingue taillé de forte dimension. Le grès poudinguiforme d'Erquy a pu même être utilisé pour l'habitat (encadrement d'ouvertures dans une maison ancienne au Dahouët : Chauris, 1998a).

\section{La «Pierre des Landes»}

Dans divers secteurs de la Bretagne, et tout particulièrement de part et d'autre de la baie de Saint-Brieuc, de nombreuses constructions anciennes ont mis en œuvre un matériau singulier, caractérisé par sa teinte rouge sombre ou bleu-noirâtre et par sa structure bréchique due à l'abondance de fragments anguleux enrobés. Cette curieuse roche est connue sous le nom de "pierre des landes »; il s'agit d'un conglomérat à 
ciment ferrugineux qui soude les éléments du substratum, ainsi que des fragments quartzeux. Les blocs, sous forme de dalles irrégulières mises au jour par les labours profonds, sont aujourd'hui remisés le plus souvent en bordure des parcelles. Il semble bien que l'exposition à l'air ait accéléré la précipitation des hydroxydes de fer, consolidant ainsi le conglomérat tout en lui conférant sa teinte rouge sombre à bleunoirâtre. Les éléments de la brèche sont de composition pétrographique variée : gabbro, diorite, amphibolite - c'est-à-dire, dans ces trois cas, des roches riches en fer mais aussi schistes et roches métamorphiques; les fragments anguleux de quartz sont nettement en relief (photo XXIII). Ces divers éléments sont hétérométriques, allant de moins d'un centimètre à plus d'une dizaine de centimètres.

La genèse de ces conglomérats - toujours superficiels - est favorisée voire conditionnée par un substrat rocheux ferrifère. Au facteur géochimique se superpose un facteur géomorphologique, à savoir un relief subhorizontal mal drainé. La pierre des landes peut être considérée comme une " croûte de battance », liée à la présence d'une nappe phréatique perchée subaffleurante. Sa formation est récente et même, dans certains cas, se poursuit actuellement.

Les défrichements ont fait disparaître la plupart de ces dépôts superficiels. En fait, c'est l'abondance, dans le passé, à la surface même du sol, d'une roche gênante pour l'agriculture mais facile à extraire et à tailler, qui explique sa présence, voire sa fréquence dans les constructions anciennes, en particulier dans les édifices religieux qui ont échappé aux destructions du xIXe siècle, mais aussi dans l'habitat (Chauris, 2001b).

Dans l'état actuel des recherches, l'emploi de la pierre des landes se répartit préférentiellement dans deux zones relativement bien délimitées : d'une part au nordouest de Saint-Brieuc, entre Kermaria-an-Isquit et Trégomeur, et d'autre part à l'est de cette même ville, entre Hillion et Hénansal. (fig. 6). L'étude architecturale des édifices, complétée par des références bibliographiques, indique que les monuments religieux ayant fait appel à la pierre des landes remontent généralement à une époque reculée : ainsi à Morieux, l'église Saint-Gobrien, pour partie du XI siècle (photo XXIV); la nef de Saint-Martin à Lamballe à l'époque romane ; la chapelle Saint-Jacques, en Saint-Alban, au début du $\mathrm{XIV}^{\mathrm{e}}$ siècle... Dans ces conditions, il est probable que de vieilles églises situées dans les mêmes zones, mais aujourd'hui détruites et réédifiées au xIX siècle, avaient dû, elles aussi, utiliser la pierre des landes. Cette interprétation est confirmée par le fait que ce matériau a été remployé localement dans le nouvel édifice. Aussi notre carte est-elle, ipso facto, incomplète : dressée au début du XIX siècle, elle aurait montré un nombre bien supérieur d'églises concernées. La présence présumée de la pierre des landes dans des églises aujourd'hui disparues est également appuyée par l'utilisation de ce matériau dans l'habitat voisin. Ainsi, à Lanvollon, les brèches ferrugineuses sont fréquentes dans les maisons aux alentours ; tout incite à penser qu'il en était de même dans l'église détruite.

Les édifices religieux ayant fait appel à la pierre des landes sont en fait polylithiques, même dans leurs parties anciennes relevant d'une unique période d'exécution. Un tel polylithisme - ou emploi de pierres de nature et de provenance diverses - s'interprète par diverses raisons. a) Esthétique, en jouant sur l'association des très sombres brèches ferrugineuses avec d'autres roches beaucoup plus claires. b) Technique : l'impossibilité d'utiliser la pierre des landes pour les parties finement ouvragées de l'édifice, comme certains porches, a obligé le maître d'œuvre à rechercher dans ce but des pierres plus 
aptes au façonnement. c) Pratique : la pierre des landes n'était pas toujours disponible en quantité suffisante pour l'ensemble de la construction, d'où la nécessité de quérir d'autres roches d'appoint. À ces trois cas de polylithisme originel (ou, si l'on préfère, primaire) est venu s'adjoindre un polylithisme acquis (ou secondaire): lors des transformations de l'édifice primitif, la pierre des landes n'était plus exploitée ou, plus simplement, les modes avaient changé, ou encore les ressources financières permettaient d'acquérir des matériaux plus prestigieux comme le granite.

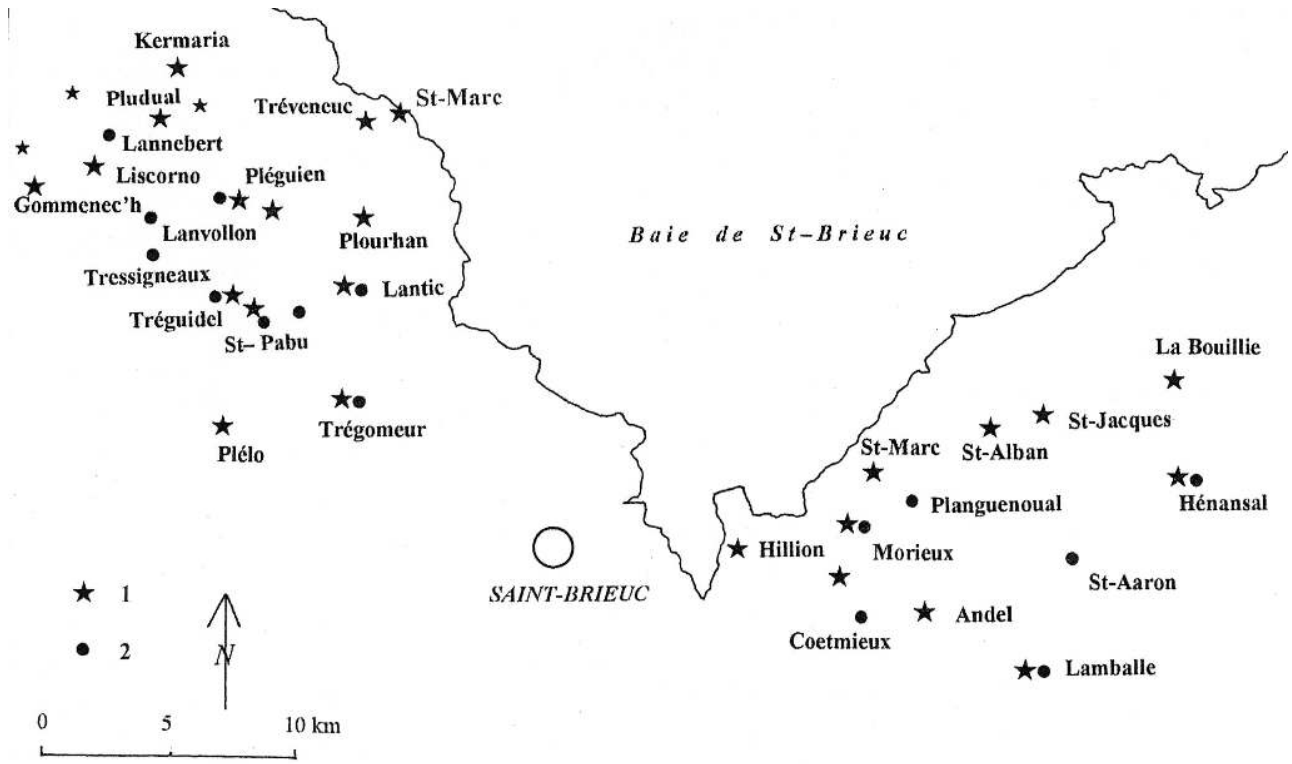

Figure 6 : Constructions ayant utilisé la « pierre des landes » de part et d'autre de la baie de SaintBrieuc (enquête préliminaire) : 1, édifice religieux; 2 , habitat.

Figure 6: Buildings using "Pierre-des-Landes », west and east of St. Brieuc Bay (preliminary survey): 1, religious building; 2 , domestic.

110 L'église Saint-Gobrien à Morieux ( $\mathrm{XI}^{\mathrm{e}}$ et $\mathrm{XIV}^{\mathrm{e}}$ siècles) fournit l'exemple le mieux caractérisé d'emploi de ces brèches ferrugineuses, ici de nuance noir-bleuté, à éléments de roches vertes, de quartz... Dans le porche roman de la façade occidentale et dans les contreforts voisins, les sombres conglomérats sont mis en valeur par leur alternance, au moins partielle, avec un granite beige clair qui affleure sur le littoral aux environs de Pont-Rouault. Les mêmes conglomérats se retrouvent plus sporadiquement dans l'élévation méridionale et le chevet, en association avec le granite beige précité. Des roches vertes en moellons complètent la palette des roches locales. La provenance du leucogranite à grain fin de la porte méridionale (XIV siècle), n'a par contre pas pu être précisée.

à l'intérieur de l'église Saint-Martin, à Lamballe, la nef romane paraît avoir fait un large appel aux brèches ferrugineuses (piliers et peut-être arcades); toutefois, ce matériau est masqué par un crépi malencontreux... La même roche se voit sporadiquement dans la façade occidentale ou dans l'élévation méridionale, en association avec des moellons d'un granite écrasé de provenance locale. Toujours dans la même cité, l'église SaintJean montre quelques moellons en conglomérat ferrugineux. Dans la chapelle SaintJacques en Saint-Alban (début du XIV siècle et seconde partie du XVII ${ }^{e}$ ), les contreforts de l'élévation méridionale, en pierre des landes sont à rapporter à la première période de construction. Le même conglomérat a été noté aussi près de la base de l'entrée occidentale. L'élévation sud montre l'emploi, en moellons, du grès rose d'Erquy et du 
même granite beige qu'à Morieux. à Andel, l'église (première moitié du XvIII ${ }^{\mathrm{e}}$ siècle avec plusieurs parties conservées de la fin $\mathrm{du}_{\mathrm{XVI}} \mathrm{e}^{\mathrm{e}}$ ) a été restaurée au XIX ${ }^{\mathrm{e}}$. Les brèches ferrugineuses sont notées dans le transept, l'élévation sud et surtout la façade occidentale où, toutefois, la porte en anse de panier est en leucogranite à grain fin. L'église de La Bouillie, construite de 1832 à 1844, est polylithique : outre les grès roses d'Erquy, relativement distaux, ont été employées une diorite orientée, toute proximale, et, passim, les brèches ferrugineuses, peut-être en remploi de l'ancien édifice. Reconstruite au XIX $x^{e}$ siècle avec large utilisation des grès roses d'Erquy, l'église d'Hénansal offre, en remploi, un certain nombre de pierres de l'édifice du XvI (pierre des landes dans l'élévation sud et le chevet; gneiss fin leptynitique), en association avec ledit grès. La chapelle de Liscorno, en Lannebert, remontait au $\mathrm{xV}^{\mathrm{e}}$ siècle mais, détruite par un incendie en 1705, elle a été reconstruite quelques années plus tard. Selon toute probabilité, c'est à l'édifice ancien (parties conservées ou éléments remployés au $\mathrm{XVIII}^{\mathrm{e}}$ ) qu'il faut rapporter l'utilisation de la pierre des landes : contreforts de la façade occidentale et mur de la même élévation, élévation méridionale. Dans l'église de Pludual, dont la première pierre a été posée en 1871, l'élévation méridionale montre le sombre gabbro local et des grès roses graveleux extraits du bassin de Plourivo ; les brèches ferrugineuses restent disséminées et proviennent peut-être de l'édifice antérieur. La pierre des landes a été également observée dans de nombreuses autres églises paroissiales: Pléguien, Tréguidel, Plourhan, Lantic, Plélo, Trégomeur, Hillion..., ainsi que dans plusieurs chapelles: Saint-Pabu en Tréguidel, Roha en Plourhan, Saint-Marc en Tréveneuc, Kermaria-an-Isquit...

Comme on pouvait s'y attendre, la pierre des landes n'a pas été uniquement recherchée pour la construction d'édifices religieux anciens; elle a été également utilisée pour l'habitat. Faute de place, nous ne pouvons que dresser une rapide énumération des localités où ce matériau a été reconnu, mais il est évident qu'une telle liste n'est pas limitative. À l'est de Saint-Brieuc: Morieux, Hénansal, Coëtmieux, Saint-Aaron, Planguenoual...; au nord-ouest, Tréguidel, Tressigneaux, Lanvollon, Lannebert, Pléguien, Lantic, Trégomeur...

113 Au terme de cette analyse, quelques points de portée générale peuvent être dégagés.

- Le savoir-faire des anciens qui ont utilisé - parfois avec art comme à Morieux, en tous les cas toujours au mieux - les ressources du sous-sol local, en particulier dans les secteurs caractérisés par l'absence d'autres matériaux, ou par des difficultés de leur extraction et/ou de leur façonnement, voire de leur mauvaise qualité.

- La présence, dans des terroirs d'extension relativement limitée, d'une pierre originale, en fort contraste avec l'omniprésence, un peu écrasante, des granites, souvent ailleurs en Bretagne.

- La nécessité de rechercher et d'utiliser, pour les travaux de restauration, les blocs de pierre des landes encore remisés en bordure des champs. Ainsi pourra être transmis, dans son intégralité, aux générations futures, un patrimoine dont la spécificité ne fait aucun doute.

114 Il importe de ne pas confondre la véritable "pierre des landes » de la région briochine avec d'autres roches conglomératiques présentes en Bretagne, mais, en fait, de tout autre mode de formation et âge, en particulier :

- $\circ$ les brèches volcaniques d'âge briovérien du Trégorrois dans les environs de Paimpol;

- les poudingues cambriens - dits « de Montfort » - à l'ouest de Rennes (cf. supra) ;

- les grès poudinguiformes situés à la base de la série d'Erquy (cf. supra) ; 
- les graviers rougeâtres du Pliocène qui, une fois indurés sont connus sous le nom de « roussards» en divers points de l'Ille-et-Vilaine et de la Loire-Atlantique... et bien d'autres roches encore.

\section{Calcaires}

115 À l'inverse de la partie orientale du Massif armoricain, la péninsule bretonne est pauvre en roches calcaires. Ces formations appartiennent à deux ensembles totalement différents : les lentilles du socle ancien et les lambeaux discordants préservés dans des petits bassins d'âge tertiaire. Ces roches ont été longtemps recherchées pour la fabrication de la chaux destinée à la confection des mortiers, ainsi qu'à l'amendement des terres acides. Les vestiges de fours à chaux témoignent encore de cette activité ; seul, aujourd'hui, le calcaire dévonien d'Erbray, en Loire-Atlantique, est encore en exploitation (photo XXV). Les calcaires ont pu aussi être recherchés pour la construction; le cas le plus célèbre est celui du bassin tertiaire du Quiou où la roche était mise en œuvre sous l'appellation de "pierre de jauge». Quelques calcaires paléozoïques ont même été travaillés comme marbres: sur la carte de Cassini, Cartravers est indiqué comme carrière de marbre ; ce calcaire était aussi utilisé comme castine (fondant mélangé aux minerais de fer trop chargés en alumine et en silice) pour les fourneaux sidérurgiques de la région.

Par ailleurs, la rareté des calcaires a motivé, pendant des siècles, l'importation de ces roches, extraites au-delà des limites du Massif armoricain pour la construction d'édifices de prestige. Trois districts ont essentiellement alimenté ces demandes en " pierres blanches » : la région de Caen, notamment pour la nef de la cathédrale de SaintPol-de-Léon (fin XIII ${ }^{e}$ siècle-début XIV ${ }^{\mathrm{e}}$ : photo XXVI) ou le réfectoire de l'abbaye de Beauport près de Paimpol ( $\mathrm{xv}^{\mathrm{e}}$ siècle)...; le Val de Loire, livrant son tuffeau un peu partout en Bretagne; la Charente, surtout en Bretagne méridionale (château de Kerlévenan en presqu'île de Rhuys...). Ces calcaires « étrangers » ne seront pas pris en compte plus avant.

Dans les développements qui suivent, un choix a dû être effectué pour ne pas allonger le propos: pour les calcaires paléozoïques, le district de la rade de Brest et de ses abords (les occurrences de Cartravers en La Harmoye (Andrieux, 1991) dans les Côtesd'Armor, de Bois-Roux et de Quénon en Saint-Aubin-d'Aubigné en Ille-et-Vilaine, de Cope-Choux et d'Erbray en Loire-Atlantique... ne sont cités ici que pour mémoire). De même, parmi les calcaires cénozoïques, seul sera étudié le district du Quiou, laissant de côté les autres bassins (Chartres-de-Bretagne...).

\section{La rade de Brest et ses abords (fig. 7)}

\section{De l'Antiquité au Moyen Âge}

118 La mise en évidence, dans le mortier utilisé pour les constructions gallo-romaines de Keradennec en Saint-Frégant (pays de Léon, Nord-Finistère), de quelques fossiles (favosites et brachiopodes) permet de préciser la provenance de la chaux utilisée (Sanquer et Galliou, 1970), à savoir un calcaire dévonien dont les gisements les plus proches se situent en presqu'île de Plougastel ou en presqu'île de Crozon. Toujours en Finistère, un four à chaux gallo-romain se présentant comme une poche de $2,50 \mathrm{~m}$ de 
long sur $0,80 \mathrm{~m}$ de profondeur creusée dans la falaise a été découvert près de Treuzelom en Argol. (Sanquer, 1972) et, vers 1910, un four à chaux contenant une sépulture datée du $\mathrm{IV}^{\mathrm{e}}$ siècle, a été décelé à Goaz-an-Eyet en Pont-de-Buis (Abgrall, 1911); il est possible que le calcaire de Saint-Urbain ait été aussi exploité à l'époque gallo-romaine (Rolland, 1972).

119 La toponymie peut contribuer à la reconnaissance des sites anciens. Selon B. Tanguy (in Calvez, 1975), «l'adjectif breton razet, formé sur le substantif raz, qui désigne la chaux, a été relevé dans plusieurs microtoponymes [de la presqu'île de Crozon]: Ty-Razet à Kerglintin ou à Trelannec en Crozon; Forn-Razet à Keradennec en Crozon, à Kerlaboussec et Guennatec en Lanvéoc. Le cas de Guennatec est d'autant plus digne d'attention qu'à moins de $500 \mathrm{~m}$ au nord-ouest on rencontre les vestiges gallo-romains du Buzit ».

120 Il est probable qu'au bord de la mer les habitants se servaient de la chaux de " croquilles", provenant de coquillages concassés. Toutefois, cette source de calcaire ne pouvait tenir lieu que d'appoint. La recherche de gisements en roche allait se développer en Basse-Bretagne à partir du XVIII ${ }^{\mathrm{e}}$ siècle, et plus encore au $\mathrm{xIX}^{\mathrm{e}}$ avec la généralisation des amendements.

\section{À la recherche des calcaires}

121 Jusqu'au XviII ${ }^{\mathrm{e}}$ siècle, les gisements de calcaire connus en Basse-Bretagne sont peu nombreux. En 1752, des encouragements sont donnés par les états de Bretagne en vue de la recherche d'occurrences pour la fabrication de la chaux. De Robien (1756) évoque les gîtes de la Harmois (Cartravers en La Harmoye dans les actuelles Côtes-d'Armor) et de l'île-Ronde en rade de Brest, mais porte essentiellement son attention sur leur intérêt marbrier. Dans le premier, «le marbre est d'un beau noir bleuâtre veiné de blanc... on en fait des tables, des cheminées... Les débris font de très bonne chaux ». Le second "n'est pour ainsi dire qu'un seul et même bloc de marbre noir veiné en quelques endroits de blanc ». (Ce caractère monolithique est pour le moins exagéré...). Ogée (1778) cite aussi « l'île Ronde dans laquelle on remarque une carrière de marbre noir ». À la fin du XVIII e siècle, Cambry (an VII) écrit encore que « rien n'est plus rare que la pierre calcaire dans toute l'étendue du Finistère ». Le gisement qui l'a le plus frappé est également celui de l'île-Ronde, «bloc de marbre... dont on fait de la chaux ", mais aussi des objets de valeur. 


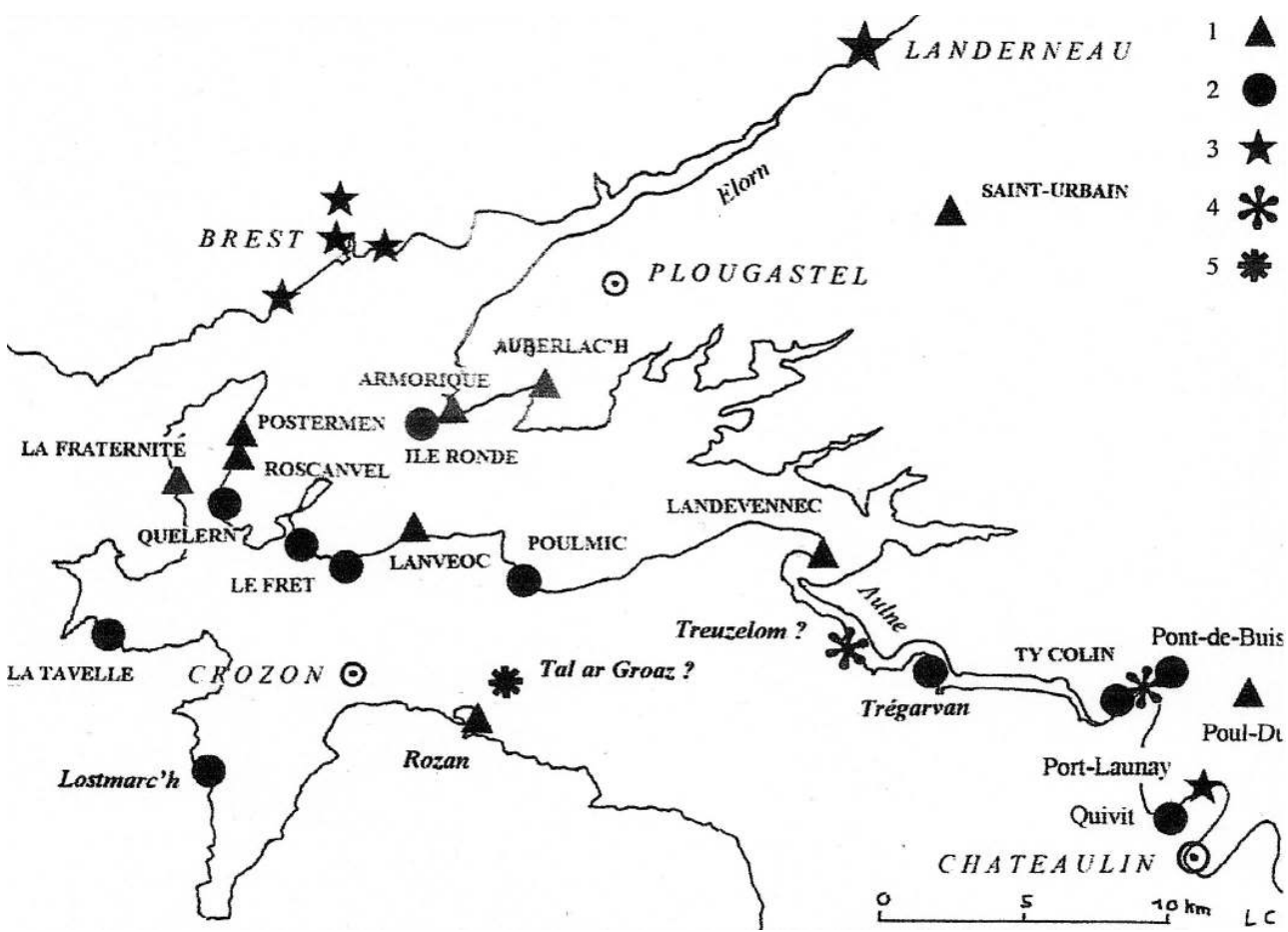

Figure 7 : Gîtes calcaires et fours à chaux du district de la rade de Brest et de la presqu'île de Crozon. 1 , four à proximité d'un gîte ; 2 , occurrence calcaire sans four moderne ; 3 , four éloigné de tout gisement connu ; 4 , four à chaux gallo-romain ; 5 , four à chaux signalé mais non retrouvé. L'âge géologique des formations est indiqué par la typographie : ordovicien, DÉvonien, carbonifère.

Figure 7: Limestone deposits and lime furnaces around the Rade-de-Brest and Crozon peninsula. 7, furnace near a deposit; 2,limestone occurrence without modern furnace; 3, furnace distant from any known deposit ; 4, Gallo-Roman furnace; 5, furnace mentionned but not found. Geological age is indicated by typography: Ordovician; DEVONIAN; Carboniferous.

En 1822, Bonnemaison décrit les occurrences de « la côte de Plougastel, [du] fort de Lanveau (Lanvéoc) et [de] Roscanvel »: «Dans tous ces lieux, le marbre est noirâtre, souvent traversé de veines blanches, spathiques, plus ou moins larges. Celui de Lanveau est d'un noir grisâtre, à cassure esquilleuse et brillante; il est disposé par bancs interposés entre masses schisteuses... le lieu de l'exploitation est très borné... presqu'au niveau des marées. " Selon le même auteur, "l'île Ronde n'est qu'un chétif rocher... Dans la partie sud-est sous un toit schisteux épais de six à huit pieds gît un calcaire noirâtre compact, parcouru par des veines spathiques blanches. Entre chaque banc se trouve interposé un schiste argileux ». (Nous sommes loin ici de la masse marmoréenne des auteurs précédents!). Le calcaire de la côte de Plougastel (il s'agit selon toute probabilité du gisement de l'Armorique) offre un « tissu compact, où différents marbres sont parfois empreints de corps organisés». L'auteur conclut ses observations en indiquant que ces calcaires sont « susceptibles d'un fort beau poli »... et il ajoute : «J'ai vu dans les ateliers du port de Brest, différents ouvrages... qui étaient d'un bel effet ». Il précise toutefois que «pour l'ordinaire, ils ne sont exploités que pour être réduits en chaux ; celle-ci est grise, éminemment hydraulique, et s'emploie avec succès dans les fondations sous l'eau ». Puillon-Boblaye, en 1827, après avoir décrit le gîte de «La Harmoët », « le seul gisement calcaire du centre de la Bretagne », s'attarde sur le bassin de la rade de Brest. Il note la présence d'une première bande se montrant « à la pointe de l'Armorique, à l'île Ronde et dans la presqu'île de Kelern », contenant " une énorme quantité de madrépores "; l'occurrence de Lanveau appartient à ces mêmes calcaires. En 1830, E. de Billy examine les gisements de la presqu'île de Plougastel : « à la pointe 
de l'Armorique, les roches dominantes sont d'abord les calcaires, exploités sur le rivage du côté du sud et du côté du nord [de la pointe]. Ils sont en général d'un gris foncé... Les couches inférieures sont lamellaires ou compactes, souvent traversées de petits filons blancs ; les entroques y sont très abondantes. Plus haut, les couches deviennent à la fois plus minces et moins pures »... "L'île Ronde est le prolongement de la pointe de l'Armorique... Les calcaires y sont exploités ».

Selon de Fourcy (1844), «les assises qui forment le passage du schiste argileux à la grauwacke présentent parfois un accident fort intéressant pour l'industrie... elles renferment en plusieurs points des couches ou plutôt des amas de calcaires... malheureusement... les gîtes calcaires sont si peu nombreux qu'on peut tous les nommer ». Il note leur répartition sur les pourtours de la rade de Brest et ses environs : Roscanvel (où la pierre est extraite d'une manière intermittente «sur la grève même où deux fours à chaux ont été construits »); la pointe du Diable (La Fraternité) ; Lanvéoc (sous le fort même, où le calcaire-marbre "paraît susceptible de poli »); AdrienL'Auberlach (trois carrières, occupant en permanence 15 à 20 ouvriers, et deux fours à chaux : «Ces carrières sont, de beaucoup, les plus importantes de la rade »); pointe de l'Armorique (carrières et fours à chaux abandonnés par ordre du génie) ; Île-Ronde (où on trouve une carrière de calcaire et une carrière de kersanton); près du fort du Corbeau (sur la grève, quelques bancs de calcaires, inexploités et recouverts par la mer). L'auteur cite enfin le gîte de Rozan « qui n'a aucune relation apparente avec les précédents» et qui "forme un amas puissant susceptible d'être exploité avec avantage ».

Parmi les occurrences citées par Frapolli (1845), on relève les localités suivantes :

• «l'extrémité de la pointe [de Lanvéoc]... formée par des couches d'un calcaire noirâtre, demi-cristallin... qui a été pendant quelque temps en exploitation»; le gîte n'est visible «qu'aux époques des plus basses marées »;

- les environs du Fret où «des schistes fétides, noir-bleuâtre [renferment] une grande quantité de nodules d'un calcaire noir très analogue par son aspect à celui qui affleure sous le fort » [de Lanvéoc] ; près du Fret encore, un calcaire qui a été pendant quelque temps en exploitation, et qu'on ne voit qu'aux époques des plus basses marées »;

- la côte orientale de Roscanvel où «de nombreuses veines de spath (calcite blanche) traversent les couches calcaires... Cette région des calcaires se prolonge sur la côte jusqu'en face de Roscanvel et au-delà » [vers le nord] ;

- les environs de Régoudan (selon la description de Frapolli, il s'agit indubitablement de l'occurrence de La Fraternité), où affleurent « de véritables couches calcaires »;

- la pointe de l'Armorique où «le dépôt... est... très puissant... l'aspect du calcaire n'est pas uniforme »... «La couleur se rapproche généralement du bleu foncé, quelquefois du bleu clair...»;

-à l'île-Ronde, la puissance des couches calcaires est d'« environ 10 à 12 mètres »... «Le calcaire est noir-bleuâtre, presque cristallin et renferme plusieurs filons de spath ».

Frapolli signale également l'existence du calcaire " au fond de l'anse de l'Auberlac'h » et décrit "la petite presqu'île de Rozan (où se trouvent une carrière et un four à chaux) ». Il fait remarquer qu'« on n'a pas trouvé jusqu'à ce jour de calcaires dans l'est du département ». Peut-on conclure de cette absence que les calcaires sont ici limités « au bassin de la rade »? L'auteur estime plutôt que " les difficultés d'observation dans un terrain aussi couvert que l'intérieur du Finistère [ont] dérobé jusqu'à présent ce trésor (le calcaire!) aux recherches de l'industrie » et il laisse à penser que «quelque 
trou de sonde nous éclairera un jour sur cette question ». L'avenir devait donner raison aux prémonitions de Frapolli. Des sondages effectués dans un but de recherche minière (Plan minier breton, 1983) ont mis en évidence des occurrences inconnues jusqu'alors : l'un, incliné à $60^{\circ}$, à Trinivel en Scrignac (Finistère), a recoupé des calcaires à partir de $50 \mathrm{~m}$ sur une épaisseur de 50 à $70 \mathrm{~m}$; l'autre, à Kerauter en Plélauff (Côtes-d'Armor), a traversé, à partir de $70 \mathrm{~m}$, des dolomies massives de plusieurs dizaines de mètres d'épaisseur.

Aux abords du fond de l'anse de l'Auberlac'h, quatre carrières importantes étaient naguère exploitées sous les noms suivants : ar vengleuz Run Avel; ar vengleuz koz; ar vengleuz nevez; ar vengleuz Godibin (ar vengleuz = la carrière, en langue bretonne).

Deux raisons ont motivé notre longue évocation des premières recherches sur les calcaires dans le district de la rade de Brest: d'une part, les publications citées sont souvent, aujourd'hui, d'accès difficile; d'autre part, les pionniers de la géologie régionale - à présent trop souvent oubliés - se devaient d'être remis à l'honneur. Depuis cette époque « héroïque », les occurrences calcaires de la rade sont maintenant bien connues, en particulier grâce aux travaux de Ch. Barrois (1889), puis de L. Collin $(1924 a$ \& b), de F. Kerforne $(1908,1927)$ et, beaucoup plus récemment, de Y. Plusquellec $(1980,1992)$.

\section{Les fours à chaux}

Edifiés sur les gisements de calcaire, ils sont dits proximaux ; construits près des lieux de débarquement des calcaires importés, ils sont appelés distaux (Chauris, 1999a; 1999b).

\section{a) Fours proximaux}

Le Père Grégoire (in Calvez, 1975) indique que, avant la Révolution, des fours à chaux étaient érigés à Lanvéoc, Rostellec et Roscanvel. D'après A. Dizerbo, le four à chaux de La Fraternité avait été « construit lors de l'établissement des fortifications » (Archives départementales du Finistère, 23 L 5, 25 Germinal an III-14 avril 1793). Lors de la construction des "Lignes de Quélern", sous Louis XVI, appel est fait au four situé à Lanvéoc; les barriques de chaux sont transportées par bateau jusqu'au chantier. Toutefois, en 1782, le four de Lanvéoc ne livre plus pour Quélern par suite de la mauvaise qualité du produit (Archives municipales de Brest, Fonds Langeron, $2 \mathrm{~S}$ 20-11). Selon H. Daniel et A. Dizerbo (1946), le four à chaux de Lanvéoc était vendu le 28 mars 1797. L'annuaire statistique du département du Finistère pour l'an XII de la République indique la fabrication à Roscanvel, à cette époque, de "la chaux pour le service du port [de Brest] et des fortifications maritimes et pour celui du Génie de terre de l'arrondissement de Brest ». L'annuaire précise que «la quantité que l'on fabrique peut s'élever à 700 barriques par mois [et que] la barrique de chaux se vend à Brest 8,50 francs ». La date de construction du four à chaux de Postermen en Roscanvel reste encore imprécise : elle remonte selon toute probabilité à l'extrême fin du XvIII siècle, après l'interdiction d'extraire du calcaire à l'île-Ronde. Selon M. Burel (1995), « c'est en 1810 que, pour faire face à une demande toujours importante, la famille Rideau décida de construire un nouveau four à chaux dans l'anse du bourg ». Selon E. de Fourcy (1844), il y avait, vers les années 1840, deux fours à chaux à Roscanvel ; le même auteur 
signale aussi deux fours à l'Auberlach en Plougastel. Quant à la construction du four à chaux de Rozan, elle fut autorisée en 1839 (Arch. départ. Finistère, 5 M 75, Crozon).

\section{b) Fours distaux}

Les très importants travaux de fortifications entrepris pour la protection du port de Brest ont conduit à la construction de fours à chaux à proximité des points de débarquement de la pierre calcaire et, autant que possible, des ouvrages à exécuter. Le développement de la ville de Brest exigeait également de la chaux pour la préparation de mortiers. Le dépouillement par J.-Y. Besselièvre (1996) du fonds Langeron (Archives municipales de Brest, série $2 \mathrm{~S} 1$ à $2 \mathrm{~S} 27$ ) fournit des renseignements précis sur l'activité chaufournière lors de la construction des forts extérieurs de Brest sous Louis XVI. Le sieur Le Lièvre possède au Bouguen deux fours construits en 1773 ; un troisième est construit en 1778. Pour alimenter en chaux les chantiers des forts du Portzic, de Penfeld et de Keranroux, plusieurs fours sont établis à l'anse Garen (près du vallon de la Maison Blanche). «Ces fours... produisent trente à trente-deux barriques de chaux vive et quarante-cinq barriques de chaux éteinte par jour "... Aujourd'hui, les fours du Bouguen et de l'anse Garen ont disparu. Selon G. M. Thomas (1963), les fours du Bouguen étaient exploités par le chaufournier Duchesne, bientôt remplacé par Dorez le $1^{\text {er }}$ juillet 1777. «La pierre à chaux provenant de la presqu'île de Plougastel ou de «la carrière du Roy " [l'île-Ronde ?] était évaluée à 27 livres la toise..., le cassage de la pierre revenait à 2 sols la barrique ». Selon M. Burel (1995), « dès 1789, A. Rideau du Sol transformait, dans des ateliers situés à Kerinou, la pierre à chaux dont la majeure partie était extraite à l'île Ronde ». Des fours à chaux ont été également signalés à Laninon (au pied du Stiff), ainsi qu'au Prat-Lédan (en Quilbignon). J. Foucher (1962) précise qu'au pied du Cours d'Ajot, sur les rochers de Porstrein, il y avait vers 1810, trois fours à chaux (le sieur Pouliquen en exploitait deux ; le sieur Derrien, un). "Ces fours étaient alimentés par les calcaires de l'île Ronde et de Roscanvel. Le chauffage se faisait au bois ». En 1834, six fours à chaux étaient en activité. Les fumées incommodant les habitants du voisinage, une enquête ordonnée par le maire concluait au bien-fondé de leurs récriminations mais l'administration militaire «tenait absolument que ces industries continuent leurs activités dont les produits [lui] étaient indispensables ». En outre, du fait de leur emplacement, ces fours étaient à la fois facilement accessibles, à travers la rade, à partir des sites d'extraction de la pierre, et proches des lieux d'emploi de la chaux, d'où des prix de revient avantageux.

\section{c) État actuel}

131 L'ouvrage de Postermen, à environ 1,5 km au nord du bourg de Roscanvel, édifié sur le flanc de la falaise, un peu au-dessus de la partie supérieure de l'estran, est dans un état de délabrement assez prononcé, la face orientale du four étant éboulée. Cette brèche béante permet d'observer sa structure interne, du type ovoïde, tapissée de moellons disposés en assises réglées, mais de hauteurs différentes (photo XXVII). Les éléments des assises accessibles à l'observation sont formés de gneiss de Brest (en provenance de la partie septentrionale de la rade). L'épaisse muraille du four est constituée par des moellons de schistes calcareux et de calcaires, extraits sur place, ainsi que de microgranite de l'île-Longue. Aux approches de la partie interne du four, et sur un mètre d'épaisseur environ, les pierres ont été rougies par la calcination. Le gueulard est encore bien visible, ainsi que les deux ouvertures latérales du défournement (un 
délabrement comparable des fours de Chartres-de-Bretagne près de Rennes livre là aussi une coupe pédagogique : photo XXVIII).

Les fours à chaux de l'Auberlac'h, sur la rive sud de l'anse, à proximité de petits quais, sont ruinés et presque entièrement masqués sous la végétation.

Le four de La Fraternité est adossé au versant méridional de la colline qui porte le fort, à proximité du bord de la mer et de l'ancienne carrière littorale. Son état de ruine le rend dangereux par suite des risques de chutes de pierres, voire d'écroulement. Vu de face, il offre une forme trapézoïdale. Au fond de l'entrée, en anse de panier, le défournement, plus ou moins obstrué, est encore visible à la base du four proprement dit, de structure ovoïde. Le gueulard est pour partie envahi par les ronces. L'appareillage extérieur de la construction, assez grossier, est essentiellement constitué de moellons calcaires admettant des veines de calcite blanche, extraits sur place; ils sont associés à des moellons microgranitiques parfois profondément érodés, contrastant vivement par leur teinte jaunâtre avec le fond sombre des calcaires.

Le four à chaux de Rozan diffère des ouvrages précédents par ses dimensions imposantes, son appareillage soigné et son remarquable état de conservation (photo XXIX). Appuyé au flanc nord d'une butte partiellement éventrée par l'exploitation du calcaire, Rozan frappe immédiatement par l'élégance de sa pièce maitresse - ou four proprement dit - qui évoque au premier abord un donjon moyenâgeux accosté de ses ouvrages de protection. Et il n'est pas jusqu'à ses ouvertures - tant médiane (au sud, donnant accès au défournement) que latérales (à l'est et à l'ouest, correspondant, semble-t-il, à des bouches d'aération) qui ne renforcent cette impression. Le ventre du four, de type ovoïde, est tapissé de briques réfractaires. Les parements extérieurs de l'ouvrage sont en moellons de calcaire (avec veinules de calcite) et de grès.

135 À l'est de la rade de Brest, quelques fours, utilisant des calcaires locaux, méritent de retenir l'attention à titre de comparaison avec les ouvrages du district de la rade. Celui de Saint-Urbain, le plus récent, a été construit en 1927 et éteint en 1958. Il appartenait à la « Grande Briqueterie de Landerneau ». Le calcaire était amené au four par télé-benne depuis la carrière distante de huit cents mètres. En 1947, 5300 tonnes de chaux hydraulique y avaient été produites. Cette chaux était vendue aux entrepreneurs qui l'utilisaient à Brest, alors en pleine reconstruction. Le four, inclus dans une tour carrée, a $3 \mathrm{~m}$ de diamètre et une dizaine de mètres de hauteur; après extinction, la chaux était écrasée par un broyeur à galets.

Un four à chaux a été élevé au Poul-Du en Saint-Ségal en 1911, par deux entrepreneurs brestois (Marc et Monfort) qui désiraient produire eux-mêmes leur chaux au lieu de l'importer. Après des essais satisfaisants dans un four de $4 \mathrm{~m}$ de haut, deux fours ovoïdes ( $9 \mathrm{~m}$ de haut sur $3 \mathrm{~m}$ de diamètre au ventre) sont édifiés. Des wagonnets amènent la pierre de la carrière jusqu'au haut des fours, ainsi que le charbon, transporté par charrettes à partir de la gare de Pont-de-Buis ou du quai de Ty-Beuz. Les deux fours fonctionnent jusqu'à la guerre de 1914. L'exploitation n'est reprise qu'en 1928 par la «Société des Fours à chaux et carrières de l'Ouest d'Angers ». La chaux produite servait alors surtout pour l'agriculture.

Le four à chaux de Scrignac (de Brun, 1903), reconstruit en 1928 par le Consortium breton, s'arrêta en 1932, suite à la faillite de la compagnie. Une tentative de reprise en 1956 devait se solder par un échec. 


\section{Marbres et pierres de construction} provenance peut être toute proche comme dans le cas des moellons bleu-gris, veinés de calcite blanche, du fort de La Fraternité où ce matériau joue un rôle essentiel. Elle peut aussi être plus lointaine: le dallage semi-circulaire, au pied de la tour Vauban, à Camaret, est constitué par de grands éléments de calcaire bleu-grisâtre fossilifère, extrait possiblement de la carrière littorale de La Fraternité. Le calcaire a aussi été utilisé dans l'église de Roscanvel et largement dans la façade occidentale de la chapelle Saint-Guénolé (xvI siècle) à Plougastel.

\section{Le bassin du Quiou et sa «Pierre de Jauge »}

Situés au sud de Dinan, les dépôts du bassin tertiaire du Quiou, appelés aussi faluns de Tréfumel et de Saint-Juvat, se sont formés au Miocène, voici environ 15 millions d'années, lorsque la mer s'est étendue largement dans la partie orientale de la Bretagne, reliant l'Atlantique à la Manche. Dans ces eaux peu profondes vivaient brachiopodes, mollusques bivalves et gastéropodes, échinodermes, bryozoaires... et algues calcaires (Milon et Dangeard, 1922; Durand, 1960). Les faciès du Quiou sont 
variés : sédiment meuble formé par une mouture de fossiles, calcaire biodétritique, roche cohérente connue sous le nom de "pierre de jauge ». Les dépôts du Quiou ont été aussi exploités pour l'obtention de la chaux et pour les amendements calcaires. À partir de 1892, les fours à chaux Bougeard étaient un important centre industriel; l'établissement a fermé vers 1975. À La Perchais, en Tréfumel, est toujours implantée une installation de broyage du calcaire (photo XXX).

La présence dans les faluns de bancs plus compacts est à l'origine de la pierre de jauge. offrant des colorations assez diverses (ocre-jaune, beige, blanc-gris), légère du fait de sa texture plus ou moins caverneuse mais conservant une grande robustesse, facile à travailler, apte à l'ornementation, la pierre du Quiou possédait de solides atouts, d'autant plus qu'elle affleure au centre d'un terroir dont le substratum est le plus souvent décomposé. Dans ces conditions, rien d'étonnant à ce qu'elle ait été exploitée pour livrer, à plusieurs kilomètres à la ronde (fig. 8), des moellons aux élévations, des pierres de taille aux encadrements d'ouvertures, des éléments de décoration (modillons, souches de cheminées... : photo XXXI). Son utilisation généralisée au Quiou, à Tréfumel, à Saint-Juvat confère au bâti de ces communes une originalité indéniable, comme une impression « d'ailleurs » au cœur de la Bretagne (Chauris, 2006a, 2007).

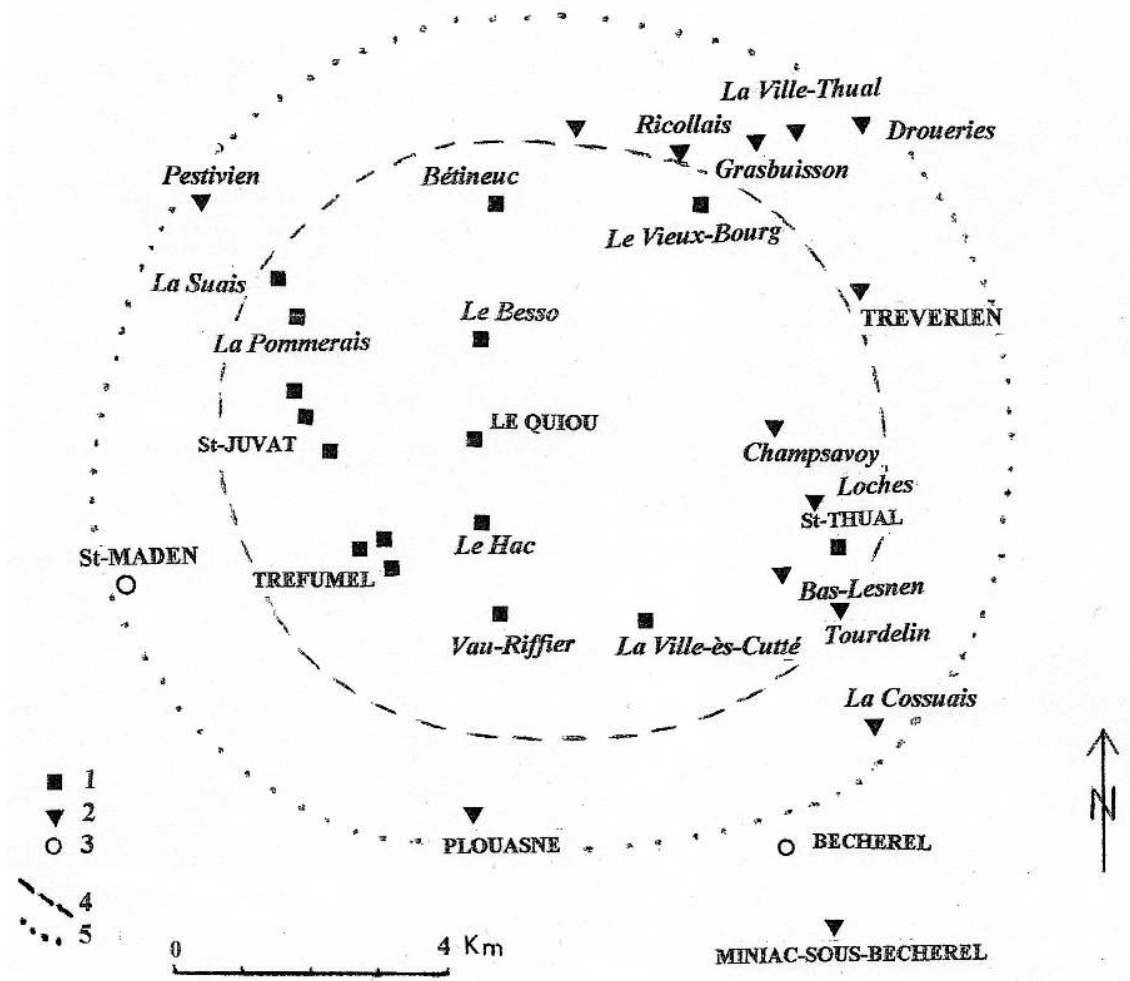

Figure 8 : Limites approximatives de la zone d'utilisation de la « pierre de jauge » du Quiou (état actuel des recherches). 1, abondante ; 2 , fréquente ; 3 , rare ; 4, zone de densité maximale autour du Quiou ; 5 , zone périphérique de densité restreinte.

Figure 8: Approximate utilization area of Le Quiou «Pierre-de-Jauge » (present state of investigation). 1, abundant; 2, frequent; 3, rare; 4, maximal density area around Le Quiou; 5, peripheral area of restricted density.

L'âge d'or de la pierre du Quiou remonte loin dans le passé. Il paraît présenter son acmé entre le $\mathrm{xV}^{\mathrm{e}}$ siècle (château du Besso et, pour partie, château de Hac) et le xvII (manoirs, églises et chapelles). Mais cette pierre était toujours mise en œuvre au XVIII ${ }^{\mathrm{e}}$ siècle (bâtiment abritant aujourd'hui la mairie de Tréfumel, daté de 1768: 
photo XXXII) et encore au XIX (église de Saint-André-des-Eaux, 1893-1895). Sa vogue était telle qu'en dépit du handicap des transports, ce matériau a largement diffusé bien au-delà des centres d'extraction, créant comme une auréole lumineuse dans les terroirs voisins, occupés au nord par les sombres schistes briovériens et au sud par le triste granite brunâtre de Bécherel. Toutefois, l'utilisation de la pierre de jauge s'est heurtée très tôt, même dans son aire propre, à l'impact des matériaux locaux (schistes et leurs argiles d'altération fournissant les éléments du pisé, cornéennes rubanées, dolérites, quartz, « pierre des landes »). Elle a subi aussi la concurrence de divers granites (Dingé, Lanhélin, Le Hinglé, Brusvily et surtout Languédias...). La mise en œuvre de ces différents matériaux a provoqué un remarquable polylithisme.

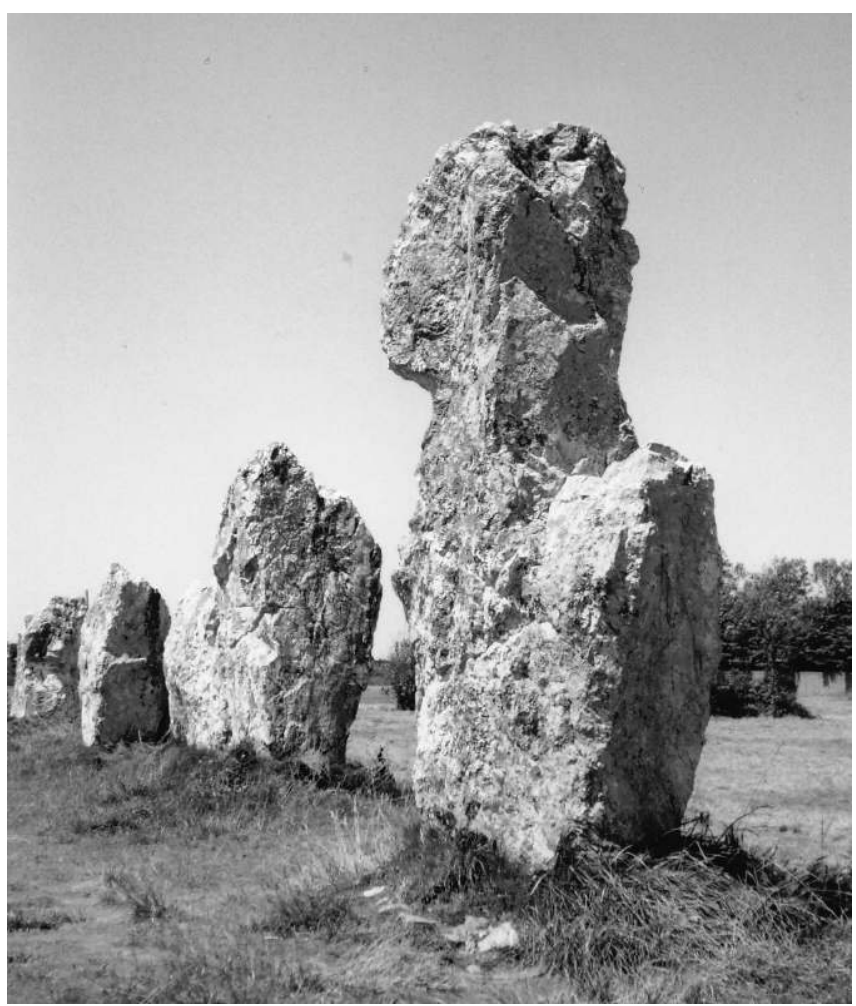

Photo I : Menhirs en « grès armoricain » de Lagatjar à Camaret.

Photo I: «Armorican sandstone » Lagatjar menhirs at Camaret. 


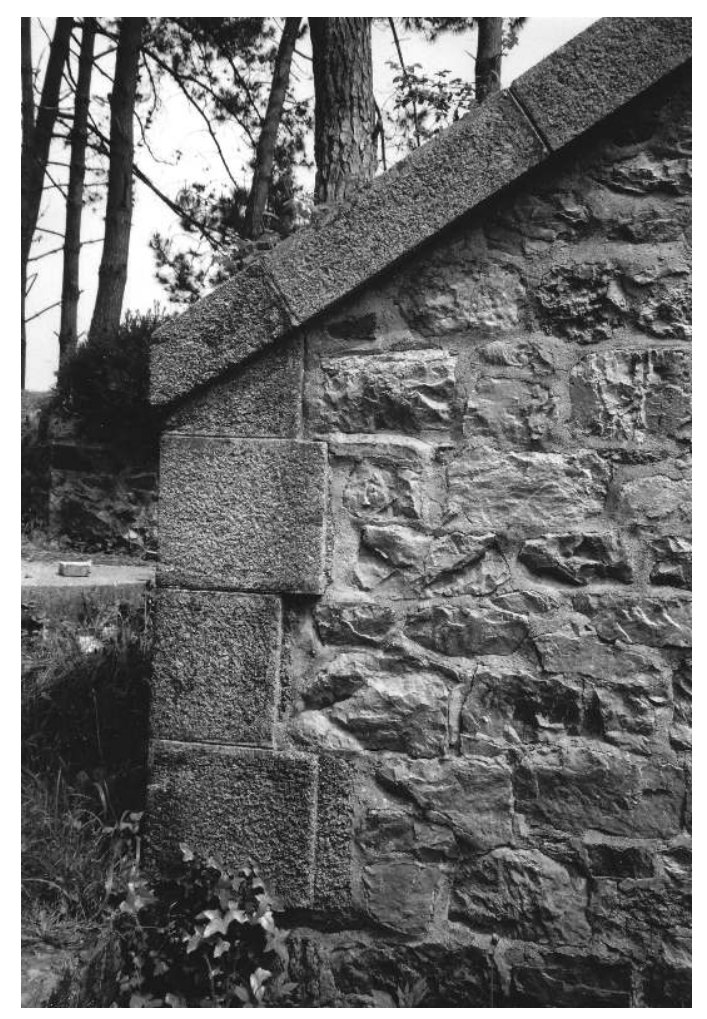

Photo II : Batterie du Kador à Crozon : le grès armoricain, utilisé en moellons, ne permet pas l'obtention de pierres de taille, d'où appel au granite de l'Aber-Ildut pour les chaînages d'angles et rampants.

Photo II: Kador battery at Crozon: "Armorican sandstone" is used as rubble but, as it cannot be dressed, Aber-Ildut granite provides cornerstones and pitches.

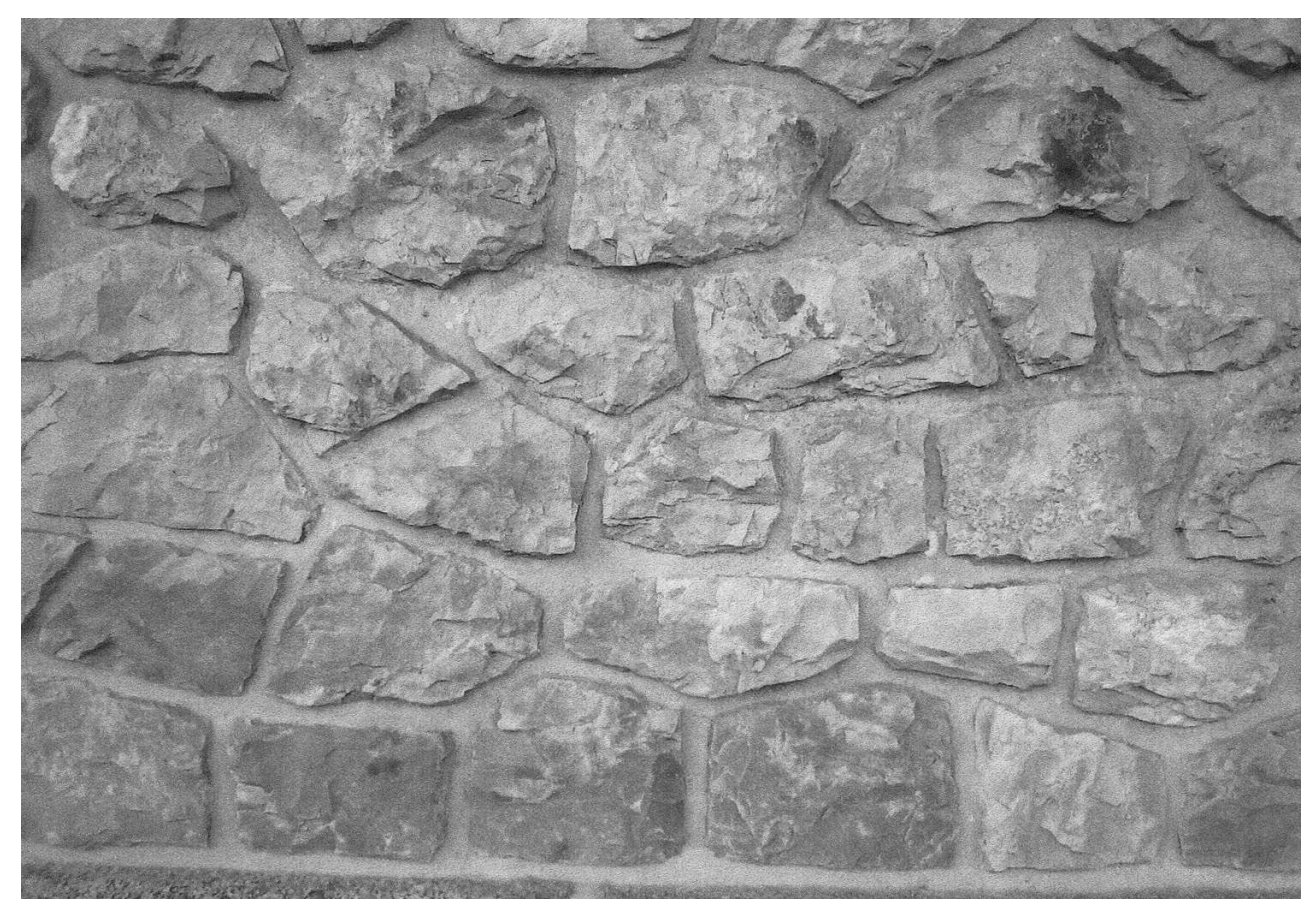

Photo III : Gare de Plomodiern : moellons en grès armoricain (l'appareil joue de leur irrégularité naturelle).

Photo III: Plomodiern railway station : Armorican sandstone rubble; the device plays with their natural irregularity. 


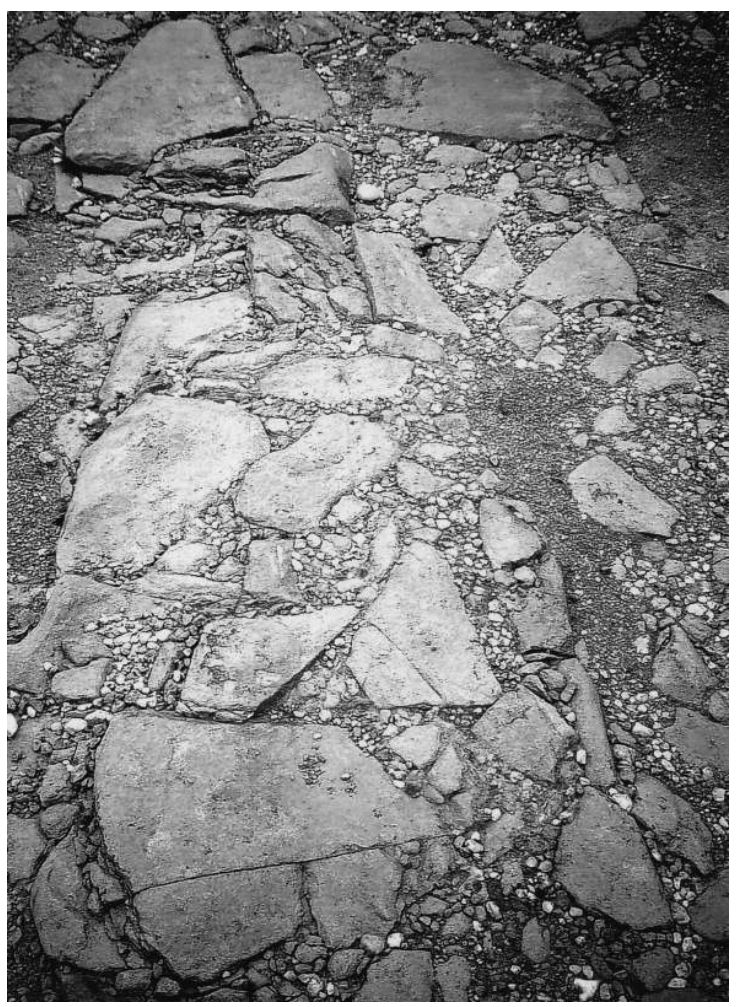

Photo IV : Dallage gallo-romain en grès vert carbonifère du bassin de Châteaulin mis à jour lors de fouilles à Carhaix (Vorgium).

Photo IV: Gallo-Roman paving of green Châteaulin Carboniferous sandstone uncovered during excavations at Carhaix (Vorgium).

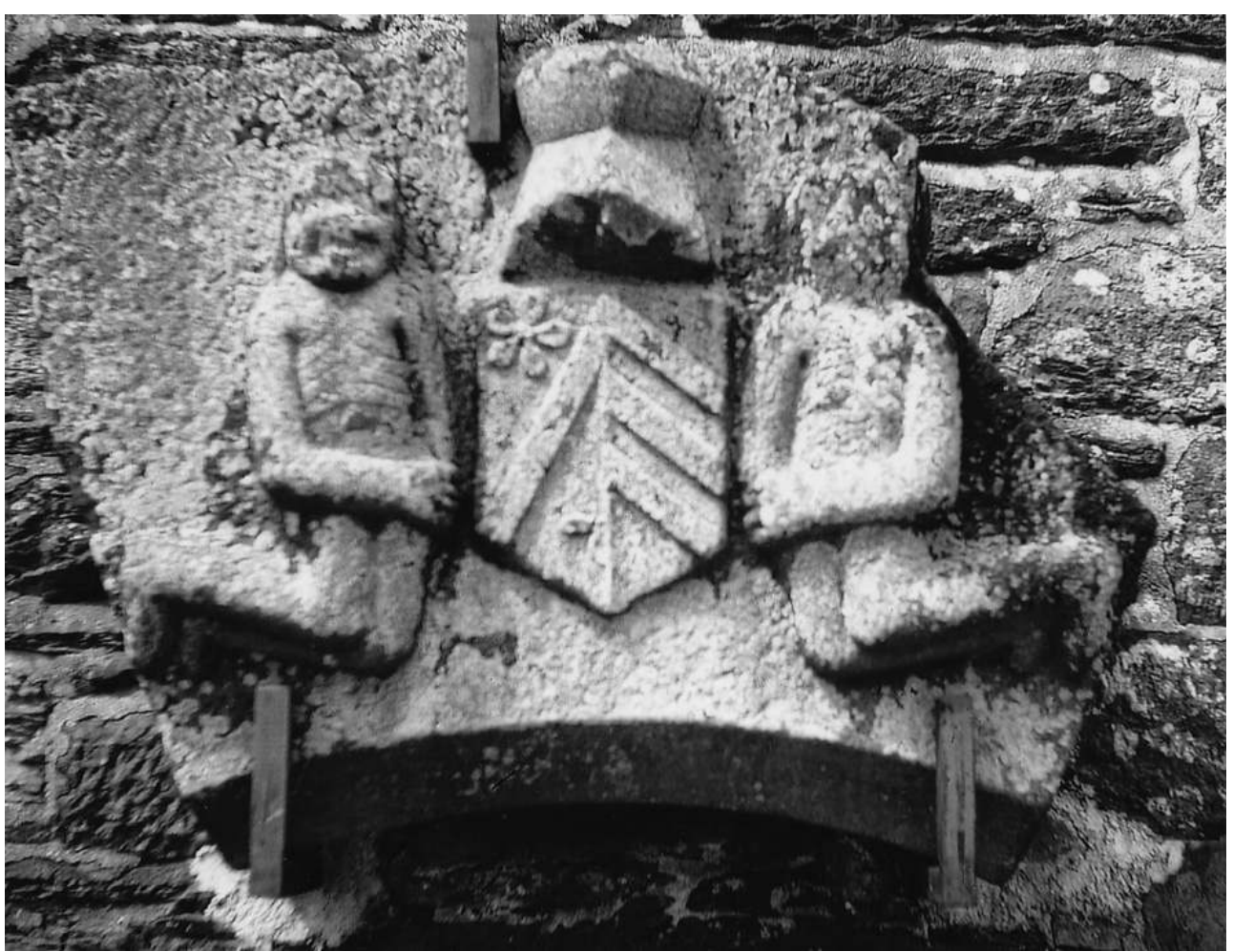

Photo V : Blason sculpté en grès vert, manoir de Maezroz près de Landeleau.

Photo V: Coat-of-arms sculptured in green sandstone; Maezroz manor near Landeleau. 


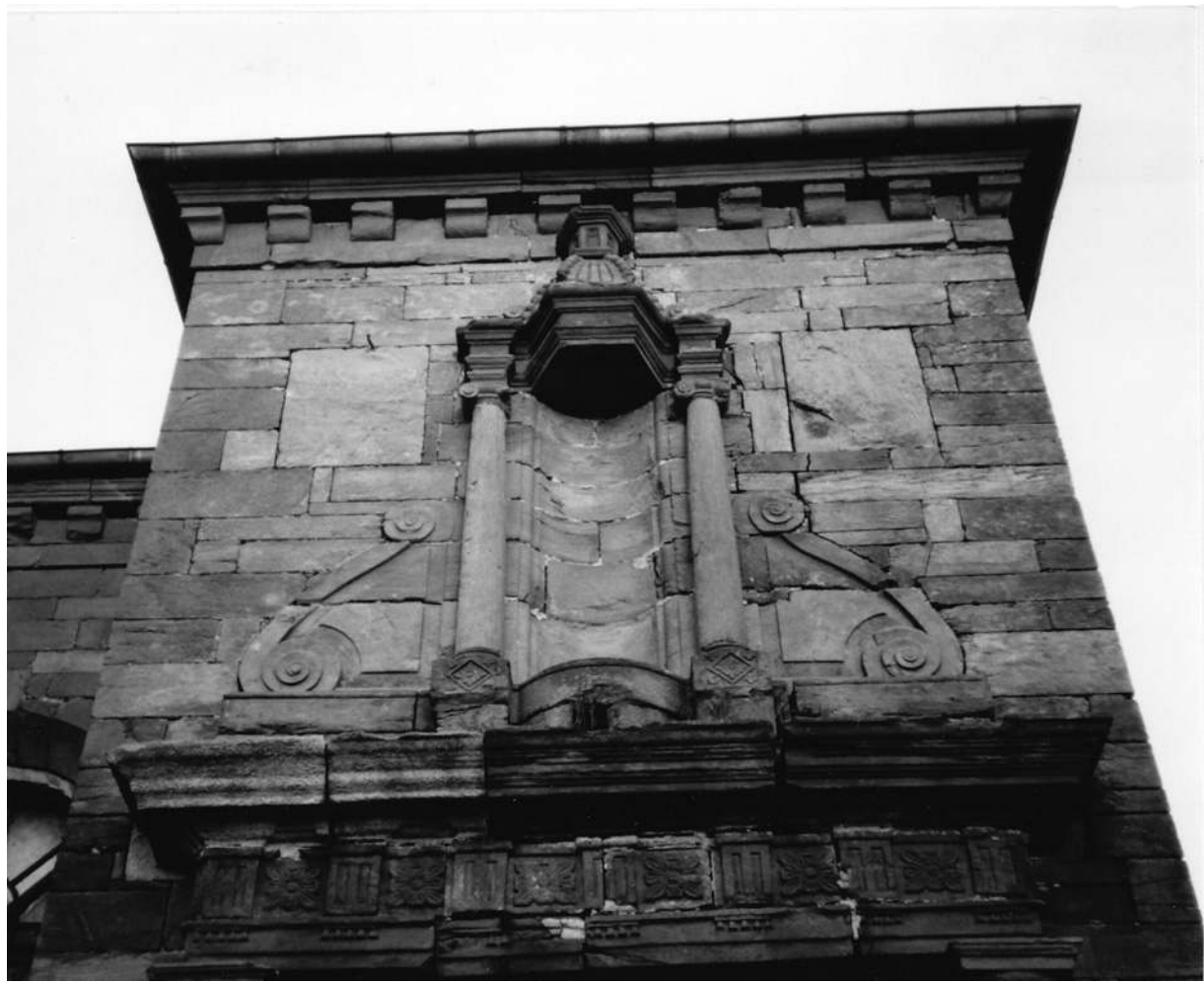

Photo VI : Chapelle du couvent des Hospitalières à Carhaix, en grès vert.

Photo VI: Chapel of the Hospitaller Sisters' convent in Carhaix, built of green sandstone.

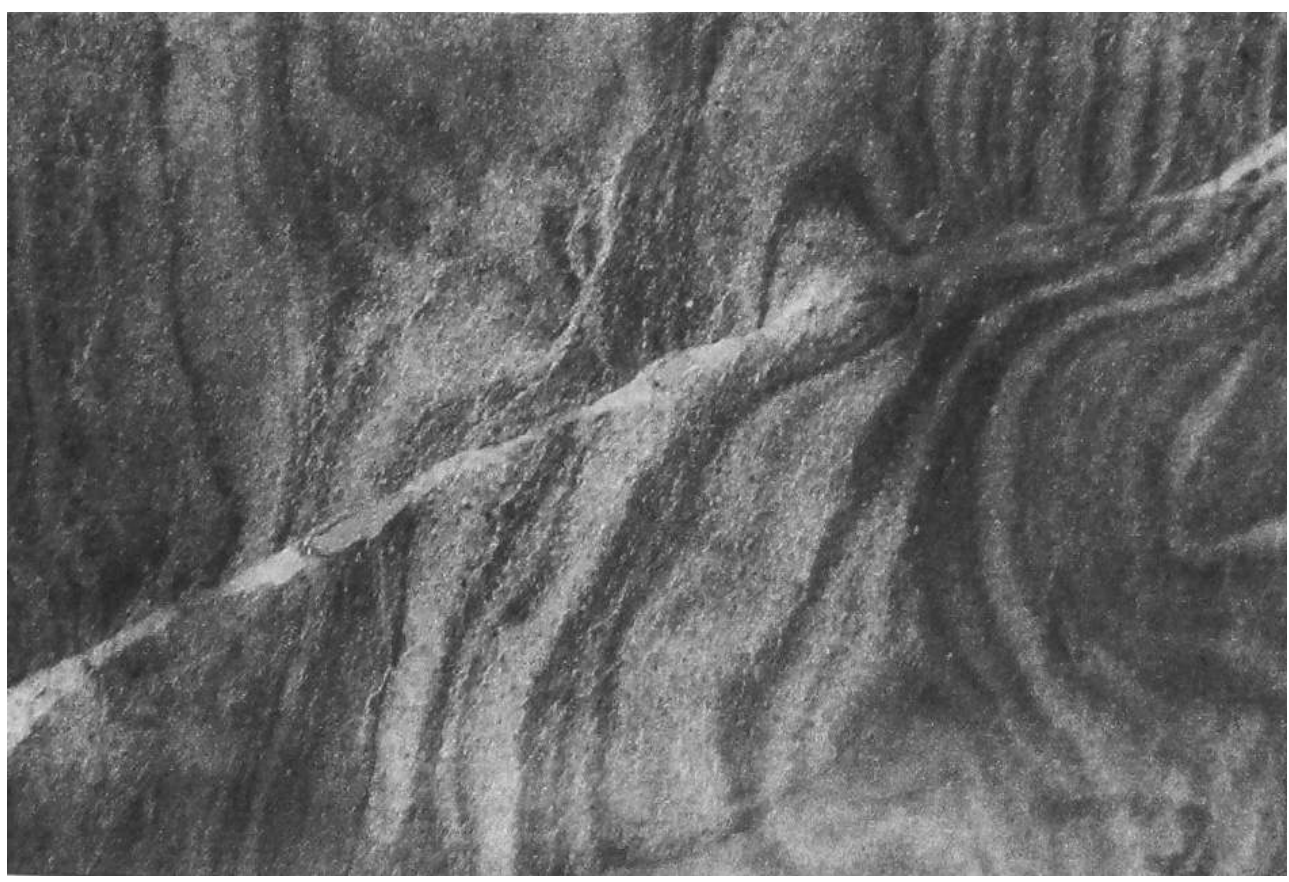

Photo VII : Sciage oblique à la stratification dans le grès rose d'Erquy, faisant apparaître des motifs en drapé.

Photo VII: Oblique sawing of Erquy pink sandstone emphazizes a drapé design. 


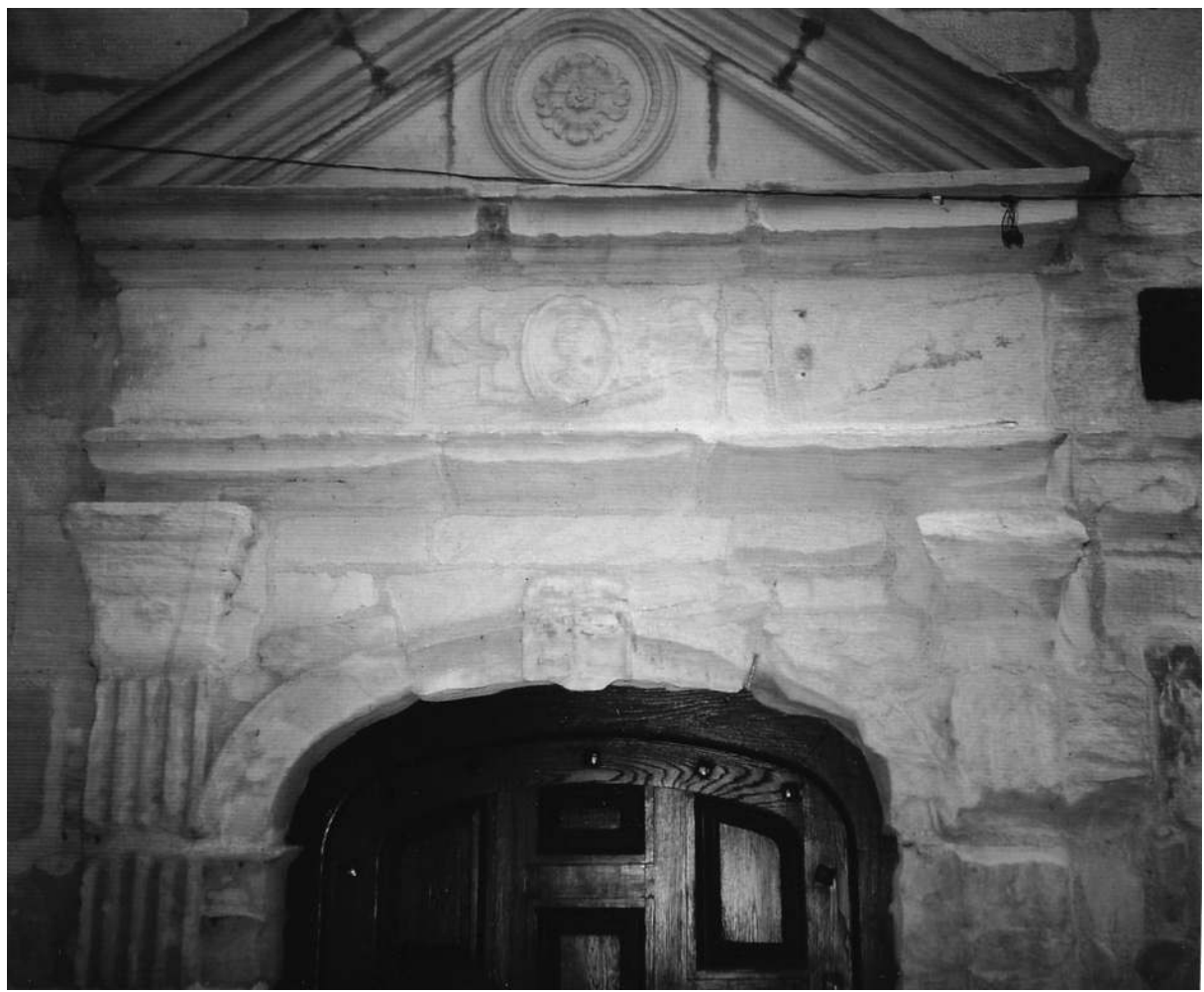

Photo VIII : Vitré, rue de La Baudrairie, $n^{\circ} 16$ : porte en grès gris-beige ordovicien.

Photo VIII: Door of grey-beige ordovician sandstone in Vitré; rue de la Baudrairie, $n^{\circ} 16$.

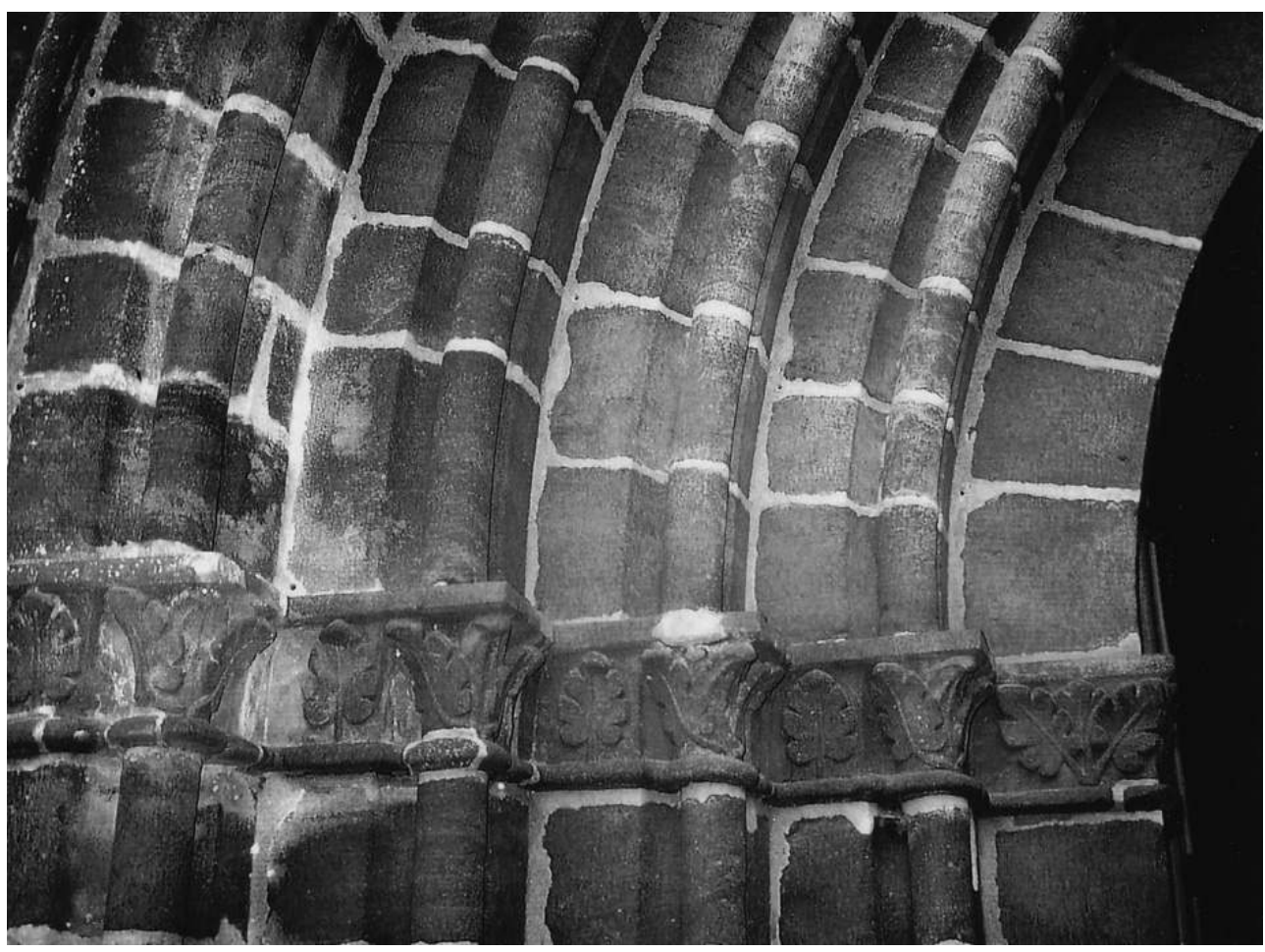

Photo IX : Saint-Gildas-des-Bois (Loire-Atlantique) : détail du porche de l'église en « roussard».

Photo IX: Saint-Gildas-des-Bois (Loire-Atlantique): detail of church porch, built with « roussard» sandstone. 


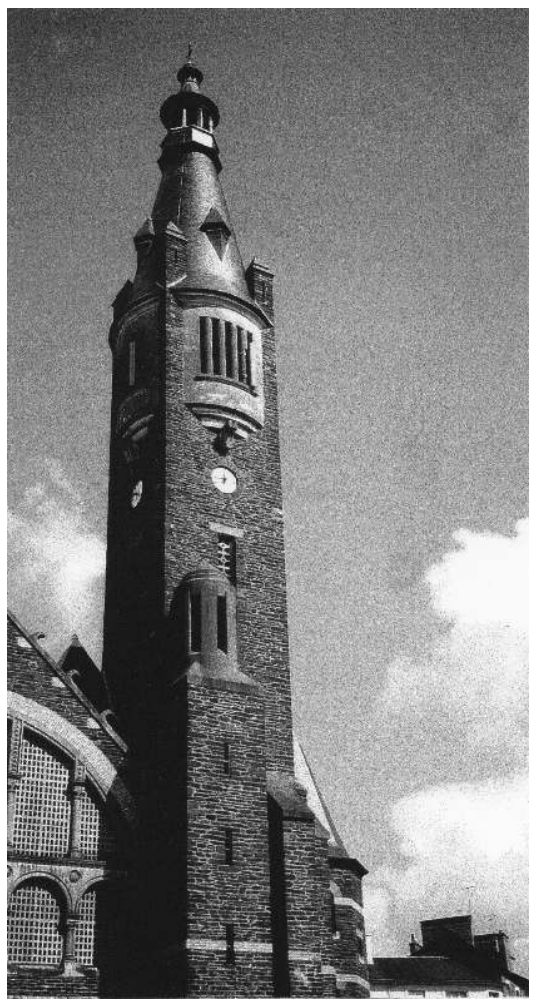

Photo X: Église Sainte-Jeanne-d'Arc à Rennes : schistes rouges associés au béton. Photo X: Sainte-Jeanne-d'Arc church in Rennes: red schist associated with concrete.

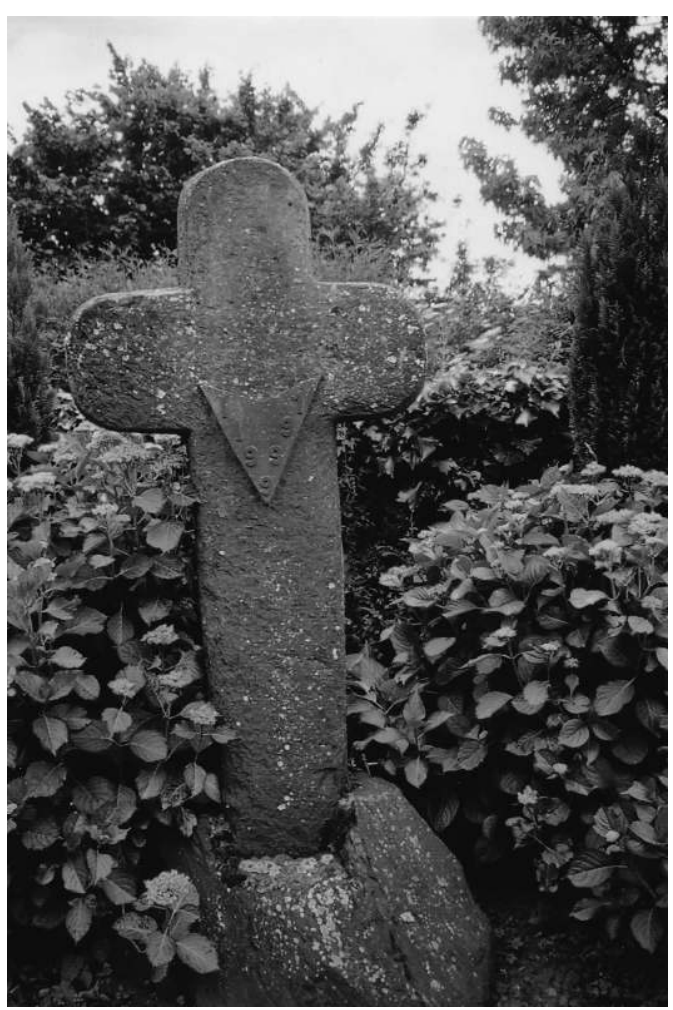

Photo XI : Abbaye de Paimpont (Ille-et-Vilaine) : croix monolithe en schiste pourpré. Photo XI: Abbey (IIle-et-Vilaine): monolithic cross of crimson schist. 


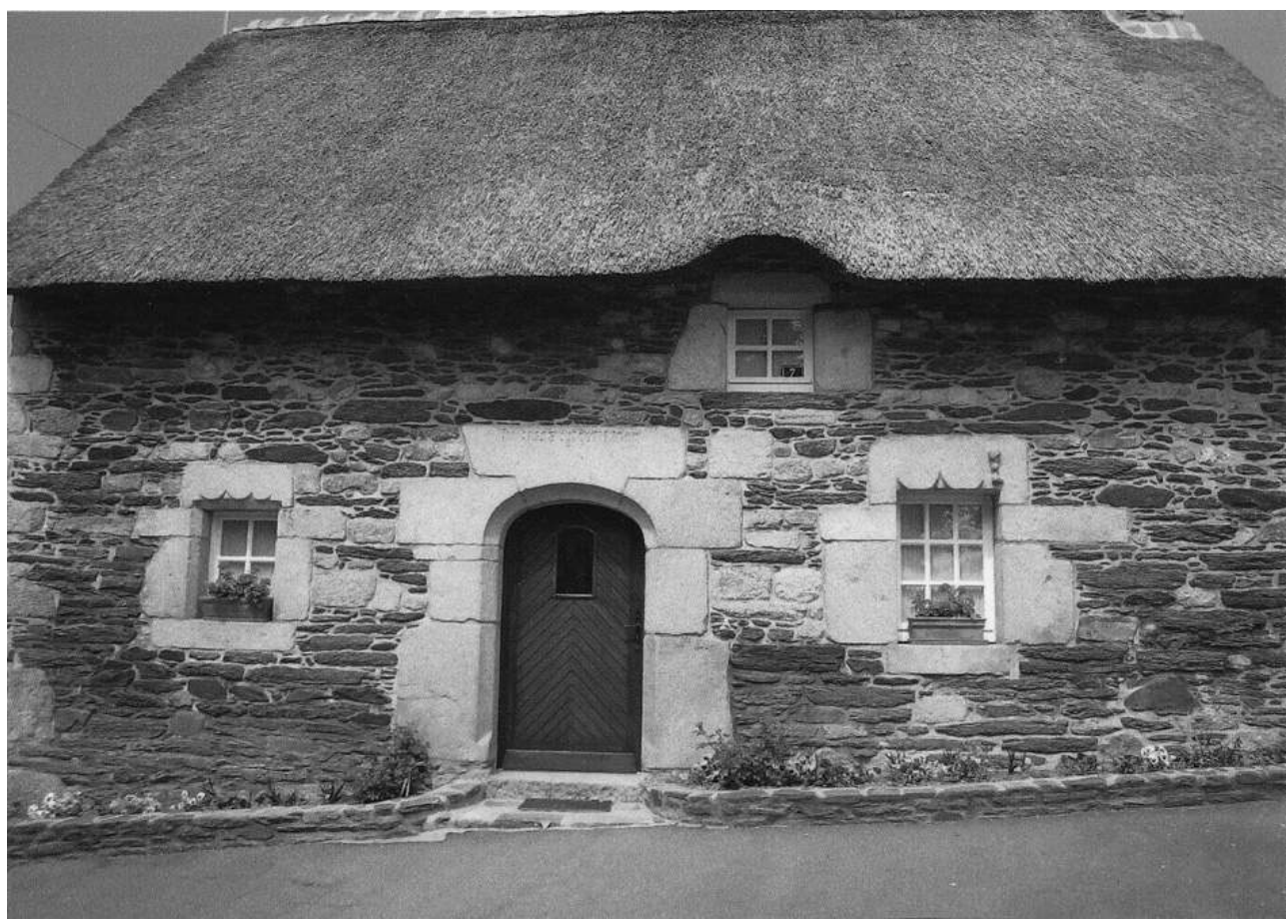

Photo XII : Saint-Nicolas-des-Eaux (Morbihan) : association de moellons en schiste bleu sombre à des pierres de taille en granite.

Photo XII: Saint-Nicolas-des-Eaux (Morbihan): rubblestones of dark blue schist associated with granite freestones.

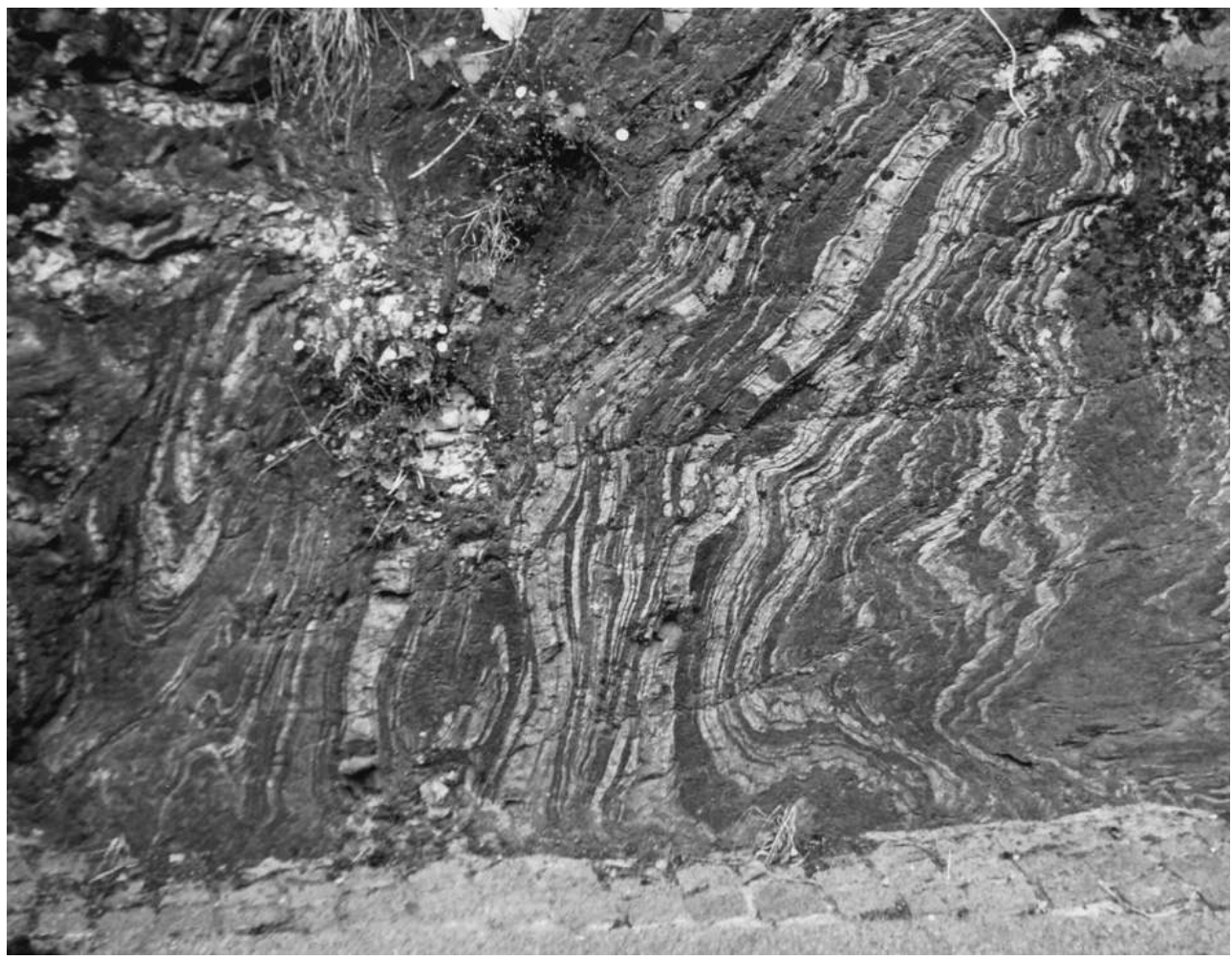

Photo XIII : Affleurement de schistes zébrés à Morlaix.

Photo XIII: Outcrop of zebra schists in Morlaix. 


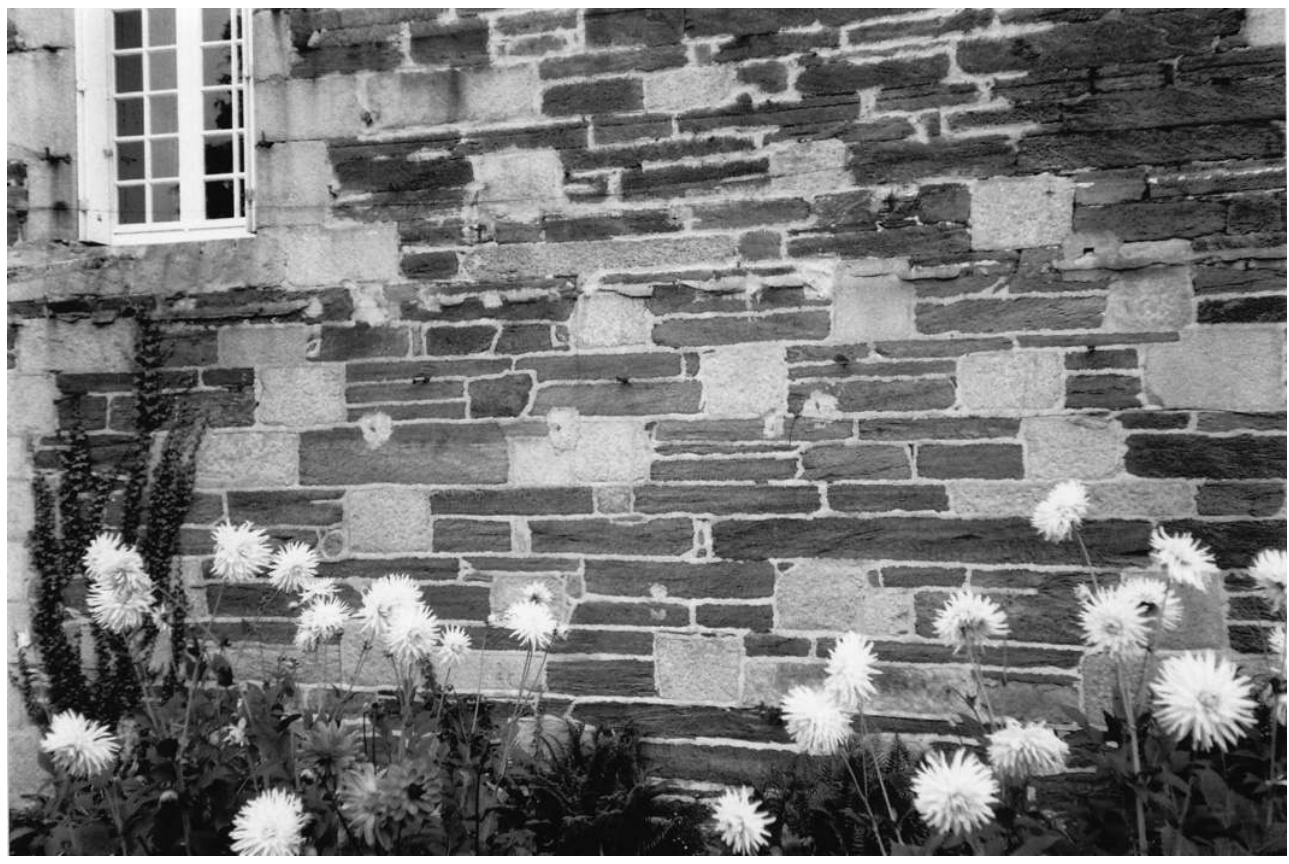

Photo XIV : Couvent des Ursulines à Morlaix : association schiste-granite quelque peu aléatoire. Photo XIV: Ursulines convent in Morlaix: random schist-granite association.

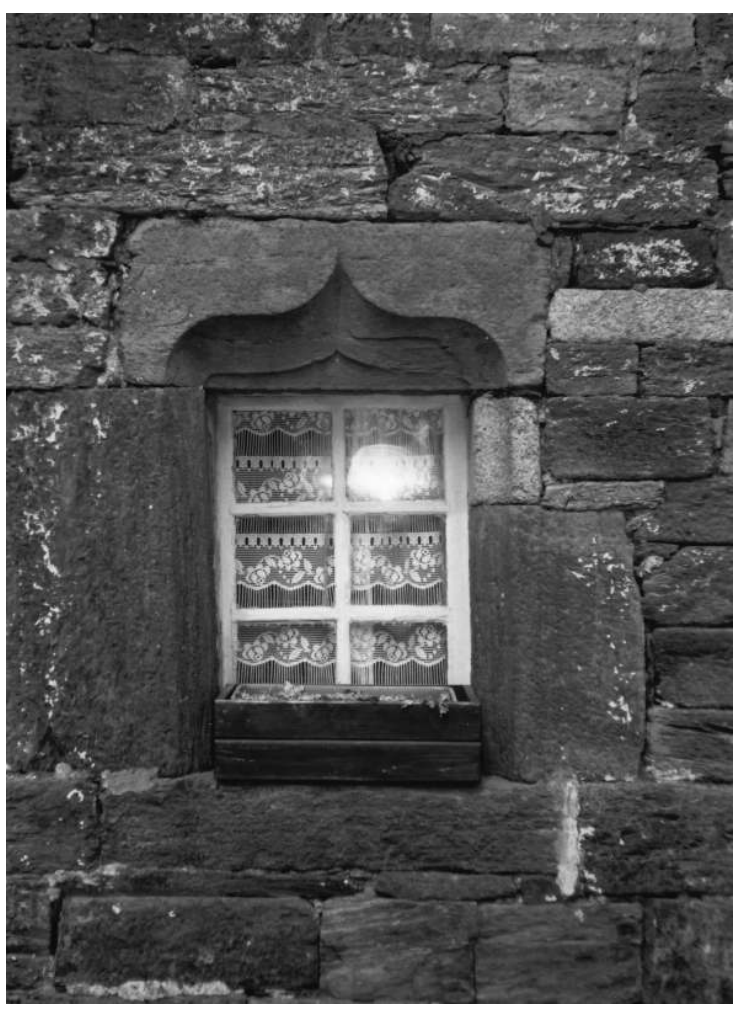

Photo XV : La Martyre (Finistère) : entourage d'une fenêtre en schiste bleu sombre. Photo XV: La Martyre (Finistère): window surround of dark blue schist. 


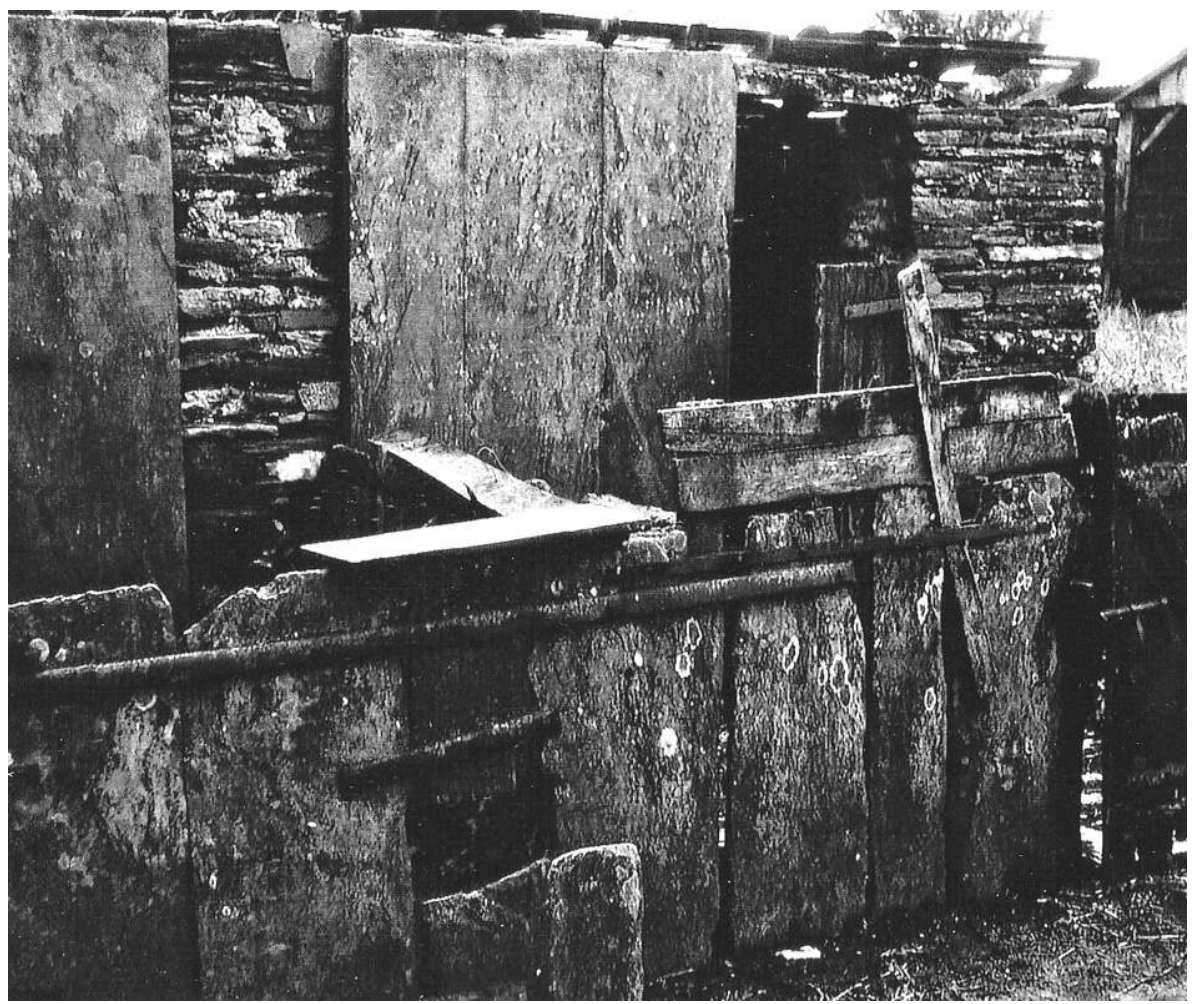

Photo XVI : Bâti en palis au Souchais (environs de Nozay, Loire-Atlantique).

Photo XVI: Slate building at Le Souchais, near Nozay (Loire-Atlantique).

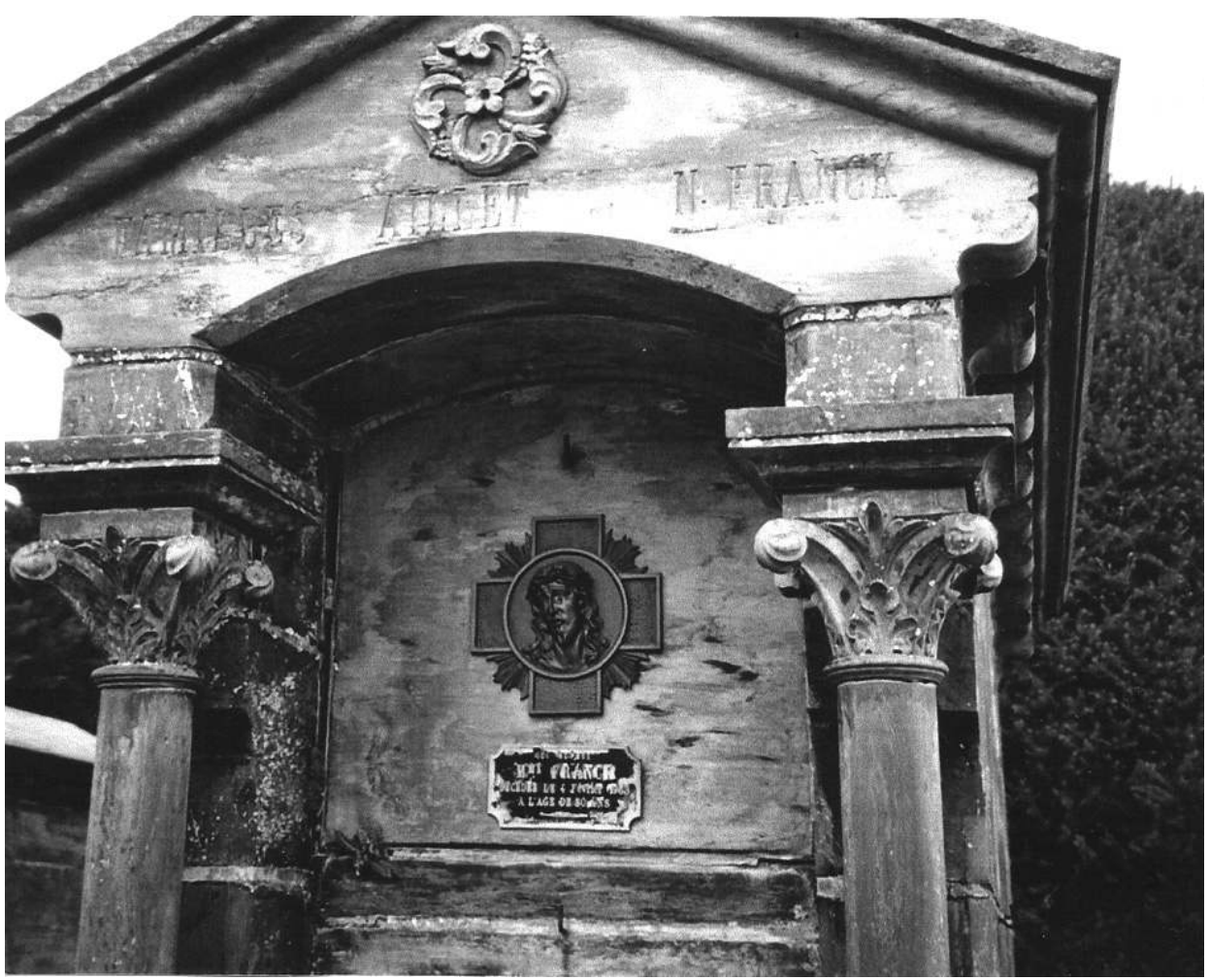

Photo XVII : Au cimetière de Nozay, tombe-chapelle en schiste local, y compris les colonnettes cylindriques et les chapiteaux finement ouvragés.

Photo XVII: Nozay graveyard; funeral chapel of local schist, including small cylindrical columns and finely worked capitals. 


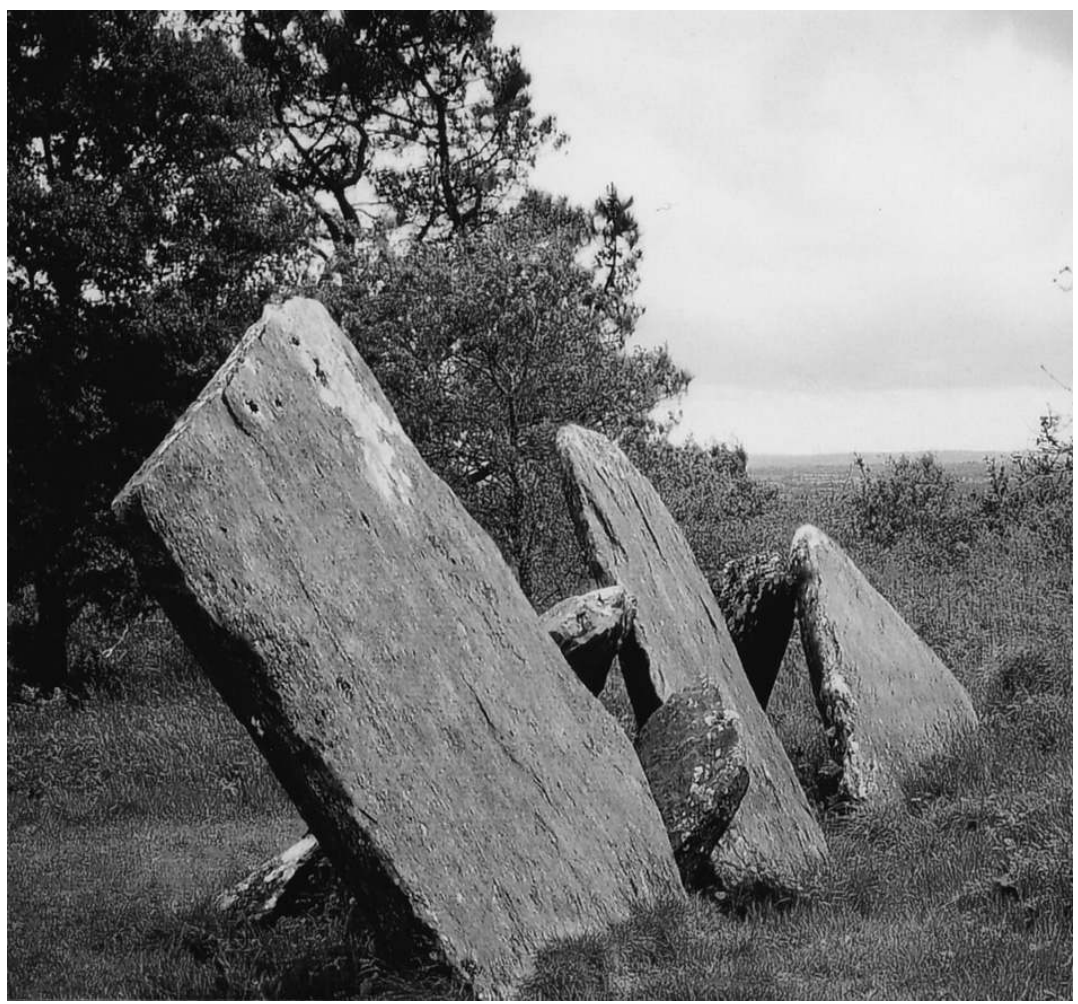

Photo XVIII : Tombe mégalithique en dalles de schiste local (Castel-Ruphel en Saint-Goazec, Finistère). Photo XVIII: The Castel-Ruphel megalithic tomb of local schist slabs; Saint-Goazec (Finistère).

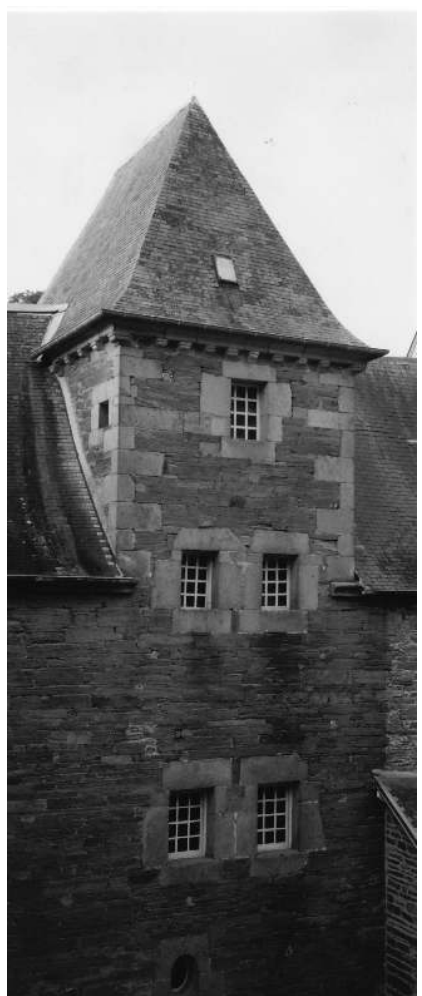

Photo XIX : Maison Penanault à Morlaix : association du granite en pierres de taille au schiste en moellons.

Photo XIX: Penanault house in Morlaix: granite freestones associated with schist rubble. 


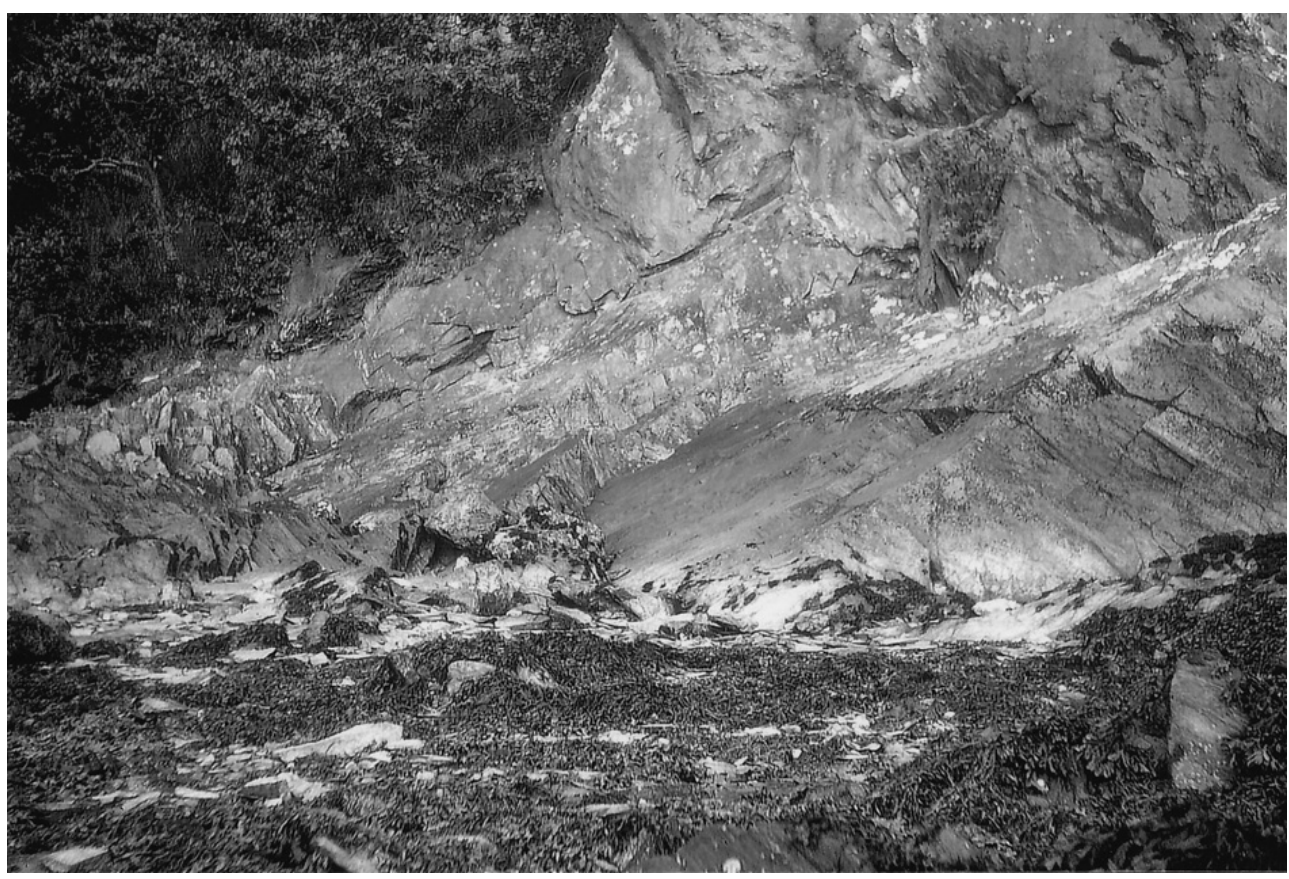

Photo XX : à Roc'h-Glas (Carantec, Finistère), exploitation du schiste ardoisier sur l'estran. Photo XX: Roc'h-glas quarry of slate schist on the strand at Carantec (Finistère).

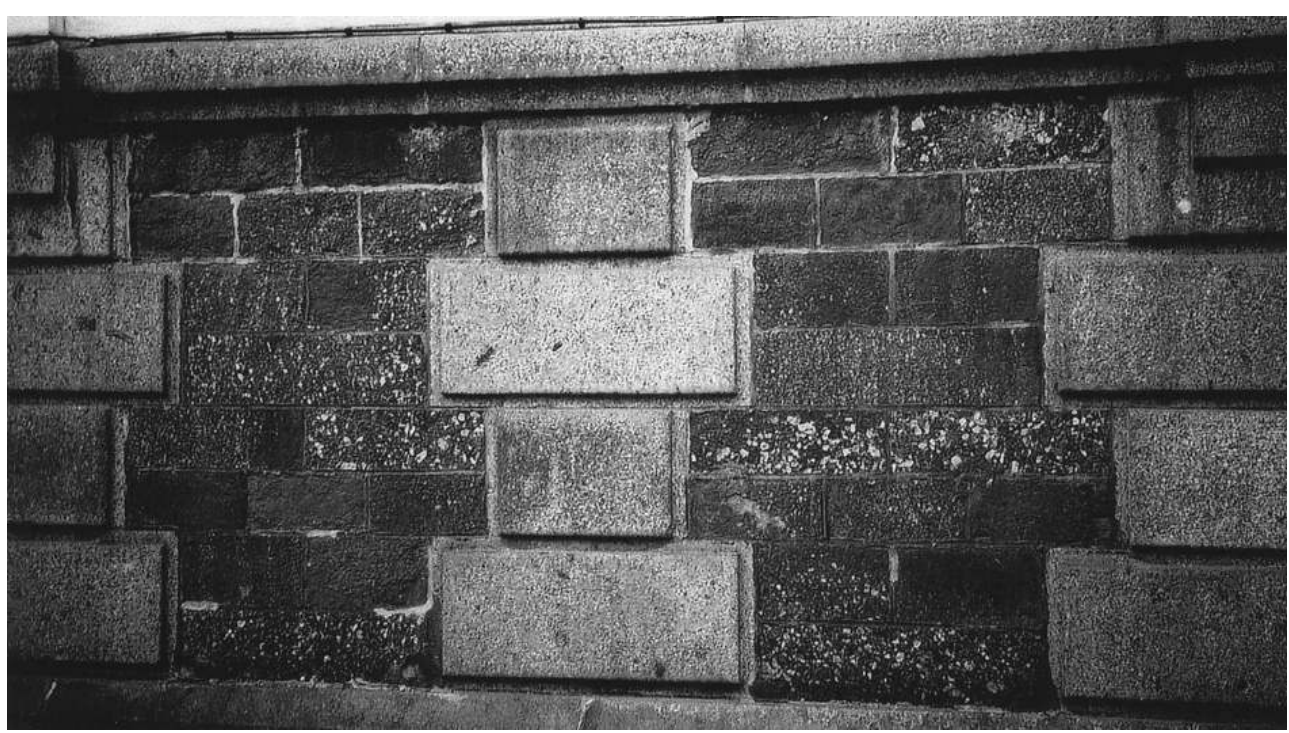

Photo XXI : Rennes, boulevard de La Liberté : poudingue de Montfort et schiste rouge associés à un granite clair du batholite mancellien.

Photo XXI: Montfort puddingstone and red schist associated with a light granite from mancellian batholith (Rennes, Boulevard de la Liberté). 


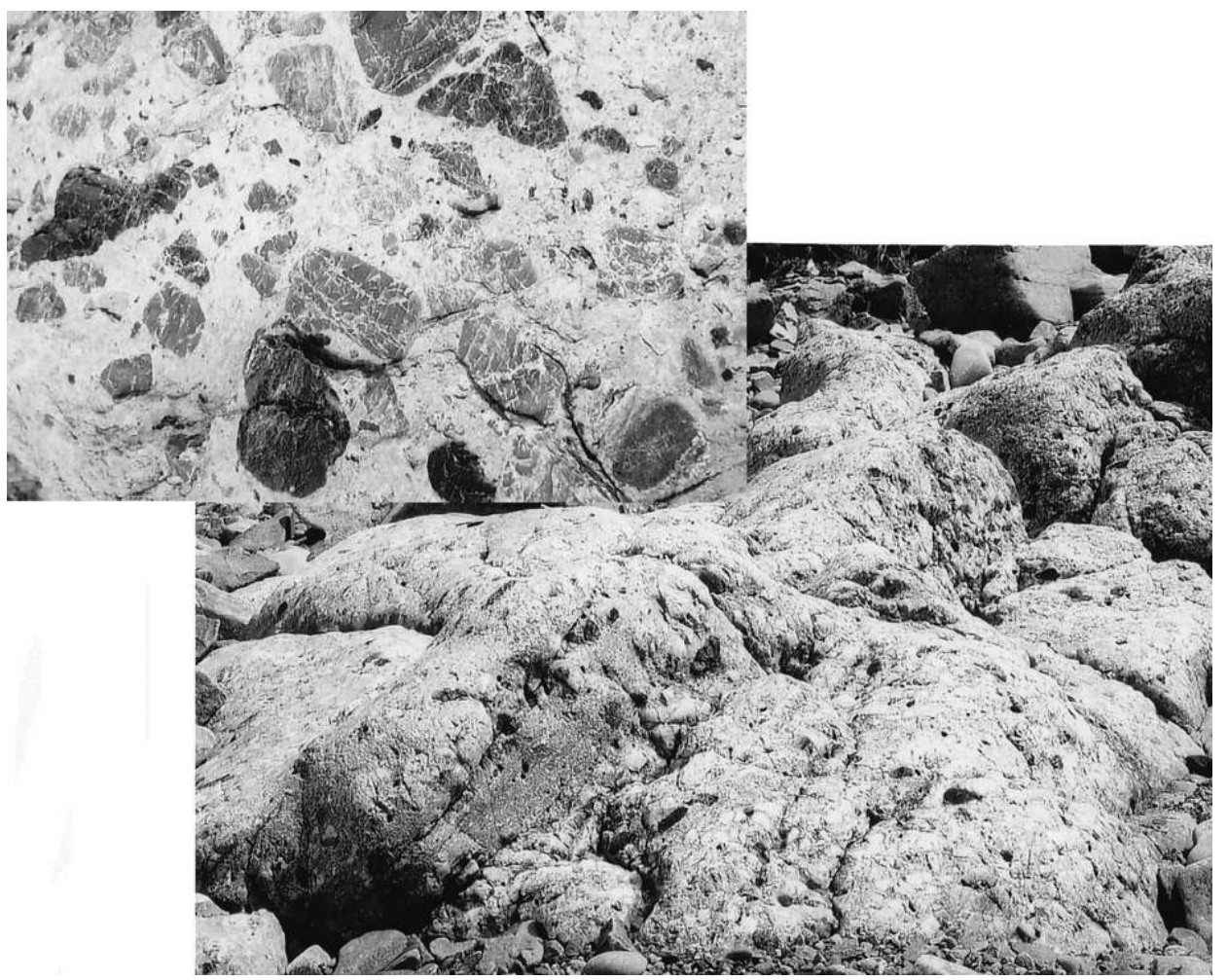

Photo XXII : Poudingue quartzeux près de Sables-d'Or-les-Pins (Côtes-d'Armor) : affleurement sur l'estran et gros plan montrant la juxtaposition de galets de phtanite et de cornaline.

Photo XXII: Quartz puddingstone near Sables-d'Or-les-Pins (Côtes-d'Armor): outcrop on the strand and closeup showing juxtaposition of phtanite and cornaline pebbles. 


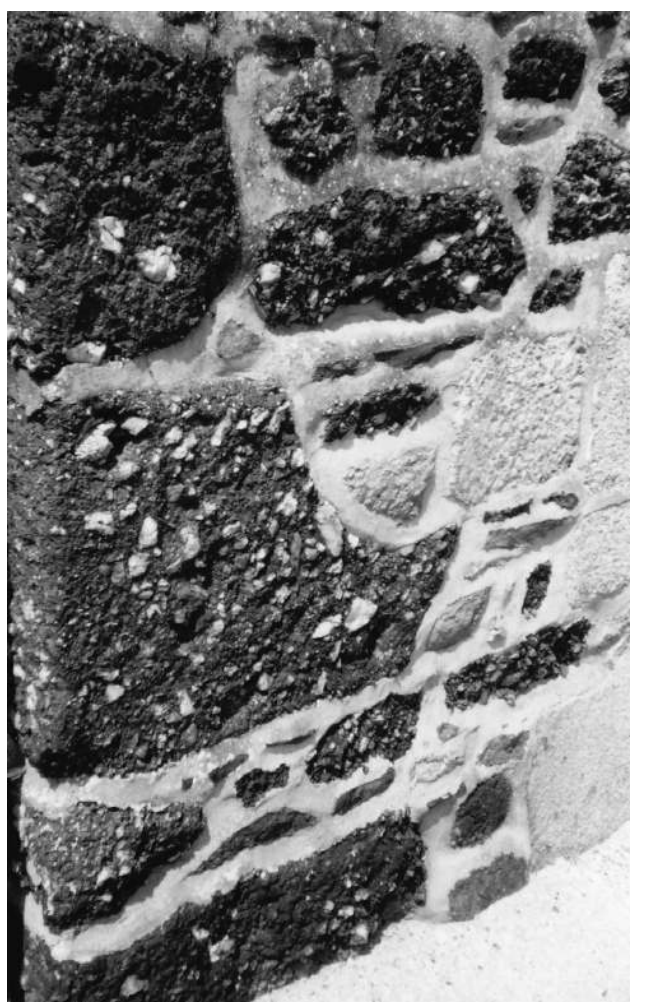

Photo XXIII : Tréguidel (Côtes-d'Armor), porche sud de l'église : « pierre des landes » avec fragments anguleux de quartz en saillie.

Photo XXIII: South porch of Treguidel church (Côtes-d'Armor): "Pierre-des-Landes" freestones with protruding angular fragments of quartz.

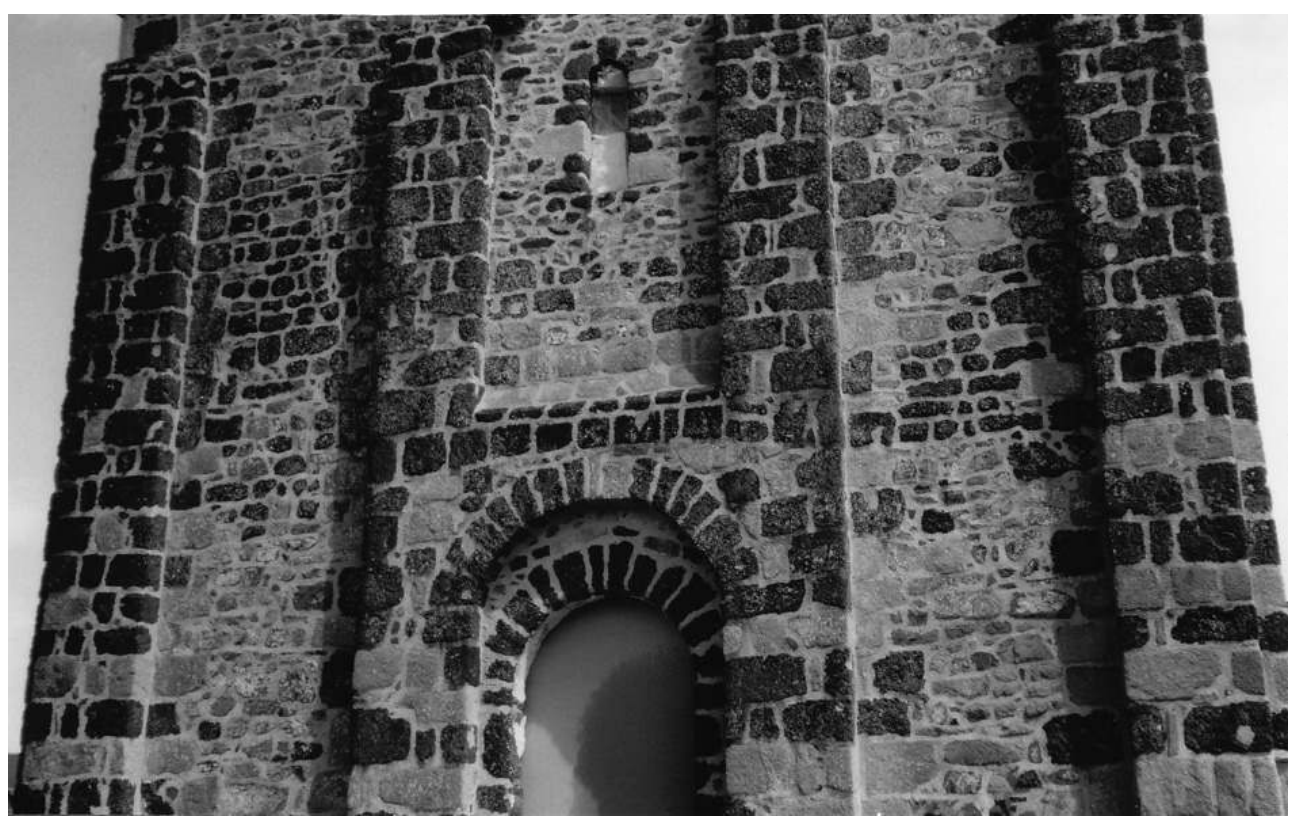

Photo XXIV : Façade occidentale de l'église de Morieux (Côtes-d'Armor) : large emploi des brèches ferrugineuses sombres.

Photo XXIV: West facade of Morieux church (Côtes-d'Armor): extensive use of dark ferruginous breccias. 


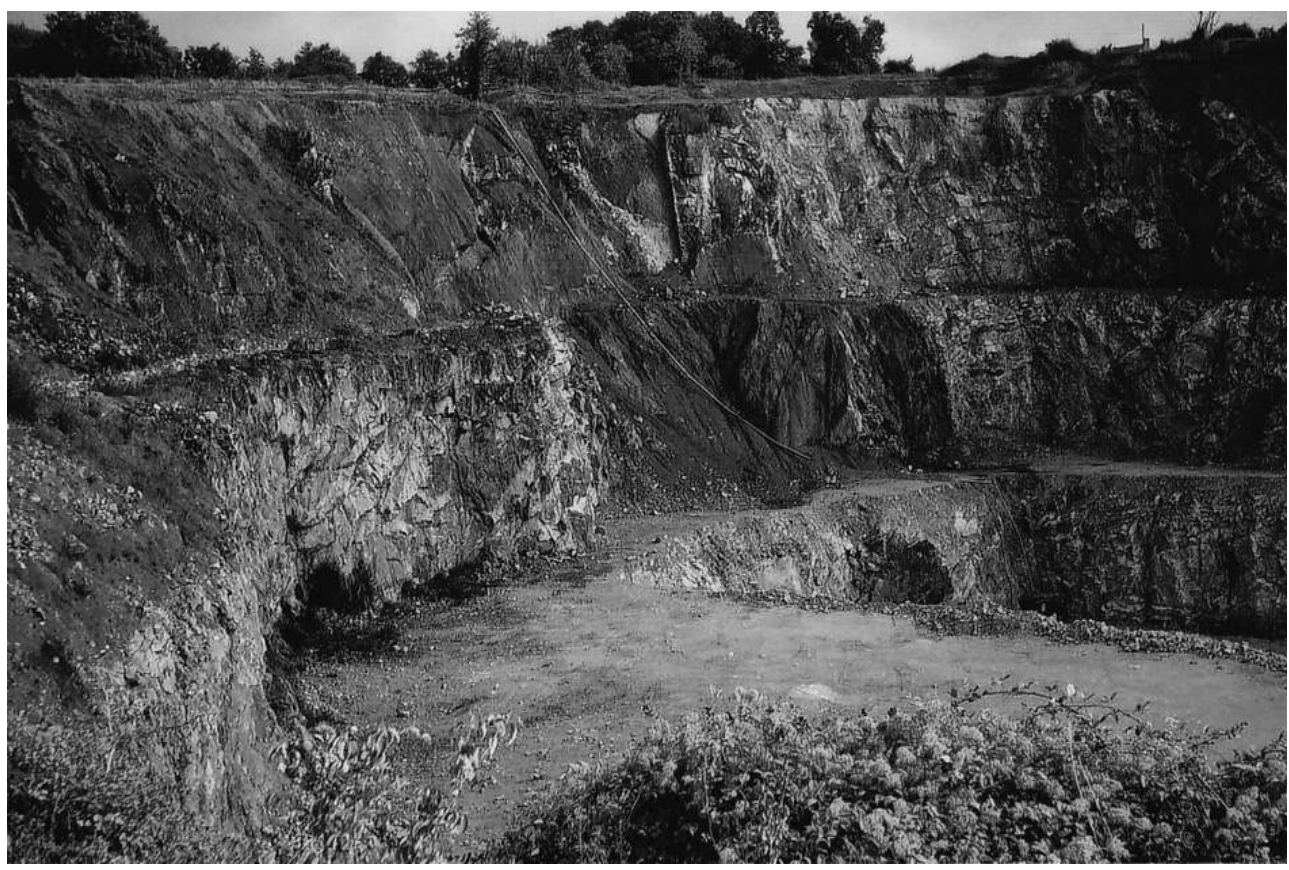

Photo XXV : Impressionnants fronts de taille dans la carrière de calcaire en exploitation à Erbray (Loire-Atlantique).

Photo XXV: Impressive working faces in the still exploited limestone quarry at Erbray (Loire-Atlantique).

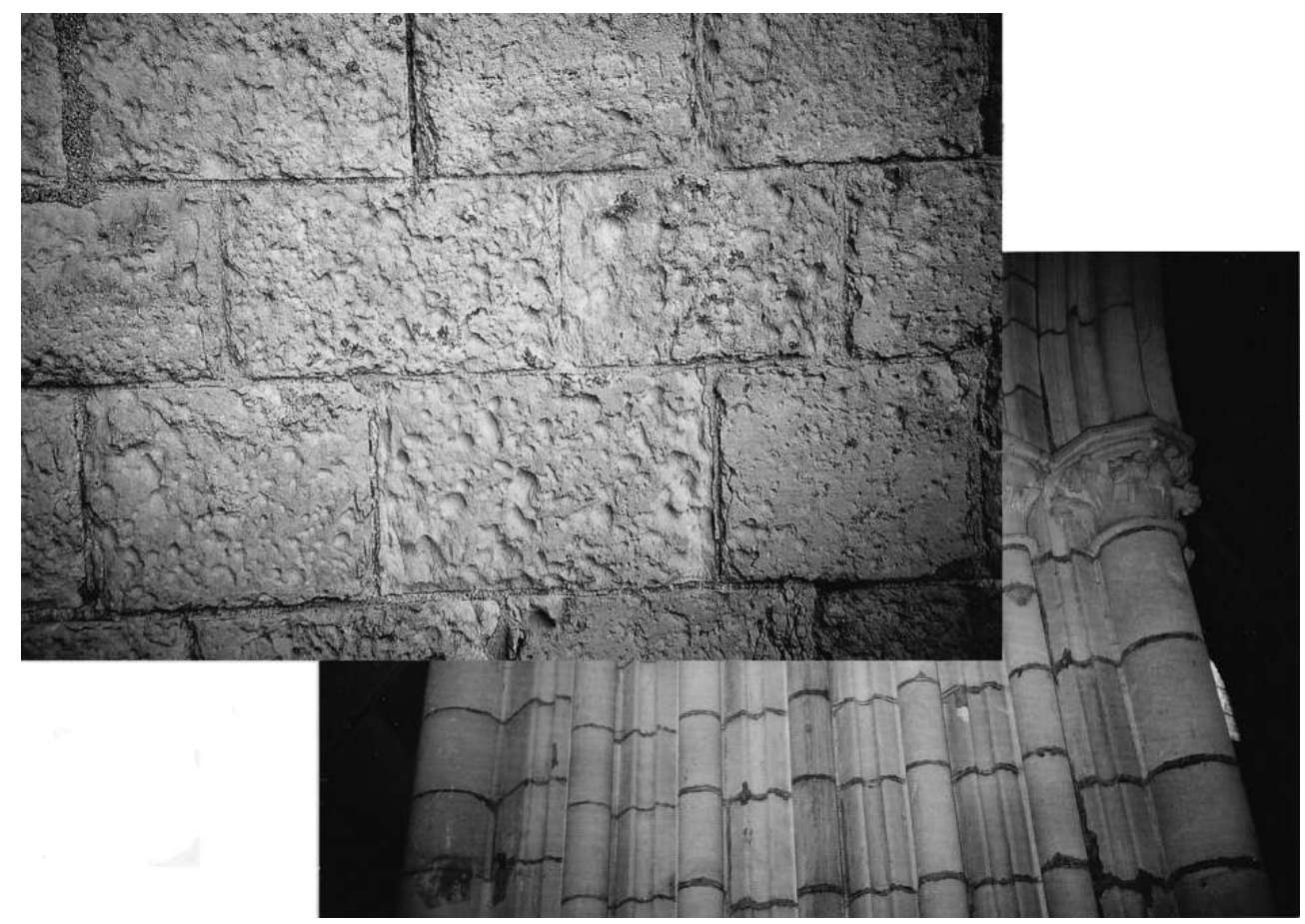

Photo XXVI : Cathédrale de Saint-Pol-de-Léon (Finistère) : pilier de la nef en calcaire de Caen et le même calcaire en extérieur, soumis à l'érosion météorique.

Photo XXVI: Saint-Pol-de-Léon cathedral (Finistère): nave pillar of Caen limestone and the same rock weathered outside. 


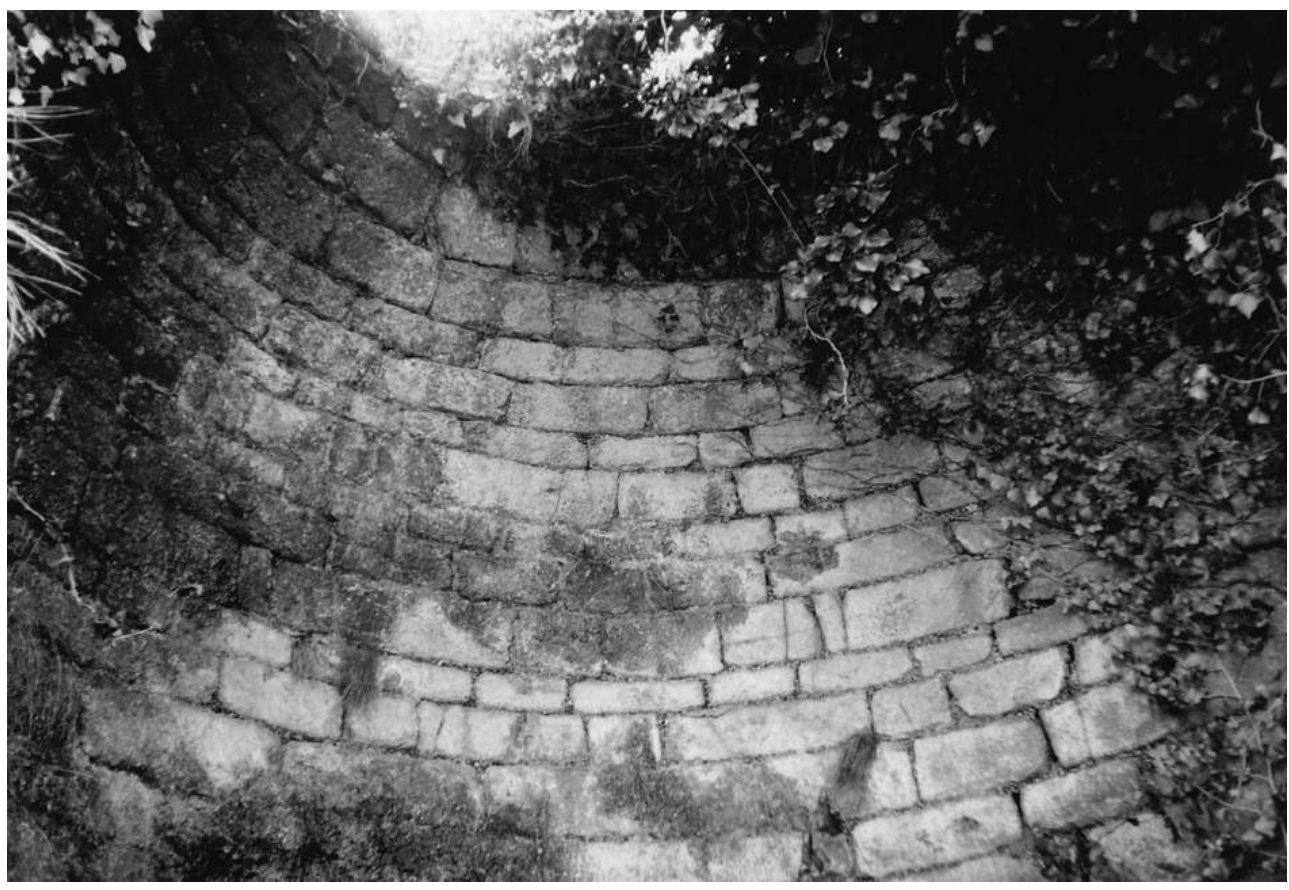

Photo XXVII : Intérieur du four à chaux de Postermen à Roscanvel (Finistère).

Photo XXVII: Interior of the Postermen lime furnace at Roscanvel (Finistère).

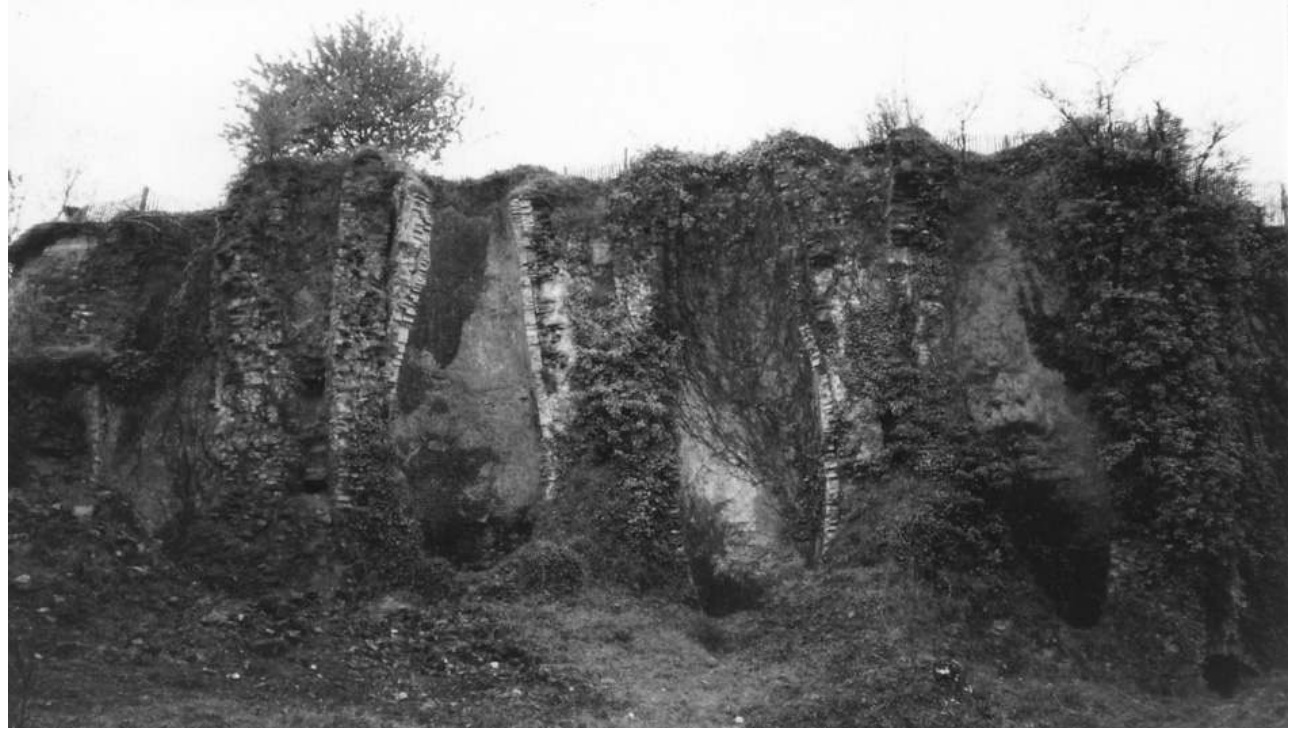

Photo XXVIII : Anciens fours à chaux éventrés à Chartres-de-Bretagne (IIle-et-Vilaine) Photo XXVIII: Ripped ancient lime furnaces at Chartres-de-Bretagne (IIle-et-Vilaine). 


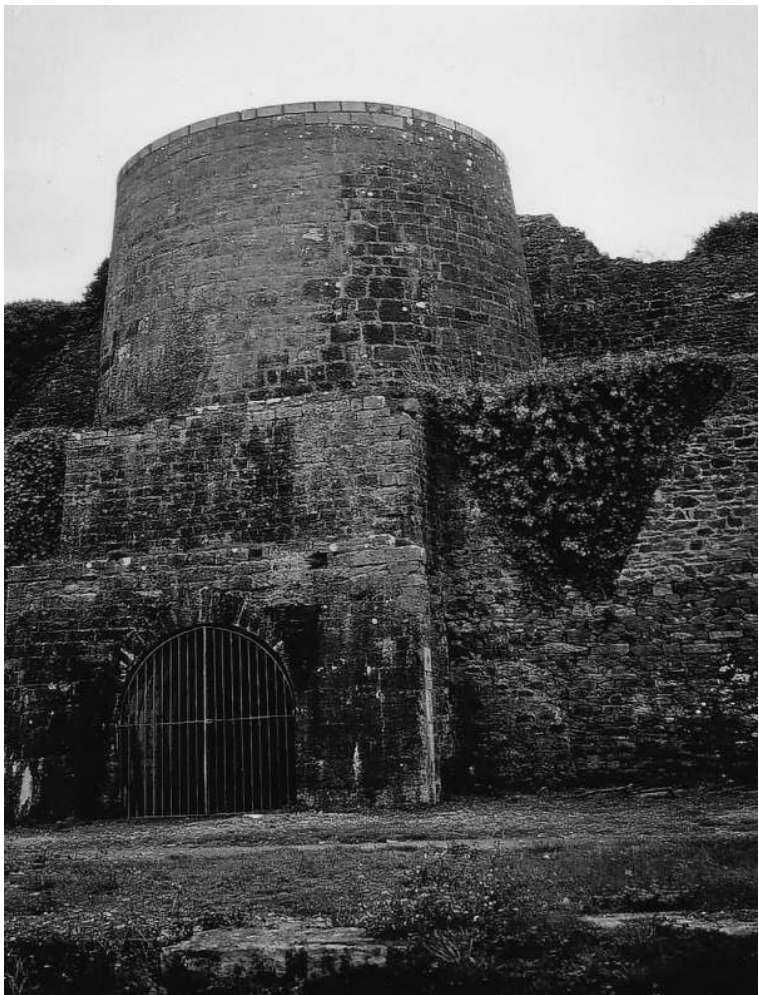

Photo XXIX: Four à chaux de Rozan, l'Aber en Crozon (Finistère) Photo XXIX: Rozan lime furnace at L'Aber, Crozon (Finistère). 


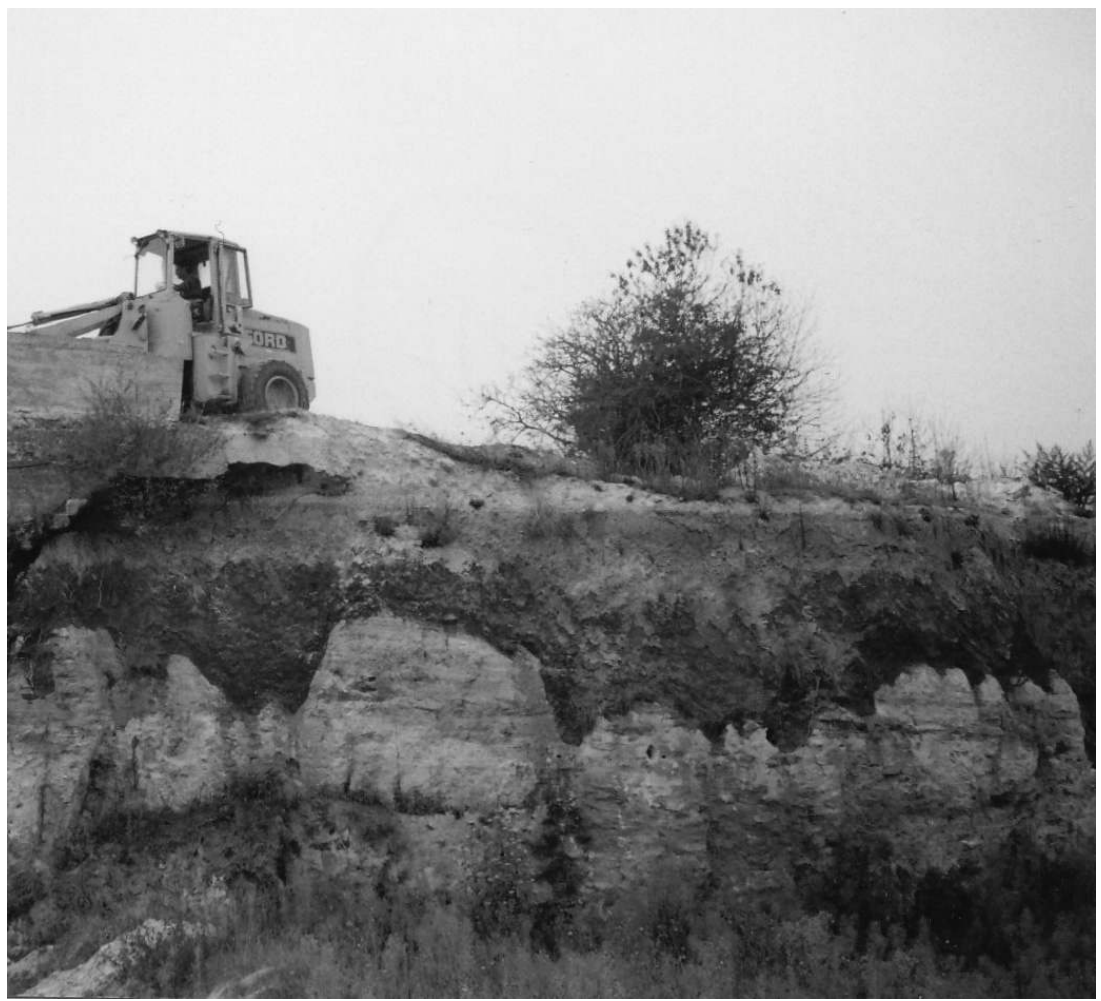

Photo XXX: Vue partielle d'un front de taille dans la carrière de La Perchais, en Tréfumel (Côtesd'Armor). La partie supérieure du calcaire miocène, blanc à ocre-jaune, est irrégulièrement accidentée par des poches de dissolution remplies par les dépôts argilo-sableux rougeâtres du Pliocène

Photo XXX: Partial view of a working face in La Perchais quarry, Tréfumel (Côtes-d'Armor). The upper part of Miocene limestone, whitish to yellow ochre, is attacked by dissolution pockets filled by Pliocene reddish sand-and-clay deposits. 


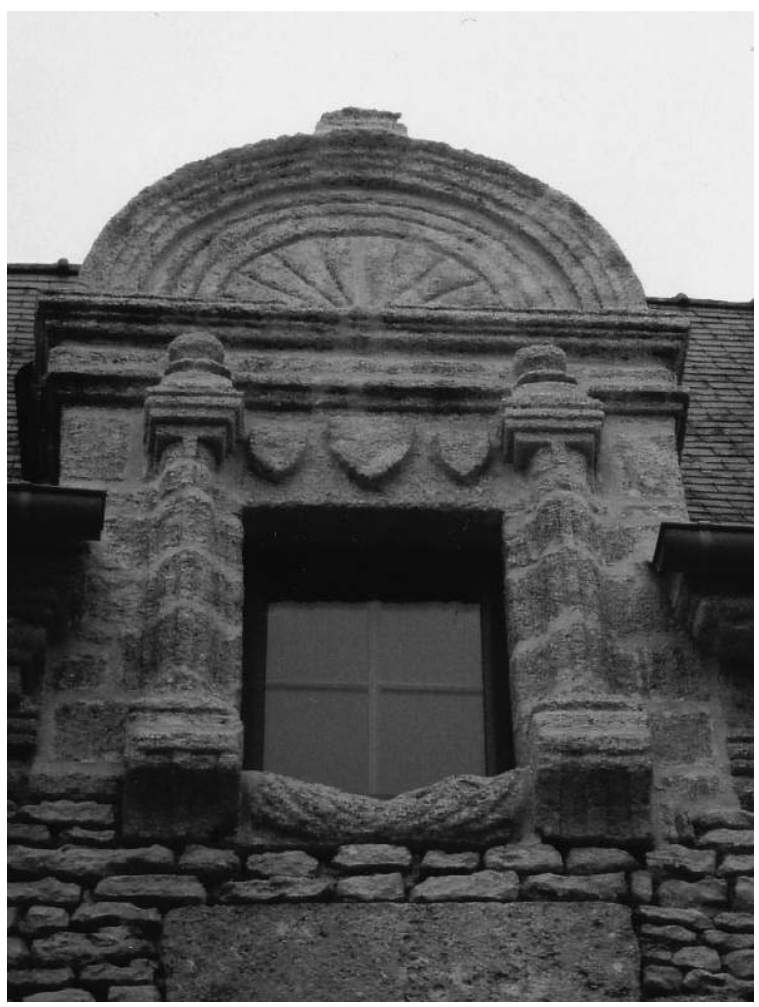

Photo XXXI : Le Marais (1668), à la sortie de Tréfumel : lucarne en « pierre de jauge ».

Photo XXXI : "Pierre de jauge" skylight frame at Le Marais, outskirts of Trefumel (Côtes-d'Armor).

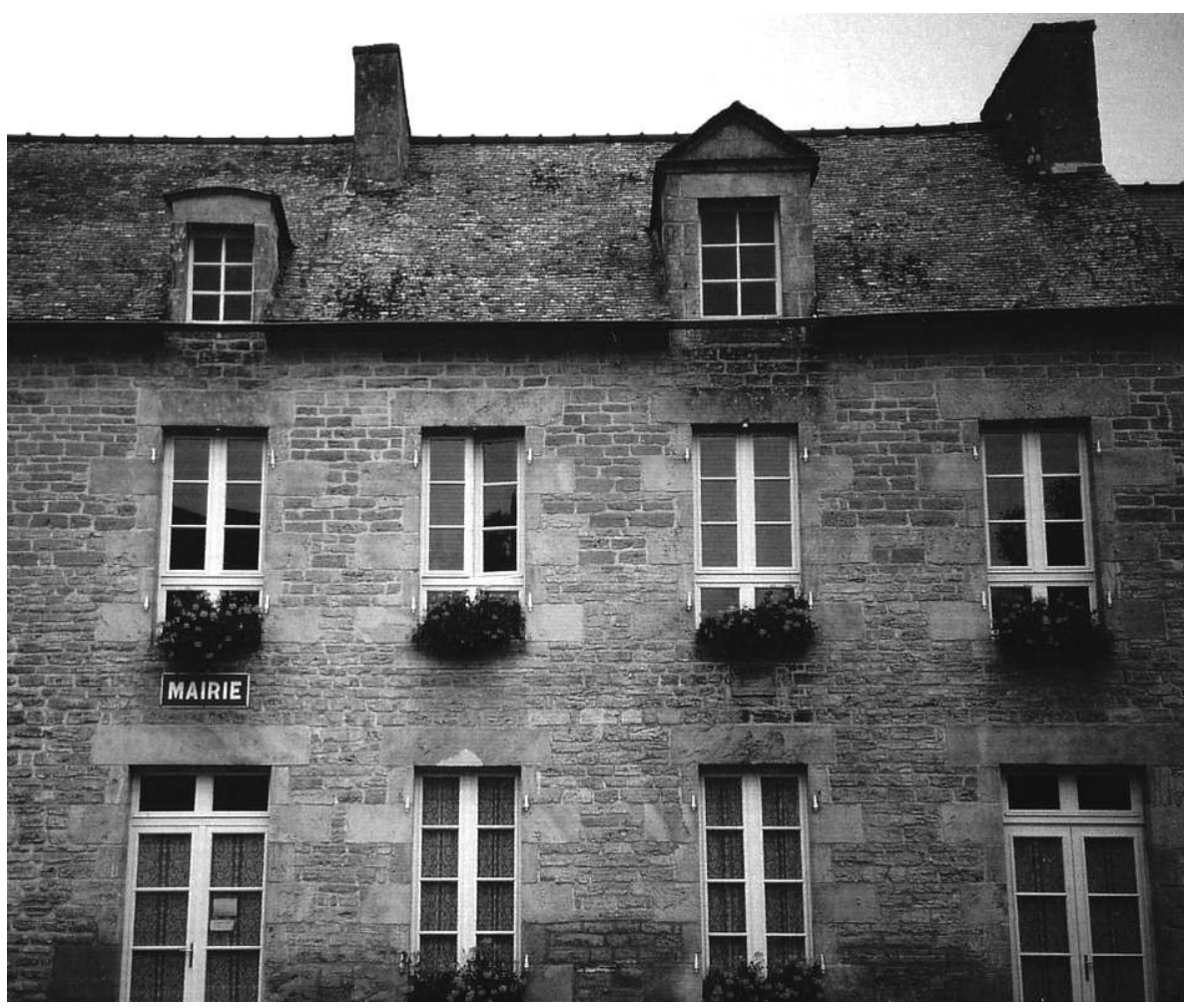

Photo XXXII : à Tréfumel, la mairie est aujourd'hui installée dans une belle demeure de 1768 qui fait un large appel au calcaire local, non seulement pour les moellons de l'élévation, mais aussi pour l'encadrement des ouvertures.

Photo XXXII : Trefumel Townhall is now installed in a fine residence dated 1768, built extensively of local limestone, also for rubble as for embrasure frames. 


\section{BIBLIOGRAPHIE}

Abgrall, J.-M., 1911 - Sépulture gallo-romaine découverte à Pont-de-Buis, Bulletin de la Société archéologique du Finistère, 38, p. 188-192.

Andrieux, J.-Y., 1991 - Les fours à chaux de Lorge et de Cartravers en Bretagne, in BARRAL I ALTET, X. (dir.), Archéologie industrielle en Bretagne, Arts de l'ouest, nº spécial, p. 85-98.

Anonyme, 1975 - Le schiste ardoisier de Nozay, Le Mausolée, p. 2121-2124.

Anonyme, 1976 - Essai de nomenclature des carrières françaises de roches de construction et de décoration, Givors, édit. Le Mausolée, 256 p.

Anonyme, 1991 (avec la coll. de J.-P. Le Marc) - Les derniers ardoisiers de Commana, Ar Men, 39 , p. 2-15.

Anonyme, 1998 - Les ardoisières en pays de Loire, Paris, Ministère de la Culture, coll. « Images du patrimoine », $64 \mathrm{p}$.

Ardouin-Dumazet, 1909 - Voyages en France. Bretagne. Îles et littoral de la Manche, Paris, BergerLevrault (cf. p. 114-116).

Autissier, A., 1891 - Notice sur les ardoisières de Rochefort-en-Terre, Bulletin de la Société de l'Industrie minérale, Saint-Étienne, 3e série, V, p. 295-309.

Barrois, Ch., 1889 - Mémoire sur les éruptions diabasiques siluriennes du Menez-Hom (Finistère), Bulletin du Service de la Carte géologique de la France, 7, 75 p. [où sont décrites les occurrences calcaires de Lostmarc'h et de Rozan].

Barrois, Ch., 1891 - Carte géologique de la France à 1/80 000, feuille de Quimper.

Barrois, Ch., 1902 - Carte géologique de la France à 1/80 000, feuille de Brest.

Barrois, Ch., 1909 - Carte géologique de la France à 1/80 000, feuille de Lannion.

Besselièvre, J.-Y., 1996 - Les travaux de fortification de Brest à la fin du XviII siècle (1776-1784) (Mémoire de Maîtrise), Brest, Université de Bretagne occidentale, 230 p.

Billy, E. de, 1830 - Observations sur les terrains de transition de la Bretagne, Mémoires de la Société d'Histoire naturelle de Strasbourg, I, p. 1-25.

Bonnemaison, 1822 - Notice géologique sur une partie du département du Finistère, Journal de Physique, p. 260-280.

Brun, P. de, 1903 - Note sur le calcaire de Kerisac en Scrignac (Finistère) et ses minéraux, Bulletin de la Société scientifique et médicale de l'Ouest, 12, p. 593-598.

Burel, M., 1995 - Roscanvel dans la presqu'île de Crozon, Bannalec, Imprimerie régionale, 232 p.

Calvez, L. (dir.), 1975 - La presqu'île de Crozon, Paris, Nouvelle librairie de France, 472 p. (cf. p. 40).

Cambry, J., 1798 (an VII) - Voyage dans le Finistère ou état de ce département en 1794 et 1795, Paris, Imprimerie du Cercle social, 3 vol. (et rééd. 2000, Paris, éd. du Layeur, 384 p.).

Chaumeil, L., 1938 - L'industrie ardoisière de Basse-Bretagne, Lorient, impr. du Nouvelliste du Morbihan, $130 \mathrm{p}$. 
Chauris, L., 1991 - Pierres de construction à Morlaix : église des Jacobins et autres édifices anciens, Bulletin de la Société archéologique du Finistère, 120, p. 171-187.

Chauris, L., 1992 - Emploi de roches volcaniques dans les édifices religieux anciens du Trégorrois, Mémoires de la Société d'émulation des Côtes-d'Armor, 121, p. 31-53.

Chauris, L., 1993 - Landerneau : musée de la pierre en plein air. II Quand les pierres de qualité font défaut, Courrier du Léon/Progrès de Cornouaille, 13 novembre.

Chauris, L., 1994a - En scrutant les pierres de l'abbaye du Relecq, Courrier du Léon/Progrès de Cornouaille, 6 août.

Chauris, L., 1994b - Les anciennes ardoisières du pays de Morlaix, Courrier du Léon/Progrès de Cornouaille, 17 et 31 décembre.

Chauris, L., 1995 - Les phares de la baie de Morlaix. Courrier du Léon/Progrès de Cornouaille, 29 avril ; 13 et 27 mai.

Chauris, L., 1996a - Les bâtiments du couvent de Cuburien près de Morlaix, reflets de l'utilisation pluriséculaire de la pierre en Bretagne littorale. Bulletin de la Société archéologique du Finistère, 125, p. 169-197.

Chauris, L., 1996b - Provenance des pierres de construction d'un couvent au XviIe siècle : Les Ursulines de Morlaix en Bretagne, Bulletin du Musée de la pierre (Maffle, Belgique), 11, p. 45-72.

Chauris, L., 1996c - Histoire des couvents de Morlaix vue à travers leurs pierres, in CASSARD, J.-C. (dir.), Bretagne, art, négoce et société de l'Antiquité à nos jours (Mélanges offerts au Pr. Jean Tanguy), Brest, Université de Bretagne occidentale / Association des Amis de Jean Tanguy, 520 p. (cf. p. 289-303).

Chauris, L., 1996d - Le Carmel de Morlaix... ou le couvent aux quatre chapelles, Courrier du Léon/ Progrès de Cornouaille, 9 et 23 mars ; 13 avril.

Chauris, L., 1996e - Histoire de Châteaulin et de ses environs vue à travers les pierres, Courrier du Léon/Progrès de Cornouaille, 4,11 et 25 mai ; 15 juin ; 10 et 31 août.

Chauris, L., 1997a - De l'héraldique à l'industrie des réfractaires ou la saga des schistes à andalousite en Bretagne, Bulletin du Musée de la pierre (Maffle, Belgique), 12, p. 71-85.

Chauris, L., 1997b - Du chemin de halage à la route de corniche : Toul Mahot entre Morlaix et Carantec. Courrier du Léon/Progrès de Cornouaille, 7 juin.

Chauris, L., 1997c - Pierres de Carantec, II, Carantec, édition du presbytère, 98 p.

Chauris, L., 1997d - L'approvisionnement en pierres de construction des ouvrages d'art du chemin de fer dans le Finistère, Bulletin de la Société archéologique du Finistère, 126, p. 217-255.

Chauris, L., 1998a - Sur les extractions littorales de schistes et de grès dans les Côtes-d'Armor, Mémoires de la Société d'émulation des Côtes-d'Armor, 127, p. 77-104.

Chauris, L., 1998b - Pierres et fortifications en région brestoise, Les Cahiers de l'Iroise, $\mathrm{n}^{\circ} 179$, p. 55-65.

Chauris, L., 1999a - Calcaires et fours à chaux des abords de la rade de Brest, Avel Gornog (Crozon), 7, p. 44-57.

Chauris, L., 1999b - Quand la Compagnie du chemin de fer d'Orléans s'intéressait aux calcaires des environs de Pont-de-Buis (Finistère), Bulletin de la Société archéologique du Finistère, 128, p. 207-214. 
Chauris, L., 2000 - Très appréciée par le Service des Monuments historiques, l'ardoise de Moulin-Lande à Maël-Carhaix, Courrier du Léon/Progrès de Cornouaille, 11 et 18 mars.

Chauris, L., 2001a - Schistes en Bretagne : des matières aux diverses couleurs, pour tous les goûts, Pierre Actual, $n^{\circ} 775$, p. 68-77 ; 776, p. 84-89; 777, p. 68-73.

Chauris, L., 2001b - Dans la région briochine, un matériau de construction original : « La pierre des landes ». Mémoires de la Société d'émulation des Côtes-d'Armor, 129, p. 137-148.

Chauris, L., 2001c - La longue histoire de Carhaix-Plouguer sous l'éclairage des pierres de construction, Bulletin de l'Association Bretonne, 110 (128e Congrès, Carhaix), p. 525-546.

Chauris, L., 2002a - L'abbaye de Landévennec sous l'éclairage de ses pierres, Courrier du Léon/ Progrès de Cornouaille, 19 et 26 janvier ; 2 février.

Chauris, L., 2002b - Pierres et constructions dans la ville de Crozon, ou quelques aspects méconnus de son histoire, Avel Gornog (Crozon), 10, p. 19-26.

Chauris, L., 2002c - Les ressources du sous-sol dans le Pays de Rohan et ses abords (du passé vers l'avenir), Bulletin de l'Association bretonne, 111 (129e Congrès), p. 521-553.

Chauris, L., 2003a - Grès en Bretagne, Pierre Actual, n 797, p. 78-86 ; 798, p. 62-69 ; 799, p. 63-69.

Chauris, L., 2003b - Sur les grès réfractaires exploités par les forges des Salles de Rohan, Mémoires de la Société d'émulation des Côtes-d'Armor, 132, p. 99-103.

Chauris, L., 2003c - Problèmes soulevés lors de l'extraction des pierres pour l'écluse du port de Morlaix, Bulletin de l'Association bretonne, 112, p. 646-652.

Chauris, L., 2004 - Recherches préliminaires sur la provenance des pierres de construction à l'abbaye de Beauport, Les Cahiers de Beauport, 10, p. 4-20.

Chauris, L., 2005a - La redoute de Landaoudec à Crozon, Bulletin de la Société archéologique du Finistère, 134, p. 61-66.

Chauris, L., 2005b - La maison Penanault à Morlaix, Bulletin de la Société archéologique du Finistère, 134, p. 72-79.

Chauris, L., 2006a - Le calcaire du Quiou - Tréfumel ou « pierre de jauge », Le Pays de Dinan, 26, p. 319-339.

Chauris, L., 2006b - Promenade lithologique à Vitré, aux marches de la Bretagne, Pierre Actual, $\mathrm{n}^{\circ} 838$, p. 83-93.

Chauris, L., 2006c - Sur les modalités multiformes de la mise en œuvre du grès de Vitré, Mémoires de la Société d'Histoire et d'Archéologie de Bretagne, 84, p. 29-54.

Chauris, L., 2007 - Quand calcaire et granite entraient en concurrence en Bretagne : les environs du Quiou entre Dinan et Bécherel, Pierre Actual, n 845, p. 74-81.

Chauris, L., 2008 - La pierre dans les constructions à Lannion, Mémoires de la Société d'Histoire et d'Archéologie de Bretagne, 86 (congrès de Lannion), p. 5-25.

Chauris, L. et Cadiou, D., 2002 - La chapelle Saint-Fiacre. Provenance des matériaux de construction et de restauration. Avel Gornog (Crozon), 10, p. 53-60.

Collin, L., 1924a - étude géologique de la pointe de l'Armorique et de l'Ile Ronde (rade de Brest), Bulletin de la Société géologique et minéralogique de Bretagne, 5, p. 21-31.

Collin, L., 1924b - Calcaires coblenciens de la rade de Brest, Bulletin de la Société géologique et minéralogique de Bretagne, 5, p. 208-219. 
Daniel, H., et Dizerbo, A., 1946 - La Révolution dans la presqu'île de Crozon. Quimper, Imprimerie cornouaillaise, $254 \mathrm{p}$.

Dizerbo, A., 1989 - Le four à chaux de La Fraternité, Bulletin de la Société archéologique du Finistère, 118 , p. 217-218.

Durand, S., 1960 - Le Tertiaire de Bretagne. étude stratigraphique, sédimentologique et tectonique, Rennes, Société géologique et minéralogique de Bretagne (Mémoire XII), 390 p.

Eveillard, J.-Y., 2001 - Les grès feldspathiques du bassin de Châteaulin dans l'architecture et la sculpture des siècles passés, La pierre en Basse-Bretagne, Brest, Université de Bretagne occidentale, CRBC, p. 41-53.

Foucher, J., 1962 - Les fours à chaux de Porstrein, Les Cahiers de l'Iroise, 9e année, p. 110-111.

Fourcy, E. de, 1844a - Carte géologique des Côtes-du-Nord, Paris, de Fain et Thunot, 172 p.

Fourcy, E. de, 1844b - Carte géologique du Finistère, Paris, de Fain et Thunot, 196 p.

Frapolli, L., 1845 - Mémoire sur la disposition du terrain silurien dans le Finistère et spécialement dans la rade de Brest, Bulletin de la Société géologique de France, 2e série, II, p. 517-571.

Galliou, P. (dir.), 1987 - Aux origines de Carhaix. (Catalogue d'exposition), Carhaix/Brest, Université de Bretagne occidentale, CRBC, $60 \mathrm{p}$.

Kerforne, F., 1908 - Sur les gisements calcaires du massif breton, Revue bretonne de Botanique, (Rennes), p. 9-18.

Kerforne, F., 1927 - Les gisements de calcaire du Finistère, Le Consortium breton, I ( $\left.\mathrm{n}^{\circ} 2\right)$, p. 164-167.

Lacroix, A., 1893 - Minéralogie de la France, Paris (et réédit. Paris, Blanchard, 1962), tome I, 724 p. (cf. p. 44-45).

Lecerf, Y., 1979 - Les sépultures en coffres de l'Âge du Bronze en Armorique, Paris (mémoire de l'EPHE), $94 \mathrm{p}$.

Le Hir, D., 1843 - Sur le calcaire de l'arrondissement de Morlaix, Écho de Morlaix, 15 juillet.

Le Hir, D., 1849 - Caractères géologiques de l'arrondissement de Morlaix, in ELÉOUET, J.-M., Statistique générale de l'arrondissement de Morlaix, Brest, 392 p. (cf. p. 9-29).

Le Portal, C., 1989 - Ardoisières de Maël-Carhaix. Le réveil de Moulin-Lande, Ar Men, $\mathrm{n}^{\circ}$ 21, p. 2-15.

Le Roux, C.-T., 1998 - La « Roche-aux-Fées » en Essé, Bulletin et Mémoires de la Société archéologique du département d'Ille-et-Vilaine, 101, p. 37-43.

Milon, Y., et Dangeard, L., 1922 - Notes d'excursion dans le bassin tertiaire du Quiou (Côtes-duNord), Bulletin de la Société géologique et minéralogique de Bretagne, 3, p. 320-328.

Mulot, B., 1971 - Atlas-guide des ardoisières dans le département des Côtes-du-Nord (BRGM Orléans, inédit), $22 \mathrm{p}$.

Perret, M., 1927 - Monographie d'une ardoisière du Poher, Le Consortium breton, I ( $\left.n^{\circ} 2\right)$, p. 151-156.

Plusquellec, Y., 1980 - Les schistes et calcaires de l'Armorique. Rennes, Société géologique et minéralogique de. Bretagne (Mémoire 23), $213 \mathrm{p}$.

Plusquellec, Y., 1992 - Géologie de la presqu'île de Plougastel, Penn ar Bed, n 144-145, 64 p. 
Puillon-Boblaye, 1827 - Essai sur la configuration et la constitution géologique de la Bretagne, Paris, Mémoires du Muséum national d'Histoire naturelle (15), p. 49-116.

Robien, C. P. de, 1756 - Histoire ancienne et naturelle de la province de Bretagne, (VEILLARD, J.-Y. éd., 1974), Mayenne, Impr. J. Floch, 386 p.

Rolland, Y., 1972 - Fours à chaux et gisements calcaires du Finistère, Penn ar Bed, nº 68, p. 197-213.

Rondel, E., 2003 - Le grès rose, De Saint-Cast au Dahouët, Rennes, éditon Astoure Club 35, p. 72-77.

Saint-Jouan, R. de, 1990 - Dictionnaire des communes. Département des Côtes-d'Armor. éléments d'histoire et d'archéologie, Saint-Brieuc, Conseil général des Côtes-d'Armor, 840 p.

Sanquer, R., 1972 - Chronique d'Archéologie antique et médiévale, Bulletin de la Société archéologique du Finistère, 98, p. 39-107 (cf. p. 42-43).

Sanquer, R. et Galliou, P., 1970 - Le « château » gallo-romain de Keradennec en Saint-Frégant (Finistère), Annales de Bretagne, 77, p. 163-225. (cf. p. 172).

Thomas, G.-M., 1963 - Les fours à chaux de la rade de Brest, Les Cahiers de l'Iroise (10e année), p. 112.

\section{NOTES}

1. .Le terme de roches sédimentaires utilisé dans le sous-titre est tombé en désuétude correspondait aux actuels étages du Siegénien et de l'Emsien (Dévonien inférieur).

\section{RÉSUMÉS}

Les roches sédimentaires bretonnes appartiennent à des types très variés : grès et quartzites, schistes (souvent ardoisiers), poudingues et brèches, calcaires (paléozoïques ou cénozoïques) souvent très utilisés pour l'obtention de la chaux. La richesse de cette palette lithologique, exploitée en Bretagne au cours des siècles, se révèle dans la diversité des mises en oeuvre (édifices religieux, habitats, travaux publics...).

\section{INDEX}

Mots-clés : Bretagne, carrière

Keywords : Brittany, buildings, quarries, sedimentary rocks 
AUTEUR

LOUIS CHAURIS

Directeur de Recherche au CNRS (e.r.) - 3 rue Goethe, 29200 Brest 